\title{
The Possibilities of Transforming Settler Consciousness: Community Spaces and White Settler Responsibility
}

\author{
by
}

Jesse Whattam

A thesis submitted to the Faculty of Graduate and Postdoctoral Affairs in partial fulfillment of the requirements for the degree of

Masters of Arts

in

Political Economy

Carleton University

Ottawa, Ontario

(C) 2019, Jesse Whattam 


\begin{abstract}
In Settler Colonial Theory, there is a growing body of work that looks at the ways settler colonization is being challenged. The understanding of how settlers are engaging with these potential transformations remains unclear. I build on Davis et. al's (2017) idea of "transforming settler consciousness" to consider what conditions, spaces, and practices are facilitating white settlers to challenge settler coloniality. Working with five white settlers in community groups, I use a narrative inquiry methodology to ask what about these initiatives did, or did not, catalyze transformed settler consciousness? Through a political ontology framework, the stories shared reveal the paradoxes, challenges and complexities about what facilitates a politics of recognition (Coulthard 2014) and what facilitates spaces of ontological negotiation. While the former does not demand a transformation in settler consciousness, the later does and with that transformation, settlers have the potential to contribute to a radical transformation of settler coloniality.
\end{abstract}




\section{Acknowledgements}

I would first like to thank all of the activist, organizers and frontline communities that spend their lives fighting for justice and a better world for everyone. I want to express my gratitude for the five people who are committed to this work and shared their stories with me- it takes a lot of love, courage and vulnerability and I am so very thankful. During times of global ecological, political and social strife, it is your resistance, art, action and dreams are that give me hope. I want to thank all my family and friends who supported me through this process. I leaned on you all and am always grateful for the love you so readily gave. I want to offer a heartfelt thank-you to my supervisor, Professor Cristina Rojas. I have learned so much from you and your endless patience and willingness to hear all my ideas was truly a gift. Thank you Donna Coghill, I really couldn't have made it to the end of this project without you. Thank you to my readers, your comments and insights made this project infinitely better. And finally, Sam. I will never have enough words to thank you. I am forever grateful for you always having the time to listen to my scattered thoughts, always making sure there was chocolate around, for holding our home and my bike together, and for so graciously loving me through all the chaos. 


\section{Table of Contents}

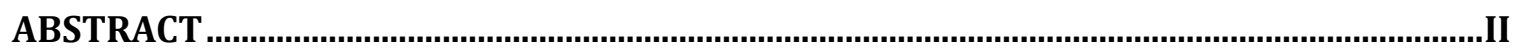

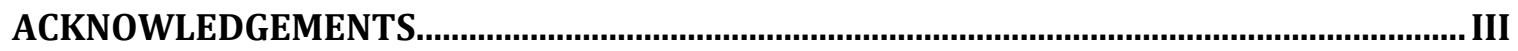

LIST OF APPENDICES ..........................................................................................................

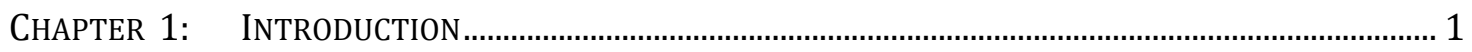

1.1 A Call for More

1.2 Budding Settler Colonial Studies and its Dangers and Potentials ....................................

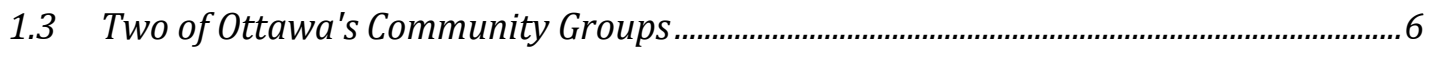

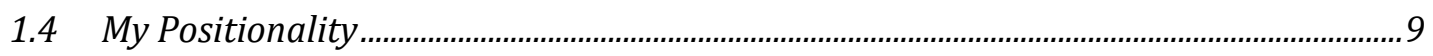

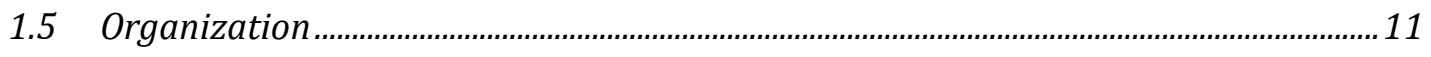

Chapter 2: Transforming SETtler Consciousness: A Frame For InTERPRETATION .............14

2.1 Transforming Settler Consciousness: A Concept .............................................................. 17

2.2 A Note on Terminology: Colonization and Coloniality .................................................... 22

2.3 Theoretical Framework: Combining Settler Colonial Theory and Political Ontology 23

2.4 Glen Coulthard and the Politics of Recognition …..........................................................29

2.5 Modernity/Coloniality, Slowing Down Reason and "world"-traveling.......................... 33

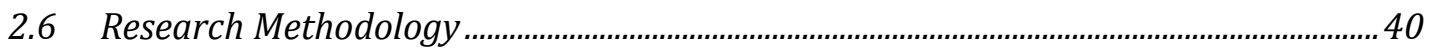

Chapter 3: Truths And Reconciliation: An ONTOlogical Dispute BetWeEn Worlds .......45

3.1 Truth and Reconciliation Commission Report: Four Years Later ................................... 47

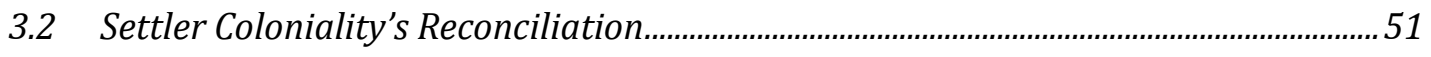

3.3 Ontological Confusion, Partial Connections and Negotiations: Reconciliation.......... 56

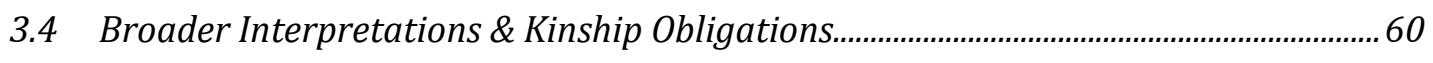

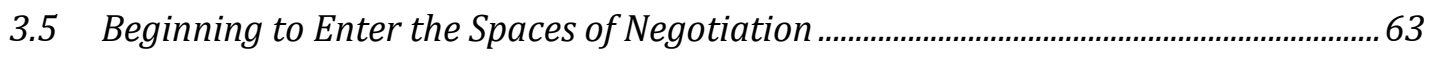


Chapter 4: Community SPaCes, Settler ResPonsibility AND the Possibilities of

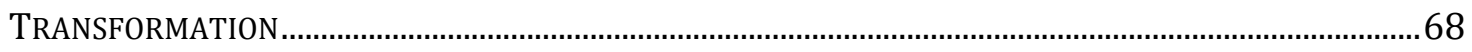

4.1 Settler Coloniality \& White Supremacy: White Settler Identity ...................................... 73

4.2 The Structure of the Community Groups: Shaping Possibilities........................................ 78

4.3 The Community Groups and Politics of Recognition ........................................................ 82

4.4 Spaces with Possibilities for Ontological Negotiation .................................................... 98

4.5 Not One Or The Other: Politics Of Recognition And Ontological Negotiation.......... 118

Chapter 5: Settler Responsibility: The Paradoxes, Challenges and Pitfalls ............... 120

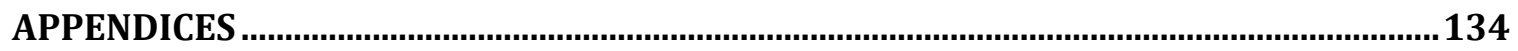




\section{List of Appendices}

Appendix A............................................................ 135 


\section{Chapter 1: Introduction}

\subsection{A Call for More}

Since the 2015 release of the Truth and Reconciliation Commission report, the momentum around 'reconciliation' in Canada has grown. Despite the claims from the Canadian state that this reconciliation movement is working for justice, many Indigenous communities and "allies" have challenged its effectiveness to structurally change the historically unequal colonial Indigenous-settler relations (Alfred 2009; Simpson 2011; Coulthard 2014; Manuel 2015; Simpson 2016). The reality is that Indigenous communities continue to experience widespread systemic injustices. The injustice is evident in the boil-water advisories and housing crisis in a growing number of First Nation communities. It is evident in the Millennium Scoop that sees the Canadian state apprehending Indigenous children from their families or in the disproportionate number of Indigenous people experiencing incarceration. The injustice is palpable in the Reclaiming Power and Place: The Final Report of the National Inquiry into Missing and Murdered Indigenous Women and Girls, released in 2019, that concluded that the violence experienced by Indigenous women, girls, and 2-Spirit, Lesbian, Gay, Bisexual, Trans, Queer, Questioning, Intersex and Asexual people are the result of a "persistent and deliberate pattern of systemic racial and gendered human and Indigenous-rights violations and abuses, perpetuated historically and maintained today by the Canadian state, designed to displace Indigenous people from their lands, social structures and governments, and to eradicate their existence as nations, communities, families and individuals" (Reclaiming Power and Place: Volumelb 2019, 174). Many activists and academics alike have demonstrated that historically rooted settler colonial structures, 
built into the foundation of the Canadian nation-state, allow for the continuation of such violence and injustices (Cardinal et al. 2004; Wolfe 2006; Veracini 2010; Manuel 2015). Though Indigenous resistance against such force is as old as the violence itself, slowly, settlers are waking up to the need to confront Canada's inherent violence. What is happening with this awakening? Is it useful or effective? Is it affecting how settlers act or how the state and other institutions act? Research in Indigenous studies and settler colonial studies argues that in order to disrupt the hegemony of settler colonialism, settlers need to understand not only how they benefit from settler colonization but also how we are complicit in its perpetuation (Mackey 2005; Wolfe 2006; Regan 2006, 2012; Morgensen 2009; Snelgrove, Dhamoon \& Corntassel, 2014). The discourses and practices that shape the way settler Canadians understand reality, nation, Canadian life and their own identity as a Canadian citizen — their consciousness— is deeply intertwined with the structures of settler colonialism (Mackey 2002; Regan 2006; Wolfe 2006). Davis et al. (2017) looked at a compilation of initiatives by Indigenous and non-Indigenous civil society groups that aim to spread awareness about Canada's colonial history and the ongoing violence against Indigenous peoples. The authors identify the need to have a deeper understanding of how and what impact these initiatives have facilitating individual and collective social action that challenges settler colonial structures. Similarly, Christine Hiller (2013) identified that while there is a growing body of work that looks at the potential for transformed Indigenous and non-Indigenous relations and the destruction of settler colonial structures, there remains a gap in understanding about what conditions settlers are engaging with these potential transformations. Hiller's later work with settler activists highlighted that within these potential transformations, white 
people need to see the prevalence of colonial violence, "a reality regrettably well-known to most settlers of color" and understand themselves as the intended beneficiaries of settler coloniality (Hiller 2017, 431). The co-constituted systems of settler colonialism and white supremacy ensure white settlers are afforded sense of entitlement to land and belonging in ways racialized settlers do not (Thielen-Wislon, 2012). Any radical change to the structures of settler coloniality demands white settlers confront the white and settler privileges afforded to them at the expense of Indigenous nations and racialized settlers. This research is attending to the specificity of white settler responsibility. Responding to the call for a deeper understanding, my thesis seeks to consider what conditions, spaces, and practices are facilitating white settlers to consciously challenging hegemonic settler colonial structures and their own complicity. This thesis involves two Ottawa-based church community groups comprised of predominately white settler individuals that seek to destabilize dominant settler colonial practices through what the groups call "transforming relations" between settlers and Indigenous peoples. I specifically ask, what about these initiatives did, or did not, catalyze transformed settler consciousness for the individuals involved?

\subsection{Budding Settler Colonial Studies and its Dangers and Potentials}

The growing interest and body of literature looking at "decolonization, settler learning, and solidarities" (Davis, Denis \& Sinclair 2019, p. 1) has been taken up with uncertainty and contemplation. Scholars such as Macoun and Strakosch (2013) or Snelgrove, Dhamoon and Corntassel (2014) have warned against its limits and dangers of focusing solely on how settlers are challenging the very system that exists to serve them. There is the danger of settler scholars denying their social location as settlers' and their specific 
epistemic knowledge, in favour of positioning themselves as neutral arbitrators, able to step back and "see the full truth" (Macoun \&Strakosch 2013, 430). Similar to Tuck and Yang's (2012) "settler moves to innocence," Hiller (2017) points to the risk of white exceptionalism, wherein, we as a white people feel we are exempt from white supremacy because we are "one of the good ones." This desire to be "one of the good ones" is often in itself a desire structured by settler colonialism, predicated on the need to escape guilt or shame. These dangers are pervasive and due to the insidious nature of white supremacy and settler colonialism, are prone to being reproduced. Though the awareness of them is not a way to completely circumvent them, contentious awareness and selfreflection is a necessary undertaking when settler scholars, mainly white settlers, seek to do the work in settler colonial theory and solidarity work for Indigenous sovereignty. Nonetheless, the task of looking at what settler's engagement with transforming settler consciousness (which is beyond just awareness) and thus challenging settler colonialism is an important one, in part because it is a space to "hold up the mirror" (Davis, Denis \& Sinclair, 2019, p 3) to our settler selves; to interrogate our motives, our actions, the challenges, and the possibilities. As a learning project, I hope this project can be a reflexive site of reflection and accountability. This project is not a site of congratulations to settlers attempting to take up the responsibility of holding our selves and the state accountable to the violence inherent in settler colonial reality, nor is it meant to be a pat on the back for an increased awareness of Indigenous ontologies and epistemologies.

Ontologies are produced, constructed and embedded in practices and narratives, shaping the categories of existence and ways of being. As ontologies are grounded in narratives and practices, the way to move toward existence beyond settler coloniality is to alter 
one's foundational narratives and one's daily practices. The experiences of these white settler individuals and their community groups' offer insight into how settlers collectively can prepare themselves to live within or alongside ontological structures beyond/outside of settler coloniality, including Indigenous political systems, legal orders and forms of reconciliations. The path to the ending of settler coloniality is unfolding and thus hard to define. At the same time, it needs to center decolonization as defined by Indigenous communities. Importantly, Tuck and Yang (2012) remind us that decolonization necessarily answers to Indigenous futures and that those goals (of which land return is central), may not be commensurate with settler futures and settlers need to sit in the discomfort of the unknown rather than fulfilling the systematic habit of denying ontological difference and destroying Indigenity. For decolonial thinker de Lima Costa, partial connections describes a relationship (in this case between ontologies) as "neither singular nor plural" (de la Cadena 2010, 347). Partial connections points to the space where "a dialogue" can manifest, consisting of possibilities beyond the parameters of settler coloniality. As Chapter 4 will describe, the stories of the five white settlers reveal that these partial connections were formative in transforming their settler consciousness. I see this space as being an important step in the discomfort Tuck and Yang are speaking of. Importantly, settlers need to challenge the settler colonial ontological positioning that our subjectivity is universal (Strakosch 2016b) and come to understand we are always in relationship with Indigenous peoples and there are always partial connections between the plurality of ontologies (de la Cadena, 2010). Settler colonial theory and this project does not (and should not) seek to define "the end of settler coloniality" with any absolution or specificity. However, this research points to the fact that coexistence 
beyond settler coloniality requires relational ontologies, as opposed to the violent universalizing ontological foundations of settler coloniality. From the premise that settler coloniality is not the only ontological reality, it becomes clear that if we as a settler society want to transform colonial impulses, we need to not only recognize but also embody alternative paradigms through our political and legal structures, through individual and collective efforts. Settler colonial studies is a space to look at transforming settler consciousness and holds the possibility to create conditions for a society built on relational ontologies. Importantly, the best of settler colonial studies recognizes its limitations and draws on critical schools of thought, namely Indigenous knowledges and studies along with critical race theory, feminist studies, critical political economy, and postcolonial studies. Critically, it must be coupled with continued engagement and action.

\subsection{Two of Ottawa's Community Groups}

This research project explores how individuals working in community-based initiatives are engaging in a transformation of settler's consciousness. I will expand upon this in concept in Chapter 2, but briefly, transforming settler consciousness will mean how settlers are working to make change to the settler colonial society they live in, including how they construe and exist in the world, or said in other words, their ontological and epistemological grounding. The two groups I worked with were fitting assemblages to collaborate with because both recognized in their mandate the individual and collective responsibility of non-Indigenous peoples to destabilize colonial structures through individual and community relations. Notably, both groups are in the national capital and are church-based. Both factors shape the context the groups form from and navigate, which was revealed throughout my work with them and will be explored in Chapter 4 . 
All five people I interviewed from the groups were white, middle to upper class and between the ages of 62-73. These intersections of race, class and age are important context to this project as each axis of identity shapes the journey of transforming consciousness. As discussed, settler colonialism and white supremacy in Canada has always dictated that agency, privileges and injustices are experienced differently along gendered, class, racial and generational lines. Working with those who hold substantial systemic privilege holds significance to the form the transformation they are engaging in will take as will become clear. They are both responding to calls to action made by the Truth and Reconciliation Commission. Group Number 1's website states that they are responding to \#48 that, "call[s] upon the church parties to the Settlement Agreement, and all other faith groups and interfaith social justice groups in Canada who have not already done so, to formally adopt and comply with the principles, norms, and standards of the United Nations Declaration on the Rights of Indigenous Peoples as a framework for reconciliation." Both of their online directives indicate they are involved in "direct support" to Indigenous-led struggles and emphasize education around the historical and ongoing injustices experienced by Indigenous communities. By nature of the mandate and actions of the two church-based groups, the individuals involved are seemingly engaged in transforming their consciousness through bringing pause to their own ontological and epistemological assumptions, engaging with Indigenous ontologies, and through the political involvement with specific issues impacting Algonquin nations. Through solidarity with Indigenous-led struggles, individuals are engaged in counterhegemonic processes that would possibly require challenging fundamental settler discourses and narratives that uphold settler colonialism. Their implied engagement 
allowed for a collaborative reflection on how these processes have transpired, common challenges, what are potentials within community groups. The two groups were also slightly different in nature. Both groups were connected through the same online listserv that served to circulate online information around upcoming events, news about Indigenous issues and matters of reconciliation. The two groups were based out of different locations and took different forms. Though they were aware of each other, there was no collaboration reported. Group 1 met regularly, held regular events, and had relationships with Algonquin First Nations and Indigenous organizations in the area. Group 2 only related via an online listserv and the occasional event that was hosted. The two people I interviewed from Group 2 had never met each other. The different rudiments, spaces and temporalities had different impacts on the individuals involved in, at times, surprising ways. To carry out this research project, I implemented a narrative inquiry (to be explained in Chapter 2) during the four months wherein I worked with the five individuals from two community groups. To answer my research question, what about these initiatives did, or did not, catalyze transformed settler consciousness for the individuals involved, I used narrative analysis to trace how the individuals themselves understood how the central elements of the group formation (including the people, discussions, activities, time, space) shaped their engagement with transforming their settler consciousness. With the stories of lived experience from the individuals, I seek to articulate the multi-layered intentions, meanings, and effects that non-Indigenous Canadians are navigating in their process of "unsettling the settler" and how these initiatives did, or did not, catalyze transformed settler consciousness. This research essay uses people's stories, as told by them, as one of the sources of knowledge shaping the 
analysis and conclusions. A part of the methodology is situating their narratives within the socio-political context of settler colonialism. The individuals are not the singular source of all meaning, and the theoretical framework I will introduce in Chapter 2 functions as a source of knowledge against which I understand the narratives in the context of Canada's settler colonialism in the $21^{\text {st }}$ century. I engaged with the white settlers, asking them to share their experience with the specific group they were involved with. The questions were designed to garner reflections on how the group formation and function impacted their awareness, choices and actions. Each question reaped different answers, and often they fluctuated between reflections on the impact of the group and their connected (or not connected) growth, changing understanding, changing values, perspectives and actions.

\subsection{My Positionality}

I am a white, queer, settler Canadian woman, with roots from Britain and Italy, two and three generations back. I grew up on the territory of Anishinaabe and Haudenosaunee Confederacy, as determined by the Dish with One Spoon treaty and home to the Mississaugas of the New Credit First Nation and the Six Nations of the Grand River (colonially known as Hamilton, Ontario). I spent seven formative years in Nogojiwanong (Peterborough, Ontario) and now live on Algonquin territory (Ottawa, Ontario) attending Carleton University. All of the pieces of my identity, the people in my life and the places I have lived shape my work and the lens through which I can engage in this project and own part of transforming my settler consciousness. As a white woman, I seek to be vigilant in the way the white womanhood is often weaponized against Indigenous, Black folks and people of colour, leveraging the construction of white women as the epitome of 
innocent and feminine to do harm. As a queer woman, I know that queer movements are not immune to white supremacy and often neglect Indigenous peoples, Black folks and people of colour. I have been actively been engaged in social justice activism ranging from Indigenous solidarity, migrant justice, anti-poverty and labour justice and it is from these struggles that I have done a large part of my learning about what is discussed in this research project. In many ways, this research paper is a piece of a constellation of efforts I commit my life and energy to in service of working towards the dismantling of settler colonialism and white supremacy. As always, this is a learning process, I do not claim to know the "right way" and I am deeply indebted to those who have guided my learning thus far, particularly the Indigenous and racialized friends, activists and scholars in my life or whose words I have come across. This project is in no small way born from the emotional and mental labour others have provided, though any errors are my own. Despite my learning, the task of looking at settler's (including my own) process of bringing pause to their own ontological and epistemological assumptions and engaging in ontological shifts is difficult by the fact that my knowledge is limited. I am immersed, born from, a part of modernity. My experiences over the past decade, learning from Nishnaabeg teachings and stories, learning from Indigenous scholars and sparsely attempting to reconnect with my own Celtic roots, has brought me many moments of a "slowed reasoning". I have little investment in the structures of capitalist colonialism, I actively struggle for them to be dismantled, yet I most definitely benefit from them regularly. Importantly, I am not connected, in a deep and sustained ontology, a different way of being or knowing outside of modernity. Because of this, my lenses and perspective on how other settlers may engage in moments of "world-traveling" will 
always be limited. In this project, it was necessary for me to be vigilant in my reflexivity and responsibility to not only those involved in the research but to the relations between the settler and Indigenous peoples linked to the community groups. An anticolonial methodology helped provide principles meant to help settler scholars work alongside resurgence work of Indigenous scholars and work towards relationally accountable decolonization (Carlson, 2017). These include resistance to and subversion of settler colonialism; relational and epistemic accountability to indigenous peoples; land/place engagement and accountability; egalitarian, participatory and community-based methods; reciprocity; self-determination, autonomy, and accountability; social location and reflexivity; wholism (attends to the heart, spirit, body and mind) (Carlson, 2017). In order to attempt to be reflexive, aware and circumvent the harm done by settler white socialization, I kept an ongoing journal and set aside intentional time to reflect on my practice and position. In part, my research was grounding in principles of anti-colonial methodologies and practices, through my commitment to working in solidarity with Algonquin struggles (some of the same as the groups I worked with) and sought to develop connections with nations and organizations here on Algonquin territory. The engagement with solidarity work and my own process of transforming settler consciousness demanded reflexivity, accountability and an attentiveness to not only the intellectual transformations I was experiencing, but those to my heart, spirit and body. That work has shaped my learning as much as the academic work used throughout.

\subsection{Organization}

In this introduction, I outlined this project and how I engaged the community groups here on Algonquin territory. I explained my social positionality and what it meant for how and 
why I engaged in this project. Chapter 2 will introduce the theoretical framework and research methodology. While I write through a Political Ontology framework (developed in Latin America's decolonial theory), this thesis is also written within Settler Colonial theory. I posit the two theoretical schools complement each other well and have allowed this research to address the complexities and nuances of transforming settler consciousness that each alone would not have permitted. Chapter Three is "Truths and Reconciliation: Ontological Disputes Between Worlds" and will discuss the project of reconciliation and the role of the Truth and Reconciliation Report. I will explore how the obfuscation of reconciliation as an equivocation allows for ongoing commitment to settler colonialism but there are potentials in Indigenous ontologies to radically transform Indigenous and non-Indigenous relations. Chapter Four, "Community Spaces, Settler Responsibility and the Possibilities of Transformation", analyzes and compares what about the community groups perpetuates both a politics of recognition and spaces ontological negotiation between the settler colonial world and Indigenous worlds. What is clear is that there is not a dichotomous roadmap, pointing to one or the other, and way forward is always emerging thus only partially visible. In Chapter Five, I offer my conclusion on how these groups transformed their consciousness. Guided through the particular theoretical frameworks, the strength of narrative inquiry promise to uncover the layers of meaning that comes from storytelling to understand the ontological and epistemological orientations that shape settlers experiences in the two community groups, as well as how they represent those experiences will help to unveil patterns of thought, identity construction, and discourses. It is my hope that this project will facilitate a deeper understanding of the work that needs to be done by white settler Canadians in order to 
challenge settler colonial relations and structure that continue to benefit settler's while systematically marginalizing Indigenous communities. 


\section{Chapter 2: Transforming Settler Consciousness: A Frame for}

\section{Interpretation}

The journey of transforming settler consciousness and of solidarity work in general, depends on both cycles of reflection and action operating in tandem and simultaneously (Hiller 2017, 432). This process, as many have pointed out, is uncomfortable and involves working through a whole host of emotions that may arise: sadness, anger, grief, shame, guilt, disappointment, or defensiveness. Mackey $(2014 ; 2016)$ demonstrates that normative narratives and practices of ontological certainty to Indigenous land and control over Indigenous people are not only naturalized through the law but also create "settler structures of feeling" that includes entitlement, anxiety, and uncertainty. These narratives and practices are the legal and philosophical logics that underpin settler coloniality and act as "the "cognitive prisons" of settler peoples and, by implication, of settler law" (Mackey, 2014, 243). The assertion of Indigenous land rights disrupts these deep-rooted expectations of entitlement to the land that often results in discomfort, more specifically, anger about the consequent uncertainty (Mackey, 2014, 239). Mackey (2014) articulates that "no matter how emotionally potent or understandable, these emotions may be, they are not simply individual emotions that naturally occur" (243). These emotions are structural and systemic and we must be attentive to them when seeking to challenge the structures and ontologies (modernity) that underpin them. Mackey (2014) argues "that decolonization, for settlers and for settler law, may entail embracing particular forms of (likely uncomfortable) uncertainty in order to imagine and practice relationships and power in new and creative ways" (237). Chapter 4 will reveal that the five white settlers I 
work with all speak to this uncertainty, while some embrace it, others seek to escape it. The uncomfortability and anger that comes when the normative settler structure of feeling echoes the work of Margaret Heffernan's well-cited book Willful Blindness: Why We Ignore the Obvious (2011) that describes how humans consciously, thought mostly subconsciously, do not interact or acknowledge information that will shift our comfort, feeling of self-worth or sense of stability. Boler \& Zembylas (2003) use the work of Nikolas Rose (1998) to argue that a "pedagogy of discomfort as an educational approach to understanding the production of norms and difference" (108) can help educators and students to understand how normative structures of oppression and power in society shape their feelings, knowledge, and behaviour (127). Educational spaces can interrogate the hegemonic norms and myths built from these structures, "as well as the deeply embedded emotional dimensions that frame and shape daily habits, routines and unconscious complicity with hegemony" (Boler and Zemblyas, 2003, p. 108). In conversation with the five white settlers, there were clear descriptions of experiences where the emotional discomfort also could help bring about a transformation to their consciousness. Boler and Zembylas (2003) articulate that the inevitable emotional responses: sadness, anger, grief, guilt, resistance, also develop people's skills in critical inquiry around difference, power, and oppression and can facilitate new worldviews, ontologies and epistemologies. J.M. Bacon's research looked at how emotions play out in anti/decolonial social justice efforts finding that astonishment, blame, and guilt are the most common and then problematizes the common trope that guilt needs to be overcome, suggesting it can be a productive mobilizer (Davis, Denis and Sinclair, 2019). Transforming settler consciousness for white settlers means coming to terms with the fact 
that you have unearned privileges, simply because you are a white settler. It means coming to terms with the fact that you likely live on stolen land that your comfort has come at the expense of Indigenous communities livelihoods and wellbeing. Critical race theory, feminist theory and Indigenous studies all have addressed the difficulty of translating the seemingly abstract concept of privilege, especially when the normative narrative of meritocracy teaches us that privileges of society (i.e. access to housing, schooling or material wealth) come to those who "work hard" and "deserve it". The literature reviewed here reveals that there is emotional labour involved in this work and that there must be discomfort for and through emotional labour by white settlers if there is to be a shifting of the status quo. However, there is a necessary cautioning against recentering settler emotions in struggles against settler colonization. Sarita Srivastava (2006) work on "a therapeutic model" of unlearning racism illustrated that focusing on white feelings re-centers white people and replaces the calls for structural transformation. Similarly, re-centering white settler feelings, "risks re-centering the [settler] subject rather than destabilizing the settler/native binary through which the settler's social power is constituted in the first place" (Jafri 2012, p 3). For a decentering of settler emotions, there is a need for settlers themselves to do the emotional labour ways that allows for them to show up in a respectful mind, head, heart space that allows for the centering of Indigenous perspectives and emotions. The work of moving through/with settler discomfort, is not linear, but an ongoing process. Distancing from the discomfort can be an impulse reaction to the desire to not see one's own complicity in genocide and injustice (Gilio-Whitaker, 2018), but sitting in the discomfort can facilitate an embrace of new worldviews, ontologies and epistemologies (Boler and Zembylas, 2003). The work 
of transforming the epistemological and ontological underpinnings of settler coloniality is necessary work if settler colonization is to be dismantled and the importance of understanding how settlers can potentially engage in that transformation is critical. The concept of transforming settler consciousness provides a touchstone or framework for my exploration into how the five settlers and their communities groups engaged in their own transformation.

\subsection{Transforming Settler Consciousness: A Concept}

I first became familiar with the term 'transforming settler consciousness' in 2014 in an undergraduate class at Trent University, taught by settler colonial scholar, Professor Lynne Davis. In this class we were tasked with building a website called Transforming Relations, which provides a growing archive of initiatives that are working to "change the understandings of non-Indigenous people in Canada about Indigenous peoples, the historical unfolding of colonialism, and settler colonialism as it is reflected in Canadian society today" (transformingrelations.wordpress.com). The website is still run by Professor Lynne Davis and her undergraduate class. Davis et al. (2017), heavily influenced by Paulette Regan's (2010), expanded the concept and I base my understanding on their foundation. The dictionary definition of consciousness is "awareness of one's own existence, sensations, thoughts, surroundings, etc.; the thoughts and feelings, collectively, of an individual or of an aggregate of people" (dictionary.com, n.d). Consciousness is not an embodiment of universal truth, or "objective" facts, but the scope of knowing, of feeling and of being. It includes both the ontological and epistemological orientation of the world(s) you are immersed in. This definition, while broad, leaves questions about the unconscious: what is repressed, denied, disavowed. For 
conceptual clarity, I want to make clear, the unconscious characterizes our awareness, feelings and thoughts and I would posit that the transformation of settler consciousness includes interrogating one's own unconscious bias, thoughts, feelings. The narrative inquiry holds the narratives, as told by the storyteller, as partial knowledge. This does not permit "access" to the unconscious. In some ways, this is a limit of the methodology, though I hold that it permits us to see what settlers are aware of in terms of their consciousness and there is value in that. Scholars have taken up looking into settler consciousness, the layers of the ontological and epistemological realities of being born from settler coloniality and the way that is challenged. Davis et al. $(2017,5)$ define transforming settler's consciousness with a four-part conceptualization:

- Creating narratives, processes, and practices that hold settlers accountable to their responsibilities as beneficiaries of colonization, both historical and ongoing.

- Naming and upsetting the status quo and challenging the power dynamics that perpetuate settler colonialism.

- Building just and decolonized relationships with Indigenous peoples, the land, and all beings.

- Engaging in an ongoing, complex, and dynamic process grounded in a lifetime commitment, which occurs at the level of the individual, family, community, and nation.

This concept includes both changes to ways of thinking (epistemological) and changes to ways of being (ontological). Of course, a change in consciousness can alone not rectify settler colonization. Further, there are questions that remain with this conceptualization. I have focused on how discomfort, uncertainty and the spaces of emotion arise for settlers, and upon first glance one may ask where does discomfort and uncertainty fit in to this conceptualization? I would contend that any use of transforming settler consciousness must account for the emotions and cognitive prisons that are borne from settler 
coloniality. Further, there remains questions if this conceptualization takes into consideration the complexity of settler privilege when it comes to race, class, gender, and migration status. For example, many people of colour have limited access to the material privileges of being a settler, such as access to job security, higher education, or secure housing. When the definition above states "beneficiaries of colonization", I argue it must hold the diversity in which those "benefits" are experienced (or not experienced). Battell and Barker (2016) articulate the need to use settler because it demands a shift to the "frame of reference away from our nation, our claimed territory, and onto our relationships with systems of power, land, and the peoples on whose territory our country exists" (12). At the same time, they articulate that it must hold the nuance that settler is "situated, process-based, disavowed, and relating in complex, non-discrete, non binary relationships with Indigenous" (Battell Lowman and Barker 2015, 18). Though I do not believe Davis et. al (2017) are excluding this, I would posit that any utilization of the transforming settler consciousness require that the settler/indigenous binary be problematized to take into account the variations in what it means to be a settler. As a use this conceptualization of transforming settler consciousness, I seek to hold this nuance. This project's focus on white, middle-class, older settlers will articulate the specificity of white, older settlers process of transforming settler consciousness that differs greatly from racialized settler's experiences or poor settler's experiences. With these added complexities and nuances, I build on Davis et. al's (2017) definition because I assert that this process is a necessary process for settlers to support the vision, sovereignty and selfdetermination of Indigenous peoples, nations and lands in meaningful ways. Without this support, the status quo of settler colonial violence is inevitable. Further, a shift away from 
the violence of settler coloniality is necessary if we are to address other global challenges including climate change, wealth inequality and white nationalism. Here, I am interested in interrogating the type of transformations that will push settlers to work to stop the theft of Indigenous lands, of Indigenous culture and language that our ancestors began and our society continues to enact. These transformations demand ontological negotiations, where settlers see beyond the universalizing tendencies of settler coloniality and are open to a shifting of worlds, and all the required de-investment from capitalism, colonialism, patriarchy and white supremacy. Modernity in Canada, as ontology, is based on the logics of settler colonial and white supremacy that by nature, has suppressed all other ontologies including Indigenous. If white settler's consciousness are subsumed by the ontology and epistemology of settler colonialism, then to challenge settler colonialism, their consciousness must be challenged and transformed. Eva Mackey (2016) postulates that it is settler's ontological certainty around ideas of land property and sovereignty ensures settler colonization is reproduced. Settlers must actively counter the ontological and epistemic traits of the colonial settler. The political ontology framework I will use in this research essay (to be discussed more in the next section) holds that there exists a plurality of ontologies that are produced throughout historically situated practices and discourses. It is important to highlight that there is the risk of settlers simply "collecting" Indigenous knowledges and consuming Indigenous cultures, without challenging settler colonial power dynamics, without building just and decolonized relationships with Indigenous peoples, the land, and all beings and without a commitment to the complexities. The political ontology framework demands I consider the political negotiations of ontologies in and of themselves but also on the interaction of different ontologies and how, through 
their encounter, work to survive and thrive. I understand transforming settler consciousness not as wandering between modernity/settler colonial ontology and Indigenous ontologies, but rather settler's effort to contest the oppression that is inherent in settler colonialism and the attempts to see, be, think and feel beyond it. This "beyond" is not to deny the ongoing reality of settler coloniality, but demands a negation of its attempted universalization. These transformations in consciousness are about how settlers can commit to a change in practices, ways of being and foundational narratives that contribute to a radical alternative of social organization that is not predicated on the oppressive structures that currently exist. Of course, there is no script for this type of transformation, and will be informed by a myriad of differences including people's life experiences, political orientation, spiritual grounding and physical location. Transforming settler consciousness is not merely about learning new perspectives or histories, and does not precede action but instead it "occurs through action, through meaningful relationships with Indigenous peoples and with other engaged settlers, and through experimentation with activism of various sorts" (Davis, Denis \& Sinclair 2017, 394). Transforming settler consciousness is not a goal, but a process, and while it necessary for a movement towards the end of settler colonialism, it is not the same as decolonization. As Tuck and Yang articulate that the reconciliation project executed by the Canadian state is meant to attend to questions about the future for settlers and "rescuing settler normalcy" (p.35), while "decolonization is accountable to Indigenous sovereignty and futurity" (Tuck and Yang 2012, 35). Transforming settler consciousness will be a part of the process of settlers taking on the responsibility of shaping settler futures beyond the violent parameters of settler coloniality. This process will need to support Indigenous sovereignty and futurity 
and necessitate settlers giving up certain privileges that have been guaranteed at the expense of Indigenous land and sovereignty, for example the certainty in and entitlement to property. I see this as a part of transformation in settler consciousness, specifically the ongoing lifetime commitment that will upend settler colonial power dynamics and structures and a redistribution of land and material wealth. The end of settler colonialism, which decolonization is foundational too, is right now always emerging and never fully defined. As Franz Fanon puts it, "decolonization, as we know, is a historical process: that is to say it cannot be understood, it cannot become intelligible nor clear to itself except in the exact measure that we can discern the movements which give it historical form and content" $(1963,36)$. Similarly, settler's responsibility in moving beyond the violence of settler coloniality is always in process and only definable as we live it out. Transforming settler consciousness is not tantamount to decolonization but is an essential piece of radical social change and the end of settler colonialism.

\subsection{A Note on Terminology: Colonization and Coloniality}

Western Eurocentric schools of though have long studied and understood "modernity" in isolation. Decolonial theory, starting with Quijano and Mignolo, asserted that modernity must be understood as co-constituted with coloniality. Quijano (2000) first discussed "coloniality of power" to describe the legacy of colonialism that shapes the social order, predicated on a hierarchy of race, determining the organization of colonial domination and capitalism, all based on the rationality of Eurocentrism (533). From within settler colonial theory, the foundational argument is the colonization is an ongoing process that has not ended (Wolfe, 2006). Differing from Latin American decolonial theory, there are not legacies, because nothing has ended- yet the social order is still fundamentally shaped 
by colonialism, based on white supremacy and serving the function of global capitalism. The school of settler colonial theory (SCT) is grounded in the works of Patrick Wolfe (2006) who explains that settler colonialism is a structure, as opposed to an event, that operates through "logic of elimination" working to dispossess Indigenous peoples, their epistemologies and their ontologies. SCT provides a frame to center this distinction from imperialism or colonization, both of which are not ongoing, and highlights the practices and discourses that function to perpetuate settler colonialism (Wolfe, 2006; Veracini 2010; DiAngelo 2011; Coulthard 2014). In Latin America, different histories of colonization and imperialism have meant conceptualizing decoloniality differently. In this paper, I will use both settler coloniality and settler colonization, as both address capitalism and white supremacy as central to social hierarches, with white Western Europeans at the top, while everyone else seen as "Other". Importantly, both concepts speak to the ongoing nature and the hegemony that Western European epistemologies and ontologies have over society as a result.

\subsection{Theoretical Framework: Combining Settler Colonial Theory and Political Ontology}

Through complex and, at times, contradictory "cycles of threat, unsettlement, and reclamation," settler colonialism maintains white settler dominance and violence against Indigenous peoples (Hiller 2013, 72). From this foundation, part of SCT responsibility is to provide a way of thinking about settler "identities, spaces, sense of place and home, and constructions of land and nation" (Hiller 2013, p. 71). Settler colonial theorists have worked to explain the complexities of settler colonialism built upon an entangled triad structure of settler-native-slave (Veracini, 2010) and can reveal the partiality and 
contradictions within the settler state (Macoun and Strakosch, 2013). Structural power, privilege and agency are experienced differently for different communities and peoples within Canada depending on overlapping axes of power whether that is race, ethnicity, gender or class (Haig-Brown 2012; Veracini 2010; Tuck and Yang 2012; Davis 2016). Along with settler colonialism, SCT can be utilized as a framework for looking at decolonization, and specifically the "roles and responsibilities, settler learning, incommensurability, accountability and ethics" (Davis, Sinclair \& Raven 2019, pg 3). As discussed, SCT needs to be enacted with care and caution, as there are dangers of replicating colonial power dynamics and epistemologies. Settle colonial theory has learned a great deal from critical race theory, which offers a way to understand how race works to structure the world and how the logic and history of white supremacy organizes difference in a hierarchy (Omi and Winant, 1993; Stasiulis and Jhappan, 1995). In the Canadian context of white supremacy and settler colonization, critical race theory has worked to explain how the narrative of multiculturalism is used to create a façade of unity that perpetuates and the invisibilization of what difference means in Canadian society- systemic inequality along divisions of race, gendered, class and sexuality (Bannerji, 2000; Mahtani, 2002). Critical race theorists have articulated how that liberal Eurocentric framework of difference within Canada claims to neutrality and universalism, erasing the normative center of Eurocentric whiteness (Philip 1992; Bannerji, 2000). Importantly, Indigenous studies have long critiqued critical race theory, ethnic studies, and postcolonial theory, for their failure to understand the centrality of Indigenous genocide and settler colonization in North America (Smith 2012, 66). Andrea Smith also points out, when Indigenous studies and critical race theory fail to center the 
analysis of settler colonialism, "both intellectual projects fall back on assuming the givenness of the white-supremacist, settler state" (2012, 67). Increasingly, there is scholarship (Razack 2002; Coultard 2014; Smith 2012) and a growing consciousness among social movements (Walia, 2012) that seeks to analyze the intersections of white supremacy and settler colonization. As I and the settler individuals involved in this project are of white-European descent, the adherence to these intersections will provide necessary reflexivity when interrogating how whiteness is (re)produced as a privileged structural position, a perspective and a normative way of being in the world. Further, there will need to be a constant consideration of the reality that the very identity of a white settler seeking to engage in social change can reinforce white supremacy and settler coloniality. This can arise through performative allyship which, similar to white exceptionalism, is about supporting struggles in order to get recognition from others (often marginalized people), gain social capital, often relying on fetishizing marginalized people, and does not require any change in awareness or action (Saad 2018, 95). Changing settler-indigenous relations "have a multitude of possible dangers if not carried in mindful and self-critical ways, because disengaged (or possessive) curiosity about the 'other' can easily become both fetishizing and objectifying" (Mackey cited in Singer 2010, 37). There is a need for intense attentiveness to these insidious possibilities. As many have pointed out, the effort to transform white settler consciousness must be vigilant in the effort to interrogate how we actively (un)learn oppressive behaviour and seek to betray both oppressive systems (Razcak 2002; Thielen-Wilson, 2012; Tuck and Yang 2012; Morgensen 2014; Hiller 2017). While the work of SCT is valuable, I have also discussed its pitfalls and the potential for its inability to see it's own end. For this 
project, I use a Political Ontology framework in hopes of encouraging conversation between the two theories that will call attention to politics of challenging settler coloniality ontological violence. The theories will complement each other as I reflect on settlers questioning the universality of settler coloniality and entering the space of ontological confusion and negotiation.

A political ontology framework is premised on the assumption that there exists a plurality of ontologies, or worlds, which are not innate, but produced throughout historically situated practices and narratives (Blaser 2009, 11). As discussed, I am arguing that a shift in ontologies is necessary if settlers are dedicated to challenging settler coloniality. Following Blaser's definition of ontologies as grounded in narratives and practices, the way to move toward existence within a different one is to alter one's foundational orientating narratives and one's habitual practices. Narrative inquiry informed by a political ontology framework will allow me to look at ontological encounters that settlers are in and look at the translation that occurs not as apolitical, but as situated in historical power dynamics (while also negotiating them) wherein modernity's settler colonial ontology has historically worked to suppress Indigenous ontologies (Blaser 2009, 16). This narrative inquiry method generally uses questions that help the storyteller address the historical, political, and cultural context. Consideration is taken for the embodied engagement of the teller -- their senses, feelings, thoughts, actions, and the values, beliefs, and intentions that shaped their experience (Etherington, 2013). Necessarily the theoretical framework informs my analysis. The political ontology framework demands I consider the political negotiations of ontologies in and of themselves but also on the interaction of different ontologies and how, through their encounter, work to survive and 
thrive. When considering how white settlers in Canada are destabilizing their consciousness, articulated through their stories, a necessary aspect is the confrontation with Indigenous ontologies and thus the rupture of the universalizing settler colonial ontology. By concentrating on the power dynamics between the dominant settler ontology and Indigenous ontologies, the political ontology framework will reject the dominant narrative of multiculturalism in Canada that reduces "difference" to culture and wherein "we exist in a power-laden world of one nature and many culturally situated perspectives of it" (Blaser 2009, 11). The political ontology frameworks take up Viveiros de Castros' (1998) idea of "multinaturalism" that sees a plurality of natures or worlds and does not seek to reduce difference but look at "what kinds of worlds are there and how they come into being" (Blaser 2009, 11). Decolonial theory will be drawn on in this project because it offers a way of analyzing and challenging modernity's universalizing epistemological and ontological assumptions (consciousness) that facilitate the ongoing hierarchal colonial power dynamics (Latour 1993; Escobar 2008; Blaser, 2009, 2013; Rojas 2016). Through this analysis, decolonial theory's political ontology framework provides a structure for the analysis of how space, identity, knowledge, and power operates at local, regional, national, and international scales. A political ontology framework acknowledges that there are inherent incompleteness and incommensurability between ontologies; yet when paradigms collide (settler and Indigenous) there are partial connections and some translation between them must occur (Lugones, 1987; Viveiros de Castro 2004; Stenger 2004; Chakrabarty 2008; Vazquez 2012; de Lima Costa 2013). This space of translation is not merely a linguistic paradigm, but a process occurring when different ontologies are interacting as a necessary process that brings "worlds into 
conversation" (de Lima Costa 2013, 79). From the understanding that interactions between ways of being and seeing the world is situated within societal relations of power, this space of translation has been described as "an activity of openness to the other", which entails a process of "continuous dislocation" (de Lima Costa 2013, 79), wherein you are "world"-traveling (Lugones, 1987) and beginning to "slow down reasoning" (Stengers 2004, 1). This understanding of translation is necessary for the consideration of settlers confronting their settler colonial consciousness (when realizing that Indigenous ontologies have been displaced, suppressed through colonization and their narratives and assumptions as settlers are a part of a specific ontology). Viverios de Castro (2004) describes that when ontologies collide often there are equivocations- not just a misunderstanding of language- but "a failure to understand that understandings are necessarily not the same and that they are not related to imaginary ways of "seeing the world" but to the real worlds that are being seen" (11). When settlers are dislocated from settler colonialism's universalized narratives, there comes the possibility to understand that equivocal categories from diverse worlds exist and thus the work to find "partial connections" through translation becomes possible (de Lima Costa 2013, 85). Here the violent tendencies of settler colonialism's motive to destroy Indigenous epistemologies and ontologies can be challenged. This framework will be essential in considering how settlers are engaging in challenging settler colonialism.

I will now explain the theoretical underpinnings of a politics of recognition and spaces of ontological negotiation that will set up my analysis for this project and demonstrate how settler colonial theory and political ontology strongly supplement each other. These two spaces were revealed through the stories of the five settlers. Chapter 4 will discuss how 
the myriad of strategies, approaches and spaces facilitated different outcomes for settlers and provided different possibilities for transforming settler consciousness.

\subsection{Glen Coulthard and the Politics of Recognition}

In Chapter 3, I will explore how reconciliation, as defined by settler coloniality, does nothing to transform colonial relations or structures. The reconciliation project piloted by the Canadian state is immersed in a recognition-based approach focusing on recognition of Indigenous cultural identity and spaces of listening and apologizing, all while neglecting the issues of land and political sovereignty. The universalization of the Canadian recognition-based reconciliation project limits the possibilities of fundamentally dismantling settler coloniality. For settlers engaged in the process of transforming their settler consciousness, a politics of recognition does not necessitate transforming their consciousness, their actions, foundational narratives, habits or the structures of settler colonization. To think and act only within the confines of the reconciliation project limits the possibility of settlers transforming consciousness. Twenty years before the reconciliation movement began, Canada's traditional violent assimilative form of colonial strategy began the shift towards a practice of settler colonial recognition and accommodation (Coulthard 2014, 25). In 1994, Charles Taylor's essay "The Politics of Recognition" sparked an academic venture to understand the multifarious and complicated nature of recognition politics and whether they had an impact on the liberation of oppressed populations. Glen Coulthard's 2014 Red Skin, White Mask: Canada's Politics of Recognition, has become well known as a principal analysis in how the politics of recognition in Canada has shaped the recent form of colonial governance and relationship between Indigenous peoples and Canada. His main thesis is that, despite 
the shift in strategy and governance form, settler coloniality's goal remains the same: dispossess Indigenous peoples of their land and self-determining authority (Coulthard 2014, 25). Further, the ongoing colonial mission, demands and depends on Indigenous people "coming to identify, either implicitly or explicitly, with the profoundly asymmetrical and non- reciprocal forms of recognition either imposed on or granted to them by the colonial-state and society" (Coulthard 2014, 25). When settlers are engaging in a transformation in the settler consciousness within a space within a politics of recognition, possibilities of challenging the status quo of settler colonialism are restricted. Coulthard conceptualizes settler colonialism as a structure of domination predicated on the dispossession of Indigenous peoples' land and political authority, based on an appraised form of Marx's primitive accumulation, "in conversation with critical thought of Indigenous peoples and thought" $(2014,8)$. He then uses Fanon's critique of Hegel's master/slave dialectic and his dual structured conception of colonial power to explain how the politics of recognition in Canada maintain the status quo. The mutuality of recognition envisioned by Hegel did not exist in colonialism. There is no mutual dependency because of the structural power imbalance, and thus, recognition does redistribute power or remedy the structural and psycho-affective impact of colonialism. Hegel's idea of recognition, which informs current recognition-based policies and theories, outlines a relational understanding of human subjectivity wherein "one becomes an individual subject only in being recognized by another subject." The Canadian form of multiculturalism is predicated on large-scale exchanges of recognition, wherein the state "recognizes" minority groups. Charles Taylor posits that "difference blind" liberalism is unreasonable and culturally diverse liberal states should "recognize and accommodate" a 
range of group-specific claims without forsaking a core set of fundamental rights (Coulthard 2014, 29). For Taylor, recognition is a human need; misrecognition is oppression, and a "liberal regime of reciprocal recognition would better enable Indigenous peoples to realize their status as distinct and self-determining actors" (Coulthard 2014, 30). Nourbese Philip (2015) explains how multiculturalism is the configuration of power with French and English at the center consistently others all other cultures and as Coulthard (2014) agrees, this structure prefigures its failures to transcend the power dynamics at play. Because it fits within the liberal pluralism of Canada, the politics of recognition allow for the structures of power to remain the same, leaving the domination of settler society intact and the dispossession of Indigenous land and sovereignty the norm (Coulthard, 2014). For individual settlers, this politics of recognition often comes with "celebration" of "culture" and does not facilitate the possibilities of ontological negotiation. This politics of recognition does not demand we have settler society relinquish any land, political, economic, or ontological power (the agency to assert your way of being in the world- that which settler coloniality denies). Coulthard (2014) takes issue with how Taylor has attempted to use Fanon's ideas around colonial social formation and emancipation, advancing that he has missed the dangers of settler recognition Fanon puts forth (32). These critiques are astute critiques of the wider politics of recognition at play in Canada. Fanon explains that coloniality depends on a dual play of the structural/objective (colonial-capitalist) and recognition/subjective (internalization, misrecognition, and alienation) to maintain its hegemonic hold (31). Recognition can be a function of colonialism, most often meaning the colonial power recognizes the colonized population as an object, not subject (Coulthard 2014, 33). 
Recognition need not address the structural economic features, and when it does, it is in the reformist mediums such as specific cultural rights and minor concessions through land claim packages (Coulthard 2014, 35). Further, the liberal form of recognition politics, as articulated by Taylor, posits that Indigenous peoples sovereignty is "dependent on their being afforded cultural recognition and institutional accommodation by the settler state apparatus" (Coulthard 2014, 35). As with reconciliation, the rules of the game are set by the Canadian state, and thus the visioning and possibilities of transformation are limited, as Fanon would say, "by white liberty and white justice" (39). The politics of recognition has a multitude of effects shaping contemporary settler colonial governance. Indigenous demands for recognition have been found to change the subjectivities and worldviews of Indigenous claimants subtly (as cited in Coulthard 2014: Alfred 2005, Nadasdy 2005 \& Altamirano-Jimenez 2004). Moreover, the Supreme Court of Canada has consistently repudiated the recognition of Aboriginal peoples' equal and self-determining status with claims to legal precedent (Asch 1999; Manuel 2015, 2017). As Arthur Manuel (2017) articulates, Canadian law the legal foundation of Canadian "Crown title" is the doctrine of terra nullius which means when Europeans original claim to sovereignty over this land rested on the fact that the land was empty. The courts now have to recognize that is not true, and in fact, the legal foundation is authorized by genocide and theft, which you cannot build a case for a legal title with (Manuel 2017, 89). In many ways, the courts perform sovereignty in order to assert sovereignty. This legal quicksand is precarious at best, but still, the dominance of the settler state has meant that Indigenous collective rights and identities are only recognized as long as they do not "throw into question the background legal, political and economic framework of the 
colonial relationship itself" (Coulthard 2014, 41). The entire legal system is born from the ontological foundation of settler colonialism and the Westphalia systems of sovereignty. When Indigenous communities make claims through colonial courts, the only means possible, not only is it a costly and onerous undertaking, it is also based on the ontological boundaries determined by coloniality (42). The land claim agreements demand extinguishment of Aboriginal title as the first principle of any land deal and the pre-designed cookie-cutter agreements ensure any negotiation is a charade by the state (Manuel 2017). Bonita Lawrence (2012) addresses a similar analysis, articulating how recognition politics has seen Algonquin land title to continuously be ceded, ensuring "self-government" really amounts to a relationship similar to municipal governance. While the politics of recognition and the movement of reconciliation embedded within it have seen a shift in the awareness around Canada's colonial history, all in all, it has

neglected any serious action around land and political sovereignty. As the main goals of settler coloniality is to eradicate all Indigenity: deny any Indigenous ontology, own all land, have complete sovereignty and assimilate all peoples, any politic of recognition and reconciliation that do not seek to dismantle those goals, have proven to maintain the status quo. Unfortunately, as Chapter 3 and 4 will make clear, the normative status of politic of recognition and reconciliation means that well-intentioned white settlers, people just like myself and those who shared their stories with me, remain prone to acting within this recognition framework.

\subsection{Modernity/Coloniality, Slowing Down Reason and "world"-traveling}

Canadian settler coloniality does not exist in a vacuum, rather it can be seen as part of the universal project of capitalist and colonial modernity that began with the beginning of 
European colonization in 1492. Modernity was established by and through Eurocentric epistemologies and ontologies and is co-constituted with coloniality. Decolonial theory holds that coloniality and modernity, two sides of the same coin, became the new global system of power, predicated on a rationality of Eurocentric capitalism and white supremacy, determining the organization of colonial domination (Quijano 2000, 533). Modernity is the epistemological and ontological frame that is inseparably bound to the European colonial project and has a hegemonic hold over ways of knowing and ways of being (Quijano, 2000). Eurocentric modernity propagated a system of binaries, primarily through the divide between culture and nature that separates the subject and object, the former as the knower, the latter as the known. Modern political theorist Thomas Hobbes popularized the idea of the "state of nature" that saw Indigenous peoples of Americas as being a part of nature as opposed to having the status of "modern culture" that European societies had. As a part of nature, Hobbes saw that "their life-worlds [were] the negation of modernity", they were not able to have "culture" as Europeans were. Modern culture had the capacity to be a Subject that has knowledge is the knower, whereas nature is the object, to be known (Rojas 2016, p 371). Western Europeans, on the other hand, were/are seen as the "culmination of a civilizing trajectory from a state of nature leads them also to think of themselves as the moderns of humanity and its history, that is, as the new, and at the same time, most advanced of the species" (Quijano 2000, p 574). Capitalist-colonial modernity claims "the right to be 'the' world, subjecting all other worlds to its terms or, worse, to non-existence" (Escobar 2015, 3), eradicating all other "life-worlds" (Rojas 2016, 370), deeming them not modern, and therefore not legitimate. Modernity established the one universal truth, with Europeans as the subjects with the capacity to 
"know" the truth of the nature that was "out there." It is the very binary that dictates a nature that is "out there" that allows for there to be "the consideration of representational knowledge as universal since observers belonging to different cultures share a universal nature that guarantees the equivalence between different representations of reality" (Blaser 2010, 150 as cited in Rojas 2016, 373). Modernity's divisions, based on epistemic and ontological grounds, have structured settler colonial Canada and elsewhere throughout the globe, through a hierarchy of humans and non-humans along with constructions of race, gender, and class. Modernity's claims to universality limits the possibilities of transforming settler colonialism or any revolutionary changes to societies structures. Many decolonial thinkers have proposed an alternative decolonial project that interrupts the modern commitment to the existence of one world and one truth, a project based on deep relational ontologies between humans, and humans and nature (Rojas 2000, p 369). Whether it is the Zapatistas in Chiapas who call for "a world where many worlds fit", the struggle of Mauna Kea or the Tiny House Warriors in Secwepemc territory who are asserting their collective responsibility and jurisdiction to their lands and waters, there are populations across the world fighting for a plurality of worlds. Radical difference between worlds is not merely epistemic but is a matter of ontology. Encounters between worlds are between not the collision of different ways of thinking, but is the possibility to "challenge the limits of what modernity can conceive of as within its limits" (Rojas 2016, p 379). It is about the space to be encounter ontologies without the presumption of universality of settler coloniality, but to see ontologies constructedness and their embeddedness in practices and narratives. This encounter opens possibilities modernity cannot imagine. For decolonial theorists such as Rojas, the 
alternative decolonial project asks "for subjectivities able to de-identify from capitalism and colonialism and instead desire and create diverse worlds" (2016, 380), "enhanced through collective projects of solidarity, new forms of sociability, and alternative visions of happiness "(2007, 585). Leanne Simpson (2016) or Coulthard (2014) posit that for Indigenous people this can mean, "turning away" from colonial settler society and focusing on the resurgence of their worlds. Tuck and Yang (2012) explain that decolonization seeks explicitly to answer Indigenous futurity but settler fragility and consequent 'moves to innocence' answers settler futurity (p. 3). Further, these moves center settler identities, feelings, and interests without supporting decolonization's demand for Indigenous sovereignty and the return of land (Tuck and Yang, 2012, pg. 28). What the authors poignantly demonstrate is that solidarities and critical pedagogies often seek to find common ground with Indigenous struggles for sovereignty, when in fact the struggles of other social justice movements or oppressed groups do not have the same, or even sometimes contradictory goals as Indigenous peoples (Tuck and Yang, 2012, p.19). What they suggest is an ethic of incommensurability between struggles that does not seek commonality, but embrace the contradictions and tensions between the goals, tactics, strategies and visions. Tuck and Yang contend that it is within these spaces of incommensurability that radical restructuring and change becomes possible (Tuck and Yang 2012, p 34). For example, the social movement in Ontario, Fight for $\$ 15$ and Fairness, is calling for reform to labour standards including a higher minimum wage. In essence, the reforms maintain the supremacy of capitalism as the economic system and the colonial state, which would enforce the reforms. If the goal of decolonization is to assert Indigenous sovereignty, the end the supremacy of colonial state is necessary (and 
the power of capitalism that underscores the states power). Clearly, the goals of the Fight for $\$ 15$ and Fairness and decolonization are incommensurable. In practice however, the incommensurability has not prohibited encounter between the labour social movement and Indigenous decolonial struggles. In early 2019, Fight for $\$ 15$ and Fairness was vocal and active in solidarity action with the Wet'suwet'en struggle against a pipeline going through their territory. $\$ 15$ and Fairness has become a part of the social movement \#UniteAgainstRacism, which is a migrant rights network demanding the protection of migrant rights, not to gain access to the settler colonial state, but to build relations with the Indigenous peoples of the land. The labour movement through narrative and action, made the move to work for the liberation of workers, migrants and Indigenous communities. Despite incommensurability between the struggles, there has been unlikely alliances built between the labour movement, migrant rights movement and decolonial struggles.

Moreover, in settler colonial Canada, whatever the project(s) is to challenge settler coloniality, settlers need to not only see their complicity and investments in it but need to be willing to let go of commitment to narrow goals, strategies, ontologies and epistemologies. For this, there is a need to "slow down reason" (Stengers 2004) in order to "travel" to new "worlds" (Lugones, 1987). These ideas are useful in thinking about how the community groups participated in spaces beyond a politics of recognition. Isabella Stengers (2004) suggests the universalizing impulse that assumes a "good common world" exists, but instead "create a space for hesitation regarding what it means to say "good" (2) and "resist the temptation of a peace intended to be final, ecumenical: a transcendent peace with the power to ask anything that diverges to recognize itself as a 
purely individual expression of what constitutes the point of convergence of all (3). A politic of recognition does not allow for ontological difference (Stengers 2004, 3) but through this slowing down of reasoning, there begins to be possibilities of negotiation between ontologies, without the intention of commensurability, and beyond the prison of modernity/coloniality universalism. Listening within this space of negotiation, confusion and understanding, that holds space for infinite possible divergent worlds, demands more than just open ears, but rather an embodied experience of listening that sees one "slow down reasoning" (Stengers, 2004, p. 1). This slowing down that challenges your consciousness opens a space for reflection and a possibility of a new awareness and subsequent action (Stengers, 2004, p 1). In exploring the potential of pluralistic feminisms, Maria Lugones (1987) developed the ideas of "world"-traveling. Acknowledging that as outsiders to the center of power women of color in the U.S. practice "world"-traveling from their "home" to the White/Anglo "world" (read modernity), out of necessity to survive (3). She argues that the compulsory nature of the "traveling" for those with marginalized ontologies has resulted in a loss and internalization of valuing of people's "homeworlds" (other than modernity). Modernity's denial of other worlds, as described by decolonial theorists, has denied whole worlds, the humanity of so many and the capacity for loving connection between radical difference. Lugones explained that she developed this concept "through the kind of ontological confusion" (9) seeking to understand how to love across cultures, racial difference-across worlds. In her words,

"For something to be a "world" in my sense it has to be inhabited at present by some flesh and blood people. That is why it cannot be a utopia... A "world" in my sense may be an actual society given its 
dominant culture's description and construction of life, including construction of the relationships of production, of gender, race, etc. However, a "world" can also be such a society given a non-dominant construction, or it can be such a society or a society given an idiosyncratic construction. As we will see, it is problematic to say that these are all constructions of the same society. But they are different "worlds...In a "world" some of the inhabitants may not understand or hold the particular construction of them that constructs them in that "world." So, there may be "worlds" that construct me in ways that I do not even understand. Or it may be that I understand the construction, but do not hold it of myself. I may not accept it as an account of myself, a construction of myself. And yet, I may be animating such a construction... The "one" here does not refer to some underlying "I." One does not experience any underlying "I." (10)

When thinking about settlers in settler colonial society, the idea of 'world'-traveling is useful, because it permits the move away from modernity's parameters and claims to universality. Travelling, in this sense, reveals the infinite plurality of ontologies and their specificity and historicity. Travelling between ontologies also reveals that ontologies are grounded in narratives and practices (not some universal truth or way of being) and thus moving beyond modernity demands existence shifting one's foundational narratives and one's daily practices. However, there is a need to caution that "travelling to new worlds" holds the danger of the facilitating a sort of "tourism" or appropriative exploration, that sees particularly white settlers reproducing colonial tendencies to study the "Other". Further, if settler's commitment to transforming their settler consciousness only focus on "learning about" Indigenous ontologies, this is the quick slippage into the settler move to innocence that focuses on "consciousness raising" with no change to practices or accountability to Indigenous sovereignty. With these dangers always in mind, I posit that the travelling worlds Lugones developed is a useful conceptualization to explain the way ontological shifts and negotiations occur. It attends to the need to move away from a 
politic of recognition that subsumes difference into the liberal narratives of multiculturalism and human rights, all while leaving the ontological foundations of settler coloniality intact. The need to unsettle ourselves from modernity/settler coloniality is paramount if we are to challenge the hegemonic hold it has on society. Similar to how politics of recognition was facilitated by certain conditions and dynamics, the space of 'world'-traveling was also made possible by specific elements of the two community groups.

\subsection{Research Methodology}

Relying on the stories of lived experience from the individuals involved, this research aims at articulating the multi-layered intentions, meanings, and effects that white settlers are navigating in their process of "unsettling the settler" and how these initiatives did, or did not, catalyze transformed settler consciousness for the individuals involved. The multi-layered complexity was revealed through my interpretation, but often participants also explicity pointed out complexity and contradictions they experienced. This research essay uses people's stories as told by them, as one of the sources of knowledge. I contend that settler's stories can teach us the nuances of consciousness in ways that traditional methods of research and views of truth cannot. As a methodology, narrative inquiry uses storytelling methods to unveil 'knowledge' as it is "created and constructed through stories of lived experiences, and the meanings created" (Etherington 2013, 5). In some ways, the narrative inquiry is limited because there is an assumption that the person's awareness of their intentions, biases and all that is meaningful to them, is fully available, particularly at the time of the interview. As Cladin (2016) postulates, "the knowledge developed from narrative inquiries is textured by particularity and incompleteness; 
knowledge that leads less to generalizations and certainties (Clandinin \& Murphy, 2007) and more toward wondering about and imagining alternative possibilities" (emphasis added). Married with a political ontology framework, the narrative inquiry understands the unveiled knowledge through a prism of knowledges from decolonial theory, settler colonial theory, the storyteller knowledges and my own lenses/biases. Narrative inquiry is a form of interpretive research which is based on the notion "that social reality is not singular or objective, but is rather shaped by human experiences and social contexts (ontology), and is, therefore, best studied within its socio-historic context by reconciling the subjective interpretations of its various participants (epistemology)" with the social context (Bhattacherjee 2012, 103). It is decolonial theory and settler colonial theory that are shaping my interpretation of the "socio-historic contexts". Like in critical feminist methodologies, knowledge is seen as situated, meaning no research can be taken from a neutral or timeless vantage point because how we know, act and communicate depends on a plethora of context. Moving from the assumption that reality is embedded in social context and not a singular truth, I use narrative inquiry to unravel and analyze reality through a "sense-making" processes rather than a hypothesis (Bhattacherjee, 2012). Though I did not have a hypothesis, the assumptions and understandings I carry from decolonial theory, settler colonial theory and my own personal experiences shaped the sense-making process. Still, I utilized a narrative inquiry method because it challenged positivist methods of research and modernist views of truth and knowledge. These ways of researching defy the reductionist nature of positivist research and resist overarching narratives by the very questioning the epistemic and ontological nature of phenomenon (Etherington 2007). Starting from individual's storytelling, narrative inquiry collects and 
analyzes people's experience through organic, dialogical processes. The researcher understands subjectivity as being a representation of their life, (not complete, but a depiction) that is told in a particular context—-the time, place, researcher, intention--- and thus all have a bearing on how the subjective stories of meaning and self are communicated by the storyteller as well as analyzed by the researcher (Etherington, 2013). The researcher is oriented from 'curious, not knowing' position (Anderson \& Gehart, 2007) and the construction of meaning is a dynamic, non-linear process between the researcher and storyteller, occurring during the research process not just after "data collection" (Etherington, 2013). The curious, not knowing, does not mean to imply a "objective stance"; I had specific curiosity, communicated by the questions I asked and pointly shaped by the theoretical framework I grounded this project in. Learning from feminist research, narrative inquiry acknowledges that the modernist research methods ideal that the researcher must be "separated" from the research in order to achieve "objectivity" is impossible to achieve. This feminist research principle will depend that I not only recognizes but also embraces that I, as a researcher, influence the process and outcome. The researcher's interest and connection to the research are also acknowledged in both the process and analysis. This can work to challenge the traditional power dynamic between researcher and participants, wherein the researcher is the "knower," and the participants are simply having "data" extracted from them. Furthermore, researchers ask questions but also are open to sharing experiences relevant to the conversation, to facilitate a conversation versus an interview (Etherington 2004). In the article Ethical Research in Reflexive Relationships (2007), Kim Etherington demonstrates within narrative and life story methodologies reflexivity, and vulnerability from researchers can 
create ethical relationships that can deepen the generation of knowledge and insights. Because stories are told and created between storytellers and their audiences, the relationship between storytellers and researcher (the audience in this case) is intertwined with how the research process unfolds. Part of this is in the analysis, the biases I brought to it and the theoretical frameworks I deployed. Part of this was how the relationship was established in the moment of meeting and the time spent together. As a young white woman interviewing older folks, age, gender and racial relations shaped how the interviewees interacted with me and what they chose to share with me. As another white settler, it is possible there was a certain level of comfort that the interviewees felt, because of the similar privileges, feelings and emotions we experience. As a younger person, there were moments where the interviewees related to me as someone they could "impart wisdom on" or I represented a generation of social change makers that gives them hope in the future. Based off of decades of narrative inquiry research with people in counselling and psychotherapy, Etherington notes that within pedagogical relations, "the researcher, as audience, may become actively involved in co-constructing previously untold stories by asking curious questions that help thicken and deepen existing stories and invite the teller into territory beyond what is already known to him or her. The stories that are told and received are therefore influenced and informed by what tellers, as well as the audience, bring to the relationship from their own lives and contexts." (Etherington 2007, 600). Reflexivity must be ongoing, meaning the researcher is continuously thinking about how your social locations, relationships, and the context shape the research you are doing and the knowledge you are producing. By bringing transparency to researchers' biases and assumptions to transparency, Etherington notes can "let slip the cloak of 
authority, lower the barrier between researcher and researched, and allow both sides to be seen and understood for who they are" (Etherington 2007, 600). However, it must be noted that there is no way biases and assumptions will ever be fully transparent. Similar to how the narrative inquiry is limited in "accessing" the interviewee's consciousness, as the interviewer I am not fully aware of all my biases and assumptions. Further, while it is important to be reflexive of the myriad of power relations between interviewer and interviewee, there is limit to degree in which they unequal power dynamics can overcome. Despite the various limitations of the narrative inquiry, the methodology provided a reflexive process of moving from exercising storytelling as the partial knowledge and then bringing in to contact with other research from Indigenous studies, critical race theory and settler colonial studies to cultivate insights of how white settlers are transforming their consciousness, and the paradoxes and challenges of the work. 


\section{Chapter 3: Truths and Reconciliation: An Ontological Dispute between}

\section{Worlds}

Understanding the ontological foundations of Canada's project of reconciliation reveals the ongoing intent to carry out settler colonial's goals of the extermination of Indigenous sovereignty and complete control over land. Though there are a myriad of ways to carry out "reconciliation", yet the one paraded by Canadian settler colonial society claims universality thereby limiting possibilities within settler colonial parameters, ignoring Indigenous ways of reconciliations. This chapter takes up the task of contextualizing the narrative inquiry with the five settlers within the current socio-political moment and developing the critique of Canada's settler colonial reconciliation project that informed how I carried out the narrative inquiry and analysis. It will lend an understanding of the difference between the functions of engaging in a politics of recognition compared to the stepping into ontological shifts where radical transformations beyond settler coloniality are possible. Despite the international proliferation of reconciliation projects and the national mainstreaming of the term "reconciliation", there is not an agreed upon or comprehensive definition of the word. Though the dictionary definition is "the restoration of friendly relations," academics, communities and policymakers have all sought to define reconciliation in different contexts, but the countless and incongruous versions and at times conflicting meanings have proven hard to pin down (Daly and Sarkin, 2007; Maddison, S., Clark, T., \& De Costa, R., 2016). Nonetheless, it remains vital to interrogate the concept of reconciliation, as it has taken hold as the primary descriptor of changing relations between Indigenous and non-Indigenous peoples in Canada. Of 
critical consequence is the fact that the Canadian settler state has effectively presented reconciliation as a unified social paradigm, representing a universalizing definition and cohesive project (Henderson and Wakeham 2013, 9). This universalizing effort, inherent in settler colonial epistemological and ontological covenants (Escobar 2013), obscures the debates, negotiations, and roots of the recent movements of reconciliation. For settler's engaged in seeking to challenge the status quo, it is essential to see the universalizing attempts and understand the settler colonial underpinnings of Canada's reconciliation project. The settler coloniality of reconciliation limits the potentials of transformation- on an individual, collective, and relational levels, and this is critical for settlers to understand if we are to engage in transforming our settler consciousness.

The proliferation of debate around the meaning of reconciliation spread in Canada after June 2008, when the federal government made a public apology in the House of Commons for its pivotal role in residential schools. It is important to note that this was not a sudden or spontaneous apology or moment of realization for the Canadian government. First, the two decades before the 2008 apology had seen the state respond to the demands of communities who have faced violence and oppression, historically and into the present, including Japanese-Canadians, Italian-Canadians, Inuit communities, Acadians, Ukranian Canadians and Chinese Canadians (Henderson and Wakeham 2013, 6). The reconciliatory attempts have taken different forms, "spanning from official and semi-official apologies to fiscal reparations and token concessions, and even settlements designed to produce the semblance of reconciliation while evading an admission of culpability" (Henderson and Wakeham 2013, 6). Secondly, rather than a random event or even a symptom of a generous and reflective state, the apology of 2008 happened 
because of decades of effort by Indigenous communities and organizations (Henderson and Wakeham 2013). When Stephen Harper's government made the apology, many saw it as a turning moment in Canadian history and there was a spike in public, media and academic attention to changing Indigenous-settler relations and the need for reconciliation (Henderson and Wakeham 2013, 3). There is no denying that since 2008, there has been a growing awareness around the history of colonization and a shifting terrain around Indigenous-settler relations and it is important to acknowledge and honour the work that has been done, particularly the immense effort by Indigenous organizations and communities demanding right relations. Furthermore, it marks a time when there began, for the first time, a national mainstream discussions about 'non-Indigenous peoples' as a significant category opposed to the habitual focus on the "problem" lying with Indigenous peoples (i.e the justification of residential schools being needing to get "rid of the "Indian problem") (Maddison, S., Clark, T., \& De Costa, R., 2016). Though the growing reach of reconciliation narratives, many have suggested it is wise to remain cautious and critical of how reconciliation is represented by the Canadian state, media, and institutions. As much as the settler society controls the representation of itself and history, it also seeks control over the meaning of reconciliation. As Henderson and Wakeham (2013) warn, "the appearance of discursive unanimity between Aboriginal groups and the state- with the invocation of "reconciliation" as a shared signifier for renewed relations - may, however, obscure the complex negotiations surrounding the slippage of meanings attributed to this word, ranging from serious political and socioeconomic transformation to the maintenance of the status quo" (9).

\subsection{Truth and Reconciliation Commission Report: Four Years Later}


Since it was released in 2015, the Truth and Reconciliation Commission Report (TRC) is often pointed to as a keystone of reconciliation in Canada and a guideline that Canadian society should follow in redressing relations with Indigenous nations, communities, and people. The TRC, which was mandated by the Indian Residential Schools Settlement Agreement, aimed to use truth-telling to promote healing between residential school survivors and Canadian society. Beginning in 2008, the Truth and Reconciliation Commission held hearings across Canada, providing a space for Indian residential school survivors and their families to share their experiences in Indian Residential School System and the residual and intergenerational effects (Truth and Reconciliation Commission Report 2015). The TRC was a space that Indigenous communities and realities were visibilized and listened to for the first time and thus held great purpose and meaning for many involved. Further, the TRC held wider meaning for Indigenous and non-Indigenous people across Turtle Island because it held that "reconciliation is about establishing and maintaining a mutually respectful relationship between Aboriginal and non-Aboriginal peoples in this country" (TRC Report, 2015, 6). The Truth and Reconciliation Report provides a list of 94 Calls to Action that intend to "to redress the legacy of residential schools and advance the process of Canadian reconciliation" (TRC Calls to Action Report, 2015, p. 1). These Calls to Action provide recommendations for all levels of government, child welfare to health to the legal system, business, media, churches, and educational institutions, asking each sector to address the legacy of colonization within their structures. Four years after the TRC report was released, the question remains, did the truth-telling and bearing witness catalyze a process of 
transformed relations? Was it enough to move settlers to challenge the settler colonial structures that are the foundation of Canada?

In many ways, the so-called "era of reconciliation" can be seen as a façade attempting to mask the continued violence and land theft at the expense of Indigenous sovereignty. Four years after the TRC was released, the actions of the state have directly and indirectly violated the call to actions. For example, number 43 states, "we call upon federal, provincial, territorial, and municipal governments to fully adopt and implement the United Nations Declaration on the Rights of Indigenous Peoples as the framework for reconciliation" (TRC Calls to Action Report, 2015, p. 4). Yet, in June of 2019, Bill C262, a legislative (and not the first) attempt to align Canadian law with UNDRIP was blocked by Senate, with Senators and MPs of the Conservative Party expressing fears of economic and legal consequences (Brake 2019). This was exemplary of the ongoing ideological opposition to the assertion of Indigenous rights, particularly when they are seen as a threat to economic profit. Moreover, in February of 2018 the Liberal federal government announced a legislative framework on the "Federal Recognition and Implementation of the Inherent and Treaty Rights of Indigenous Peoples in Canada" that, in essence, aims to replace the Comprehensive Land Claims and Inherent Right Policies, which have defined the modern treaty framework between Indigenous peoples and the Canadian government since the 1970s (King \& Pasternak, 2018). Immediately, grassroots Indigenous groups Defenders of the Land, Idle No More and Truth Campaign, mobilized to challenge this legislation. They issued a press release calling for direct action to "stop the Trudeau government's Indigenous rights termination plan... the existing path the government is taking [is] a direct threat to our sovereignty, our international right of self- 
determination, our Treaties and our Aboriginal Title and Rights" (Indigenous Action Network, press release 2018). As the Trudeau government constantly touts the prioritization of reconciliation, this framework epitomizes the critique of many: reconciliation requires no changes to the ongoing colonization by Canada. Former Justice Minister and Attorney General Jody Wilson-Rabould, a member of the We Wai Kai Nation, explained that her "fear and disappointment is that, despite sounding the alarm, providing advice, pushing and challenging, sharing perspectives of lived Indigenous experience ... the federal government has fallen back, once again, into a pattern of trying to - quote - manage the problem with Indigenous Peoples" (Kane, 2019). Moreover, as I write this, the Canadian state is carrying out multiple violent attacks on Indigenous land to facilitate the expansion of resource extraction industries. On the east coast, the federal government has sanctioned the invasion of unceded Mi'kmaq territory to allow Alton Gas Company build a natural gas storage facility, even though the project violates Treaty law and entails releasing brine into the river which violates Environment Canada's guidelines (Googoo, 2019). The Nova Scotia Supreme Court upheld an injunction from Alton Gas that banned Mi'kmaq water protectors from protecting their territory (Council of Canadians, March 2019). On the west coast, there has been multiple court injunctions ordered to allow Coastal GasLink Pipeline Ltd to build pipeline on Wet 'suwet' en territory, despite the violation of Constitutional law that this entails. Both invasions validated by the Canadian state have seen RCMP presence and the violent arrests of water and land protectors (Unist 'ot' en Camp, 2019). While acknowledging constant awareness and challenging of the ongoing violence is crucial, it is important to hold nuance and complexity for the TRC and other elements of reconciliation. The TRC was a 
space for Indigenous peoples to be heard and importantly has acted as an important catalyst for many spaces across society including education, religion, community and media. There is not a universal denunciation of reconciliation by Indigenous nations and peoples, and many still are invested in the efforts as a means of advocating for their rights and sovereignty. While at times "reconciliation" is mobilized by settler colonial society (the state, corporations, media) only in rhetoric, without any substantial action. Indigenous communities will also mobilize the reconciliation rhetoric to hold Canada accountable. Nested within the context of the continual violation of Indigenous rights, it is clear Canadian settler society continues to systematically dispossess Indigenous peoples of their land and sovereignty, all while giving lip service to reconciliation.

\subsection{Settler Coloniality's Reconciliation}

Undeniably, despite the continued reference to the TRC as the bedrock of reconciliation and the important role it played in providing space for survivors of residential schools to be heard, there remains vast colonial injustice built into the structure of Canada. Indigenous peoples and allies have criticized the Truth and Reconciliation Commission, but more so the with broader reconciliation movement. While proponents of reconciliation believe that it has the power to right historical wrongs, those more critical think reconciliation is a smokescreen and ineffective in making any material change. From a political ontological framework, I will now discern the ontological foundation of reconciliation. In this important task, it is critical ground this discernment in the reality that the settler colonial society holds the systemic power to define reconciliation in the mainstream and is built on the denial of other epistemologies and ontologies. As introduced in chapter one, the reconciliation project steered by the Canadian settler 
colonial society is immersed in a recognition-based approach wherein Indigenous peoples' "assertions of nationhood with settler-state sovereignty [are reconciled] via the accommodation of Indigenous identity-related claims through the negotiations of settlements over issues such as land, economic development and self-government" (Coulthard 2014, 151). This reconciliation celebrates and respects Indigenous rights only insofar as it does not interrupt colonial-capitalist imperative. As Arturo Escobar puts it, "the project of capitalist and colonial modernity arrogates for itself "the right to be 'the' world, subjecting all other worlds to its own terms or, worse, to non-existence" (Escobar $2015,3)$. The framing of reconciliation as a universally defined and controlled project, a partnership between Indigenous and non-Indigenous nations is not coincidental, but a strategic move that aims to maintain control over the political and ontological order of this land (Henderson and Wakeham 2013). Strategically, the universalized narrative of reconciliations, upholds Canada's image as a peacekeeping, multicultural haven and allows the Canadian state to keep up with the global trend of liberal-democratic nationstates engaging in historical redress, to which is now a "criterion of admission to the international civil society of free-trade zones and corporate investment" (Henderson and Wakeham, 2013, 8). The Canadian reconciliation project, that is revered to be transforming relations, is a creation of its own understanding of the political- that is the modern sovereign nation-state, underscored by the colonial goal of completion. The portrayal of one unified meaning of reconciliation, allows for the invisibilization of the multifarious meanings and ontological foundations of reconciliation, always resulting in the universalization of the settler colonial aims and definition. Moreover, this project of reconciliation demands "Indigenous forgiveness and Indigenous consent to continued 
occupation" (Erica Lee 2016, as cited in Strakosch 2016b, p 20). From the liberal foundation of the Canadian state, reconciliation means understanding colonialism as a thing of the past, ending with the last residential school closed in 1996, and now reconciliation, for settlers, means apologizing and moving on (Epp 2008; Coultard 2014). A few scholars have pointed out that the reconciliation movement tends to have a focus on residential schools and as a result, discourses on reconciliation tend to ignore the broader structures of colonialism that continue to shape the very fabric of Canadian legal systems, education systems, media and policies (Simpson 2011, 22). Kahnawake Mohawk Professor Audra Simpson (2016) sees reconciliation, especially the TRC, as a voyeuristic project, wherein the state is seeking innocence and absolution, through the exploitation of residential school survivors' pain, without actually addressing the structure of settler colonialism, land retribution or Indigenous sovereignty. Within reconciliation, forgiveness is demanded, and the "cost of justice is pain, and value is set in the market of sympathy" (Simpson, 2016, n.p). However, as Manuel points out, "the issue is not behaviours but fundamental rights - our land rights and the inalienable right to selfdetermination. The remedy is not apologies and hugs but recognition and restitution [of land and sovereignty]" (Manuel, 2017, p. 27). The focus of cultural recognition ensures that the violence and dispossession of land and sovereignty remain the status quo (Coulthard 2012).

In her article, The Ruse of Consent and the Anatomy of Refusal, Simpson (2017) describes how the state created the need to "manage" First Nation reserves and forgotten through settler colonial amnesia and myths of peaceful Canada. As settler coloniality works to forget its drive, it then use structures of so-called "consent" in land claims and 
'citizenship,' framed through ideas of reconciliation to complete it. These settler colonial structures are contested by Indigenous people very existence, as they serve as a reminder of the ongoing colonial drive, that we are so desperate to forget. Here, 'settler time' is revealed as the fiction of the presumed neutrality of time itself, demonstrating the dominance of the present by some over others, and the unequal power to define what matters, who matters, what pasts are alive and when they die" (Simpson 2017, 22). It is through modernity's linear and universalized conception of time, wherein the future and past are understood as one story of "progress" (Chakrabarty 2008) that settler coloniality operates. Settler time demands the continued dispossession of land and Indigenous sovereignty, marching "forward" to progress" to settler colonialism's end goal. The past decade of reconciliation has seen the federal government put a rush on land claims (Henderson and Wakeham, 2013). Though there have been significant wins for Indigenous nations and land rights, including the 2014 Delgammukw decision or the Haida decision, the state refuses to alter the comprehensive land claim policy to align with the Supreme Court's decision protection of Aboriginal title and rights (Manuel 2017, 101). This policy continues to demand that Indigenous nations surrender their Aboriginal title and rights and the decision is, in reality, determined by the Canadian state before the nations even get the negotiating table (Manuel 2017, 102). Through Canadian law, Canada manages to "pretend that this, in fact, was not a theft, that all parties consented to this fully and that appropriation of land was just" (Simpson 2017, 28). Further, since the late 1970 's neoliberalism has changed the way reconciliation, specifically land claims are conducted. From the assumption that settler society's judgment of what is right and needed, ethics of "heritage" commodification and 
individualism facilitations a narrow selecting of certain historical injustices to be commodified into state directed reconciliation actions (Henderson and Wakeham, 2013, 19). Individual equality and economic participation go hand in hand and are prioritized over collective rights and sovereignty (Strakosch, 2016a). Policy is used to depoliticize the fundamental colonial issues of land dispossession, and narratives of economic management are used to assimilate Indigenous peoples economic (and social) behaviour, intervene in nations and communities decision making to force assimilation (Strakosch, 2016a). This continued dispossession of land stems from, not only settler coloniality's time, but also the conception of land. For settler coloniality, the land is a resource for an ever-growing expansion of sovereign control and serving to satiate the capitalist expansion of Canada. Coulthard explains how the imperatives of colonial-capital accumulation have always tried to destroy the Indigenous worldview and place-based ontological framework for understanding relations (Coulthard, 2010, 81). From an Indigenous ontology, "it is a profound misunderstanding to think of land or place as simply some material object of profound importance to Indigenous cultures (although it is this too); instead it ought to be understood as a field of 'relationships of things to each other.' Place is a way of knowing, experiencing, and relating with the world..." (79). The continued theft of land, even when obscured through narratives of reconciliation, land claims or management, still constitutes settler coloniality's "time-oriented understanding of the world" Coulthard" and the denial and repression of Indigenous ontological placebased orientations. In sum, the obstinacy of an assimilationist, recognition-based reconciliation project, as defined by the Canadian state (though portrayed as universal), focuses on recognition of Indigenous cultural identity and spaces of listening and 
apologizing, neglecting the issues of land claims and political power. This universalized recognition based reconciliation project limits the possibilities for Indigenous rights to be met. For settlers engaged in the process of transforming their settler consciousness, understanding the ontological foundations of settler colonial state reconciliation is necessary because it illuminates the limits and potentials. What are the intentions behind the project of reconciliation discursively framed by the state? Do they challenge the status quo? Are they inclusive of Indigenous ontologies? And the question remains, how do we move beyond the settler colonial impulse to define Indigeneity and reconciliation?

\subsection{Ontological Confusion, Partial Connections and Negotiations: Reconciliation}

To discern the ontological differences between alternatives, a postcolonial analysis of cultural translation is useful. Claudia de Lima Costa's (2013) insights on decolonial feminism in Latin America lends a brilliant conceptualization of ontological encounter. De Lima Costa explains how the concept of difference here does not mean "difference from", but "the Derridean concept of difference...which according to [Stuart] Hall, points to "a process that is never complete but remains in its undecidability" (de Lima Costa 2013, 78-79). In de Lima Costa's work, she looks to decolonial theorist Boaventura de Sousa Santos, that any perspective being communicated or encountered between this kind of difference will always be incomplete and incommensurable. For this encounter, Santos suggests a theory of translation as dialogic negotiation, "articulating a mutual-- and nonhierarchical--- intelligibility of the world" (de Lima Costa 2013, 79). This space of encounter and translation requires a process of "continual dislocation" (Santos, 2006) a readiness to not be where you usually "are" and an openness to other and radical 
difference. de Lima Costa asserts, "translation - based not only on a linguistic paradigm but more importantly, on an ontological one ---is a key element in forging political alliances and feminist epistemologies that are pro-social justice, anti-racist, antiimperialist and decolonial" (de Lima Costa 2013, 91). Through encounters, equivocations are inevitable. Borne from Amerindian perspectivism, equivocations are what appears to be the same but may not when signified by different communities, "not only deception, misconception, but failure to understand that there are different understandings of different worlds" (de Lima Costa 2013, 84). This "miscommunication" between ontologies demands translation. It is from an intentional and political space of translation "that the pluralities of worlds [can become] interconnected without becoming commensurate" (de Lima Costa 2013, 85). Translation permits the radical difference of the pluriverse and embraces the equivocations between them while creating space for what Marisol de la Cadena calls "partial connections". While looking at the way Andean indigenous communities' challenges the Andean nation states attempts to deny ontological difference, she posits that Indigenous nations are "partially connected" with Andean nation-state institutions because of the history of relations, colonial as they may be (de la Cadena 2010). Partial connections, first developed by Marilyn Strathern (2004), "refer to a relationship composing an aggregate that is "neither singular nor plural, neither one nor many, a circuit of connections rather than joint parts" (54). Partial connections create no single entity; the entity that results is more than one, yet less than two" (de la Cadena 2010,347). This conceptualization evokes an imagery of a space of tangled encounter, where translation is possible without the tangles subsuming each other. For the Canadian state and Indigenous nations, for settler communities and 
Indigenous communities, the encounter is between settler coloniality and the plethora of indigenous worlds that have been on this land for time immemorial. The difference here is not merely different from each other as cultures, but a difference of worlds, of ontologies and epistemologies. From this perspective, reconciliation can be seen as an equivocation- carrying diverging meanings for different worlds. In order to see the potential of reconciliation, beyond the colonial version perpetrated by the state, requires a space of translation where the partial connections are not denied, as they habitually are by settler coloniality. Though Coulthard's analysis of the violence of recognition-based reconciliation, discussed in Chapter 2, is astute, I posit that reconciliation remains important for many Indigenous peoples and listening to partial connections is critical if forms of reconciliation beyond settler coloniaity's parameters are to exist. It requires a space of negotiating ontologies, not violent oppression of Indigeneity by settler coloniality. Settler coloniality cannot imagine an end to itself that does not include achieving its goal, "it is trapped in its own tragic and permanent incompletion" (Strakosch, 2016b, p16). Elizabeth Strakosch (2016b) posits that settler visions for decolonization or reconciliation are inherently intertwined with settler colonization central aim of completing colonization and erasing Indigenous political independence (i.e the settler colonial reconciliation project). Similar to the ideal of partial connections, Strakosch explains instead of settler colonial society conceptualizing politics as a means to an end, we ought to treat the political as a 'middle thing' where two political orders can meet (Strakosch 2016b). The political order, though Strakosch alludes to it, is never fully explained as an ontological difference, but recognizes that the idea of a plurality of political orders is possible, though denied by settler colonialtiy. In settler coloniality, the 
middle thing is "suppressed, not by potentially incommensurate understandings of what is acceptable and politically possible, but by the dominance of one understanding, which preconfigures political possibilities" (Strakosch, 2016b, p 17). Any relation with Indigenous peoples and nations should happen through settler political and legal frameworks because they are understood to be universal. With this understanding of relationality, "translation" is prevented, partial connections denied and radical difference not understood. Settler coloniality imagines that our reconciliation project is transformative, but always with setter colonial visions of transformation, politics, and Indigeneity and never with the possibility of a plurality of worlds. As Strakosch (2016b) puts it, "we imagine we are in conversation, but this conversation is held with an imagined other rather than with the 'Aboriginal polity that already exists' (Murphy 2000)" (20). However, similar to de la Cadena's idea of partial connections, and to what Tuck and Yang call the "spaces of incommensurability," Strakosch sees that the middle space need not swallow each other and goals need not become commensurate. Beyond settler coloniality, there are different imaginaries of the dismantling of settler colonization, such that we, white settlers, cannot even begin to imagine because we have spent so long denying possibilities of genuine ontological negotiations. It is worth repeating, Tuck and Yang (2012) remind us that decolonization necessarily answers to Indigenous futures and that those goals (of which land return is central), may not be commensurate with settler futures and settlers need to sit in the discomfort of the unknown rather than fulfilling the systematic habit of denying ontological difference and destroying Indigenity. For de Lima Costa, de la Cadena and Strakosch, the middle thing or partial connections, is about the beginning of a dialogue where what will come out of it is unclear and possibly 
unending. I see this space as being an important step in the discomfort Tuck and Yang are speaking of. Importantly, settlers need to challenge the taught ontological understanding that our subjectivity is not universal and understand we are always in relationship with Indigenous peoples, by nature of being colonizers on this land, that we are always engaged in partial connections (Strakosch 2016b). Settler colonial concepts are not enough to destabilize settler colonial, and these spaces of encounter, or the middle space, hold the possibility to destabilize the ways of thinking and being for settlers and settler states in ways that the politics of recognition will not. It requires reconciliation beyond settler colonial visions.

\subsection{Broader Interpretations \& Kinship Obligations}

Leanne Betasamosake Simpson, Michi Saagiig Nishnaabeg activist, scholar, writer, and poet explains "for reconciliation to be meaningful to Indigenous Peoples and for it to be a decolonizing force, it must be interpreted broadly" (Simpson, 2016, p.22). She describes that the resurgence of Indigenous peoples' political traditions are necessary for real reconciliation because that will enable true nation-to-nation relationships, not a homogenous group with all Indigenous peoples forced into a box of "Aboriginal Canadians" (Simpson, 2016). From the premise that settler coloniality is not the only ontological reality, it becomes clear that if we as a settler society want to transform colonial impulses and engage in true nation-to-nation relations, we need to not only recognize but embody alternative paradigms through our political and legal structures, through individual and collective efforts. In Volume 6, the TRC states, "if Canada is to transform its relationship with Aboriginal peoples, Canadians must understand and respect First Nations, Inuit, and Métis peoples own concepts of reconciliation. Many of 
these concepts are found in Indigenous law" (TRC Report Volume 6, p 46). If Indigenous peoples' traditions and practices of truth-telling and reconciliation are not centered as a part of the ongoing movement to transform relations between Indigenous nations and Canada, the reliance on settler colonial logics and ontologies will merely recreate settler colonial relations of oppression and violence. The first European colonizers arrived at the shore of Turtle Island to find complex legal and political systems amongst and between First Nations, that shaped how nations already here engaged in relations through trade, marriages, war, treaties and justice (Borrows 2002). Though in small ways Canadian constitutional law has "incorporated" Aboriginal law, most often, "Canadian law seems to be more attentive to non-Aboriginal legal sources, which consider Indigenous legal rights as emanating only from the sovereign" and results in Indigenous people, lands, rights, and treaties all facing colonial violence with very little help from the law (Borrows 2002, $\mathrm{p} 8$ 8). . After hundreds of years of Indigenous nations forcibly torn apart and their legalpolitical-spiritual systems viciously prohibited, First Nations, Inuit, and Métis communities are recovering and revitalizing their legal orders (TRC Report Volume 6, p 47). Val Napoleon, from Saulteau First Nation and a legal scholar, notes that "Indigenous law is a crucial resource for Indigenous peoples. It is integrally connected with how we imagine and manage ourselves both collectively and individually. In other words, law and all it entails is a fundamental aspect of being collectively and individually selfdetermining as peoples" $(2012,230)$. If there is to be any challenge to settler coloniality, then these efforts must be support and foundational to any form of reconciliation. For Simpson, there is "no evidence whatsoever that there exists a political will on the part of the state to do anything other than neutralizing Indigenous resistance, to not impinge 
upon the conveniences of settler Canadians. The only way to not be co-opted is to use our own legal and political processes to bring about justice" (Simpson 2013, p 24). Here on the territory of the Algonquin Anishinabeg, the Anishinaabe peoples have traditional legal order that has guidance for truth-telling, redress, and reconciliation, based on principles of mino-bimaadiziwin (good living). The TRC highlights the Anishinaabe's Seven Grandfather and Grandmother Teachings, that "encourage Anishinaabe peoples to live in accordance with nibwaakaawin (wisdom), zaagi'idiwin (love), mnaadendiwin (respect), aakwaadiziwin (courage), dbaadendiziwin (humility), gwekwaadiziwin (honesty), and debwewin (truth)" (TRC Final Report Volume 6, p 67). The report points out that if the Seven Grandfather and Grandmother Teachings were incorporated meaningfully into Canadian law, this would challenge the Canadian Charter of Rights and Freedoms and renew how treaty relations are honoured- based on the principles, not precedent as western law does (TRC Final Report Volume 6, p 67). Though the Report does not explain how this ontological shift for the Canadian legal order could happen, it is a significant proposition for the movement of reconciliation. Nishnaabeg legal orders are fundamentally restorative and seek balance and as such restorative processes demand the perpetrator takes full responsibility for their wrongdoings and future wrongdoings (Simpson 2013, p 23). There is an inherently different power dynamic in this form of reconciliation because the perpetrators must admit and come to terms with the full impact of their violence (Simpson 2013, p 23). The process of reconciliation happens "in a collective setting, amongst the person s/he violated and amongst the people both the perpetrator and the survivor hold responsibilities to be that their family, clan or community" (Simpson 2013, p 23). If this Nisnaabeg legal convention of reconciliation 
were embodied between the settler state and Indigenous nations, it would mean the Indigenous nation would have the power to hold the settler society accountable, and the state would have to face the full impact of the history of violence and colonization (Simpson 2013, p 24).

\subsection{Beginning to Enter the Spaces of Negotiation}

There are a growing number of resources inside and outside of academia written by Indigenous people that perhaps provides the "broader interpretation" Simpson is referring to. These resources are an interruption to the discourses being pushed by settler colonial society. They interrupt settler narratives and make room for Indigenous folks to narrate their vision of reconciliation, their own history, and world, outside of the confines of settler colonial idea of Indigeneity and relationality. Tallbear (2016) explains that reconciliation paired with the rhetoric of multiculturalism accumulate to only the tolerance for diversity and Indigenous culture, echoing Coulthard's work. For reconciliation, she speaks of the need to take on the 'obligations of kinship',

"I see indigenous peoples' critiques and ongoing agreement-making as continued calls for non-indigenous people to engage in good relations, which involve exchange, not cruel evangelizing of settler lifeways. Rather than courage, I think in terms of acting out of obligation to the indigenous collective. And this not a moralistic sense of obligation, but it has been crafted through the steady work of kin-making to live. We need kin to survive. In turn, indigenous peoples speak out not necessarily from individual courage, but rather their irrepressible voices cannot but call attention to injustices, and they continue to call the settler state to account for its failures at kin-making here, with both humans and nonhumans." (Tallbear, 2016, n.a.)

Through a sense of obligation to kinship, which requires an ontological shift for Canadian society, relation building becomes a way to and a way of dismantling settler colonization. 
As Tallbear points out, "this isn't about indigenous peoples being incorporated into your world. It's about you learning how to live here in relation with this place and with peoples who were long co-constituted in relation to these lands and waters and skies" (2016). Though critical of the settler colonial discursive mechanisms around reconciliation, Tallbear (2016) still encourages people to read the TRC calls to actions because broadly, they seek to redress centuries of neglecting kinship obligations. To understand and fulfill kinship obligations is a piece of transforming consciousness. It is a process of unlearning how settler colonialism and capitalism teaches us to relate to one another in a utilitarian, individualized, and commoditized manner. To fulfill kinship obligations requires a "slowing down of reasoning" and a "traveling between worlds" and while a multifarious task, many Indigenous folks have generously provided guidance on what that could look like for settlers to engage in a new form of relations. For example, Lynn Gehl, an Algonquin Anishinaabe-kwe, wrote the "Ally Bill of Responsibilities," where she lists 16 "rules" for non-Indigenous peoples to work alongside Indigenous communities. Listed among them was the need to be aware of one's own social position and privilege and working to understand larger oppressive power structures. She poignantly dictates that settlers "must listen more than speak...allies cannot perceive all the larger oppressive power structures as clearly as members of the oppressed group can" (Gehl, n.d, n.p). This can be seen as a moment of incommensurability, wherein the ontological position of settler colonialism dictates a universal world, shaped by a hierarchical ordering of human and non- human beings, and their exclusion from politics (Rojas 2016, p). Marginalization and oppression are not seen by the privileged (settlers, white settlers), not only because they do not experience it, but because the liberal foundation assumes 
that, sure there can be a disadvantage, but assimilation into the structures of settler colonialism can solve that. Notably, while listening is necessary, it does not mean that settlers do not have the responsibility of doing the work of interrupting settler coloniality through speaking. Chapter 4 will highlight the ways the balance of the two played out with the five individuals I interviewed. The Montreal Urban Aboriginal Community Strategy Network released the "Indigenous Ally Toolkit" which provides three steps: be critical of any [of your own] motivations, start learning and act accordingly. The toolkit differentiates between an ally (who disrupts oppressive spaces by educating others on the realities and histories of marginalized people), an accomplice (works within systems and challenges the systemic racism, colonization, and white supremacy there) and a coresistor (stands in solidarity, together with Indigenous peoples, in resistance against oppressive forces and requires constant learning) (Ally Toolkit, 2019, p. 2). The Indigenous Action published "Accomplice Not Allies; An Indigenous Perspective" takes a more critical perspective on ally-ship, noting that "allyship is the corruption of radical spirit and imagination. It is the dead end of colonization" and recommends that what is needed to destroy settler colonialism are accomplices who "fight back or forward, together, becoming complicit in a struggle towards liberation" (Accomplices Not Allies, 2014, p.5). The word and concept of "ally" is highly contested in activist circles, and though the complexities of the debate around the word is beyond the scope of this chapter, it is often because of the prevalence of those claiming "allyship" are engaging in performative allyship. Maintaining the status quo, performative allyship indeed can be seen the "corruption of radical spirit and imagination". Despite the controversy, it has become more commonplace for mainstream traditional media sources, such as $\mathrm{CBC}$ 
News and Huffington Post, to publish content centering Indigenous voices and perspectives on what it means to be "an ally." Consistent through both the communitybased and mainstream sources are several ideas. One is the importance of settlers becoming cognizant of Indigenous histories, stories, and cultures to challenge the narratives typically dominating Canadian history that do not honestly confront the reality of Canada's relationship with Indigenous people. Becoming aware of the complexity of Indigenous nations, history, and culture can, in part, rectify the dehumanizing narratives that dominate the stereotypes and one-sided history tales we Canadians tell ourselves. Another consistent piece of advice through the academic, community, and mainstream sources is the importance of settler's listening while not centering ourselves, our needs, emotions, or ideas. This entails respecting cultural traditions and protocol and asking, not assuming what particular struggles or communities need. Though I have outlined some examples of the visioning of numerous Indigenous peoples and communities for relationality, reconciliation, and solidarity, this by no means is a comprehensive list. Each context, struggle, and community has specificity and will demand different kinds of solidarity. Each person and community will have a different vision of what allyship looks like. Each situation will call for a specific understanding of good relations. Finally, it is essential to remember that settlers should not expect Indigenous people to do all of the intellectual and emotional labour to communicate what we need to know and do in the struggle against settler colonization (Davis, Denis \& Sinclair, 2019, p. 53).

The task of discerning the ontological foundations of reconciliation clearly demonstrates that Canada's project of reconciliation is built around settler coloniality's foundational goal to complete colonization through the extermination of Indigenous sovereignty and 
complete control over land. Since 2008 the movement of reconciliation has become a part of mainstream narratives in Canada, and while some see this as a positive shift, the settler colonial imperatives and injustices remain. What's more is that there is double negation: settler coloniality denies the existence of other ontological formations of reconciliation and then denies the first denial. This denial has been fundamental to violence carried out by us colonizers for hundreds of years, and yet, as demonstrated, is constantly challenged by Indigenous peoples very existence and the Indigenous place-based ontologiesinclusive of the legal, political orders and spirituality. It is clear that if Indigenous forms of reconciliation are not centered in the transformation of Indigenous and non-Indigenous relations, that colonial habits will be reproduced. Coulthard's articulation of Indigenous place-based ontological orientation and Tallbear's call for kinship obligations are insights into alternative ways of carrying out reconciliation. Reconciliation as perpetrated by the settler colonial state is the dominant narrative that works to facilitate a "transformation" of relations between Indigenous and non-Indigenous communities. This mapping of the reconciliation project in Canada was necessary to articulate Canada's ongoing nefarious actions that are now somewhat concealed by the rhetoric of reconciliation. Further it nests this narrative inquiry with the five settlers within this current, ongoing socio-political context. For settlers engaging in transforming settler consciousness, understanding the ontological orientation of reconciliation is necessary to understand the limits of possibilities as a framework for engagement. This critique of the reconciliation project and complexity, but need for ontological plurality lends clarity to the understanding from which I engaged the narrative inquiry. Importantly, it will lend an understanding of the 
difference between the functions of engaging in a politics of recognition compared to the stepping into ontological shifts where radical shifts beyond settler coloniality is possible.

\section{Chapter 4: Community Spaces, Settler Responsibility and the Possibilities of Transformation}

Based on stories shared by five white settlers, this chapter compares how the five individuals engaged in transforming their settler consciousness. The five people shared their experiences working with two different church-based community groups, both of which were a part of the same wider network aimed at forming "right relations" with Indigenous communities. The narrative inquiry conducted revealed there was a multiplicity of strategies, approaches, and spaces that these groups and the individuals involved engaged in under the mandate of forming right relations. Different conditions and elements of the two community groups contribute to these two moves that the settlers engaged in: a politics of recognition and Ontological Negotiation between settler coloniality and Indigenous (most often Anishinaabeg for these settlers living on Algonquin territory) 'worlds.'. While I characterize the different strategies, approaches and spaces as facilitating two different outcomes to serve an analytical and pedagogical purpose, I do not mean to imply that it the outcomes for individuals or groups involved were in a direct, clear cut or linear way. They cannot be fully separated, and most often, people were engaged in both, sometimes at the same time. As discussed in Chapter 2, a politics of recognition, as described by Coulthard, reinforces settler coloniality by negating the issues of land and political sovereignty (and ontological sovereignty). 
Ontological negotiations, on the other hand, demands 'world'-traveling through a "slowing down of reasoning," holding the possibility of engaging in transformations beyond settler coloniality. The stories of the five white settler community members provide insight into how other settlers may engage in transforming their settler consciousness. Though it is not a decisive analysis, learning from those who are attempting to transform their settler consciousness has the potential to provide guidance to other settlers who are or will be committed to the same thing. Research in Settler Colonial Theory has asked, "what happens when settlers engage with and seek to transform the system? What does such action look like? What challenges, complexities and barriers are faced? What are the stumbling blocks? And what opportunities and possibilities emerge" (Davis, Denis \& Sinclair 2019, 2018, p 2). I set out to look at what about community spaces facilitates a transformation in settler consciousness. My intention was born from a gap in the growing body of work around settler colonialism, that Davis et al. (2017) identified. The authors called for a deeper understanding of how and under what conditions settlers are engaging with potential transformations in their consciousness and the broader struggle to dismantle settler colonialism. Further, my drive to engage in this project came from my personal (ongoing) experience as a white settler in the work of solidarity and transforming my own settler consciousness. The reflections and analysis of academics and other community activists have been invaluable when it comes to how I understand what it means to be a white settler seeking to refute the power of settler colonization, what it means to navigate social justice spaces as someone with an immense amount of privilege. Making many mistakes along the way and having resources to learn from, especially the work of Indigenous activists and academics, has 
been vital. As with any social justice struggle, documented reflection adds to the living archive that can reach communities and individuals across time and space. I wanted to engage in this project specifically in hopes of adding to the growing body of reflections and analysis that is documenting the wide arc towards an end to settler coloniality. ${ }^{1}$

With the guiding question, "what about this initiative did or did not impact people to challenge the status quo of settler coloniality" I engaged in a 60-80 minute conversation with the five community members. Of the five individuals, four identified as women and one as a man. Their ages ranged from $60-73$, two of the five were retired, and the three others are still working, in different capacities. Though they all are tied to a church-based group, only four of the five identified as Christian and three of the five noted their spirituality was "eclectic" or "a hodgepodge." They all identified as white settlers with ancestors from Northern and Western Europe. It should be noted that it was my intention to work with white settlers. As the "cycles of threat, unsettlement, and reclamation" (Hiller 2013, 72) settler colonialism maintains white settler dominance, white settlers have deep investments in their white and settler privilege and demands specific work in the struggle to dismantle settler colonization. As white settlers, the intended and main beneficiaries of settler coloniality, I believe it is our responsibility to be vigilant and reflective in our efforts because the danger of reproducing colonial habits and relations is liable. Four of the five noted that they only began to understand and work around supporting Indigenous sovereignty and their complicity in settler coloniality within the

\footnotetext{
${ }^{1}$ I have discussed that the end of settler coloniality needs to center decolonization as defined by Indigenous communities, and further is always unfolding and always emerging, and therefore impossible to define with any specificity. However, this research points to the fact that coexistence beyond settler coloniality requires relational ontologies, as opposed to the violent universalizing ontological foundations of settler coloniality. Transforming settler consciousness holds the possibility to create conditions for a society built on relational ontologies.
} 
last decade. The fifth person has been engaged in anti-colonial struggles for over forty years. Though I had eight set interview questions (see Appendix), each conversation took its own route, a balance between the settler community member telling stories, and myself, asking questions to try and wreathe a fuller story as possible within the confines of the 80 minutes. The questions were meant to provoke answers about their involvement with the specific initiatives and how they shaped the transformation of their settler consciousness. Of course, as storytelling goes, the dialogue did not always go as planned. The story weaved into unexpected places, breaking the boundaries of the time and space they have spent with the specific community. Many spoke of the early years of engaging in solidarity work, decades before becoming a part of the current group. Some spoke of the other social justice struggles they are currently involved with, some of which are entangled with their church community group, some of which are not. The temporal and spatial breaks should not be seen as diverting attention away from the main research question, but rather embellishing our understanding of what can shape settlers experience towards engaging in transforming their settler consciousness and challenging the hegemony of settler colonialism. The side stories, "oh, just this one other thing", and the "not sure if this is related..." all contribute to the understanding that the work settlers are doing to challenge the system of settler colonialism does not exist in a vacuum of one initiative but is connected to a vast array of experiences, understandings, and motivations. Their stories demonstrated far beyond what the community spaces they were in offered to their journey and wider social change. They also provided insights into the emotionality of the work settlers must do to acknowledge their settler privilege, the different colonial narratives we must unlearn, the dangers of settler fragility and the complexity of 
solidarity work and relationship building. In some ways, their experiences support findings from scholars such as Willie Ermine's (2007) idea of ethical space, Dina GillioWhitaker's (2018) concepts of settler privilege and fragility or Chris Hiller's (2017) twoway spiral of anti-colonial and decolonial processes settler activists' experience. Their experiences add to the ever-growing diversity of ways transforming settler consciousness occurs and how it fits within the wider movement towards decolonization and resistance to settler colonialism. The following analysis will focus in large part, on answering the question, "what about this initiative did or did not impact people to challenge the status quo", but inevitably will overlap with intersecting reflections on transforming settler consciousness. Although these five individuals had separate individual experiences and commitments, there were distinguishable patterns in how specific parts of their community group facilitated different parts in transforming their settler consciousness. The reflective analysis will fall into four parts. First, I will briefly contour Canadian white settler identity, illuminating how deeply settler colonialism and white supremacy shape us. I do this with the intent of grounding the narrative inquiry in an understanding of what hegemonic forces are at play and what need be transformed if settler coloniality is to be challenged. I will then turn to the reflective analysis, first by focusing on the structure of the community groups. Both groups were a part of the same network in Ottawa, and the configuration of the network holds the possibility to facilitate both a politic of recognition and spaces of ontological negotiations. Laying out the specificity of the groups provides a deeper understanding of the conditions that contributed or hindered the work that arose. The second part will describe what strategies, approaches and spaces allowed for a move towards a politics of recognition, embedded in coloniality and liberal 
understandings of difference. The third will unravel how community groups allowed for a radical ontological shift in the settler's consciousness. The first move fits within the dominant liberal structure of Canada's settler colonialism. It is possible within the framework of "multiculturalism" while maintaining the colonial attack on Indigenous land, sovereignty, and communities. The second shift allows for ontological negotiations between settler coloniality and Indigenous ontologies, challenging the fundamental assumptions, narratives and practices of settler colonialism. Importantly, it allows for the understanding that challenging settler coloniality must centrally focus on the return of land and sovereignty. The distinguishable pathways found in these five peoples experiences, mirror Chris Hiller's work with settler activists. Hiller (2017) describes the downward decolonial spiral and upward anti-colonial spiral settlers engage in, as interconnected "spirals of praxis cycles" (427) and constituting "a series of choices, reflection, and action" (423). Like Hiller's work with activists, the experiences of the five settlers I worked with teach us about the space of the groups, and the conditions of their experiences that facilitated their work and commitment. The following reflections are in no way meant to imply there is a universal pathway to transforming settler consciousness. The work settlers need to do to confront and subvert settler coloniality will look different for each person due to their social position, political commitments, the territory they live in and the relationships they have. With this diversity in transformation in mind, learning from each other's experiences is a piece of the process for settlers who seek to engage in challenging settler colonialisms hegemony and be accountable to Indigenous struggles for decolonization.

\subsection{Settler Coloniality \& White Supremacy: White Settler Identity}


White supremacy and settler colonization have always been inherently tied together, allowing for the creation and maintenance of settler colonial Canada. Critical race theorist, Sherene Razack (2002), names explicitly Canada "a white settler society" because of the ways racial and colonial power structures have operated throughout the nation's history. Andrea Smith explains the three logics of settler colonialism as the "social, ideological, and institutional processes through which the authority of the settler state" is enacted and permeates the discursive and material technologies of mainstream society's systems and structures, sustaining settler-colonial consciousness and colonial practices (Rifkin 2011, 343). For Smith, white supremacy is constituted by separate, but interconnected, logics: "(1) slaveability/anti-black racism, which anchors capitalism; (2) genocide, which anchors colonialism; and (3) orientalism which anchors war" (2012, p. 2). Settler coloniality is not just about structures and systems of law, policy, and politics or even systems of racism, but rather is deeply embedded in the Canadian identity (recall Mackey's structures of emotions and ontological certainity). Systems and structures should not be abstracted from the embodied society, "no one is outside them, or can be, but we can begin to become aware of our surroundings, our complicity, and to make choices about how and why we will struggle against them (or not)" (Battell Lowman and Barker 2015, 16). The nation-building project of Canada has always depended on constructions of non-white immigrants to justify fictitious borders solidified on stolen Indigenous lands for the benefit of white European immigrants (Stasiuis \&Jhappan 1995; Thobani 2000). In the 18th century, intending to develop a settler colony in the image of Britain, European settlers were prioritized for land and settlement, whereas racialized bodies were used for exploitable labour (Stasiulius \& Jhappan, 1995. Today, the 
Canadian state continues to use law, political rhetoric, and immigration policies to construct its population along racial, ethnic, and even gendered lines (Stasiulius \& Jhappan, 1995). To critically explore how systems of oppression shape the discursive and material technologies that constitute our selves and society, means to unearth that what seems to be natural, including how we understand/conceptualize difference, norms, knowledge systems, relations of power, and ideas of morality (Boler and Zembylas, 2003, p. 116). Chris Hiller (2013) notes that because these narratives that makeup settler consciousness is,

"so deeply woven into the fabric of (white) settler societies... any meaningful recognition of these rights and relations - one that acknowledges and addresses ongoing histories of Indigenous dispossession and settler dominance - will profoundly rock the very foundations of such societies and cultures... demands a radical rethinking of foundational concepts... a reexamination of the colonizing discourses and grammars" $(2013,71)$.

In many ways, Canadian settler subjectivity and identity is disturbed by the presence of Indigenous people because of the assumptions that "they" are supposed to be gone and assimilated, and acknowledging their presence challenges the justification of our colonizing nature (Yegenoglu, 1998). The founding mythologies of terra nullius, the doctrine of discovery and the Two Founding Nations (Britain and France) facilitated the original dispossession of Indigenous peoples and continues to justify ongoing violence against and imagined erasure of Indigenous peoples (Hiller, 2013). National traditions, stories, expectations, and ongoing relationship to land inform what Edward Said (1978) calls, "imagined geographies." Other settler colonial imaginaries include the "frontier complex" wherein Canada is thought to be a found empty land with primitive peoples, and thus the invasion of settlers was benevolent (Furniss 1999), which continues to 
permeate Canadian identity through ideas of the "peacemaker" (Razack 2002; Mackey 2002; Regan, 2009). The understanding of land as being earned property that Canada rightfully owns, and grandiose narratives of "Canada's great outdoors" continues to shape settler attachments to land (Mackey 2005; Banivanua, 2010). Solidifying these stories of belonging are the legal and political relationships that bind them to the physical land (Battell Lowman and Barker 2015, 2013, 58). Canadian legal systems are premised on the condition that Aboriginal title cannot be said to interfere with Canadian sovereign claims to land (Battell Lowman and Barker 2015, 61; Manuel 2017). Citizenship law is entrenched in ideas of property and right-to-land, protected for "Canadian citizens," though access is shaped by the hierarchies of race, nationality and gender. White people have always been the intended beneficiaries of the settler colony and as Thielen-Wilson describes, "whether our bodies have a literal and direct bloodline to actual colonizers of the past or not, our white skin secures our membership-both symbolically and materially — in the nation Canada and announces our sense of belonging and entitlement (ownership) of the nation. This sense of belonging and ownership is not (easily) extended to non-white, non-Indigenous people of colour" (2012, p. 320). Rather than a relic of the past, white supremacy is part of the foundation that the settler colonial project continues to unfold upon. And yet, white settler narratives maintain, through an imagined benevolence, a feeling of innocence (Mackey, 2002; Razcack, 2002; Wolfe 2006; Veracini 2010). Since the 1980 s, one central discursive political narrative that is utilized by the Canadian state in attempts to mask its foundation of theft and violence is the grandiloquence around multiculturalism (Philip 1992; Mackey; 2002; Bannerji, 2000; Povinelli, 2002; Tuck and Yang 2012). Whether it is about the "reconciliation" between 
Indigenous and settler relations, the welcoming of refugees, or the diversity of its big cities, Canada crows about being a place where the difference is celebrated and a country free from the racial struggles of the United States. The multicultural narrative implicitly points to the French and English at the center of Canadian society with "the Other" being invited in (Bannerji, 2000). Multiculturalism as a narrative and policy is taken for granted as an equalizing force, smoothed by the "nice" nature of Canada (Mahanti, 2002). This self-narrative decrees that race is meaningless in Canada while ignoring the violent racism experienced by Indigenous peoples, Black people, and people of colour (Mahanti, 2002). Furthermore, some scholars have identified two dominant "camps" of discourses on Indigenous rights: conservative and the liberal (Battell Lowman and Barker 2015; Gilio-Whitaker 2018). The Conservative discourses reinforce the belief that colonization is a thing of the past, as well as an inevitable process of "progress" and "modernization." Ongoing inequality is framed as an individual failure on the part of Indigenous communities (Battell Lowman and Barker 2015, 6). On the other hand, liberal discourses perpetuate the imaginary of a unified Canadian identity with immigrant roots that bind "us" while recognizing the contributions of Indigenous people, all of who make up the Canadian mosaic (Battell Lowman and Barker 2015, 6). There is no call for the protection of Indigenous rights and sovereignty, rather the prescribed solution is funding and policy changes (Battell Lowman and Barker 2015, p.6). For Paulette Regan (2006; 2012), settler consciousness is fundamentally split between feelings of empathy and guilt about the dispossession of Indigenous peoples along with an ongoing refusal to address the ongoing social, political, and material consequences of settler colonization. It is easier for settlers to deny this settler consciousness that is linked to the continual violence 
against Indigenous peoples than it is "to unlearn 'truths' and engage with counternarratives (Regan 2012) and practices (ontologies). Further, settler denial often leads to a violent reaction when there is an assertion of sovereignty, land or rights by Indigenous nations - these assertions challenge our sense of identity and legitimacy (Mackey 2005; Hiller 2017, 418; Battell Lowman and Barker 2015). When settlers seek to challenge settler coloniality, in solidarity with calls for decolonization and against the violence and injustice of it, the task ahead demands a transformation of consciousness, our identities, ontological and epistemological bearings, that have been shaped by settler coloniality. While it is extremely important to center the demands of Indigenous communities, nations and peoples in the process of challenging and transforming settler coloniality, if settlers are going to support these demands, there is a need for us to be able to hear and honour those demands in ways that are not re-colonizing. For that, a transformation of settler consciousness is necessary, and so now I turn to how two community groups on Algonquin territory (Ottawa, Ontario) shaped that very task of transformation for five white settlers.

\subsection{The Structure of the Community Groups: Shaping Possibilities}

With the five participants involved in two separate (three in Group 1 and two in Group 2) there was a layer of complexity to this analysis. It was not possible to discern that one group had one way of transforming settler consciousness and the other group had a different way. Though they both were part of the same network of Church groups and had the same goal of engaging in indigenous solidarity and forming "right relations" with Indigenous communities and peoples, the two groups operate in different ways, through different structures, and with different mandates. Both groups are part of an Ottawa wide 
network of church-based groups that formed roughly around 2011-2012. Elena described the network as "supporting each other in our own communities when we have our own events, we will show up and support, and we will share information." Both groups run an email listserv that function as the principal form of information sharing and hold an extensive reach throughout the city. Near the beginning of forming, the network has held consistent monthly meetings, where representatives of the different groups would gather, and Elena noted, "those meetings were really crucial, they really helped to build up a commitment, to be able to sit in circle." Further, the network has had a book club that also meets consistently, which four of the five individuals I sat with talked about a lot as an essential site of learning, support, and emotional processing. Group 1 started around 2011, and remains very active, continue to host regular events, have relationships with a handful of Algonquin elders, support several local Algonquin nations' struggles, and meet semi-regularly. Nell, Janelle, and Amber were the three I interviewed from Group 1. They have all played leadership roles in the group, and the size of the group seems to fluctuate between 5-10 core people, who plan, support, and execute actions. Group 2 also began around 2011 when an Algonquin speaker came and catalysed the idea to start a local group. For the past few years, the group has only hosted one event per year but continues to operate an email listserv. Elena, whom I interviewed from Group 2, was the primary contact, organized the events and ran the listserv. Kevin was the other member and joined the listserv after attending an event hosted by Group 2. Both Group 1 and Group 2 are explicitly engaging with the Truth, and Reconciliation Commission's Call to Action. For three of the five individuals, the Truth and Reconciliation Commission was explicitly described as the spark that began their commitment to addressing the injustices 
experienced by Indigenous peoples. Janelle described the TRC as a personal "aha" moment and a primary motivation for the group's formation. Looking for a "core group that would grow" and get people engaged, Janelle explains the thinking was "let us wake up to this very broken relationship and let us find out some more truth and get some heart readiness. So when it comes to Ottawa or Montreal, people will want to go, and they will have their hearts open... Why don't we have this year be a year of preparation to go to a TRC hearing and sit there and witness? So let us prepare to witness with an open heart." It was noted that the group was nested into a broader movement within the Church, nationally and locally, that was responding to the TRC and continuing its efforts to rectify the relations with Indigenous communities. This movement could contribute to the way Elena, Nell, and Janelle described supportive responses from the higher-ups at the Church. When asked about "digital spaces" there as a unanimous agreement that the listserv and the internet, in general, can increase people's access to information and alert people to upcoming and urgent happenings. The listserv was repeatedly mentioned as serving a significant purpose, and many expressed gratitude for the content and consistency. The information shared is often Indigenous stories, events or perspectives, told by Indigenous voices, interrupting the mainstream narratives of settler coloniality. Further, the listserv was described as being able to reach people quickly in order to raise funds needed, like when an Indigenous food bank in Ottawa experienced funding cuts or when Barriere Lake community was facing a quickly accelerating invasion at the hands of a copper mining company, the listserv was able to reach hundreds of people within 24 hours in order to gather and take action. For digital spaces in general, Janelle and Elena noted how it will never replace relationship building and cannot build community in the 
same way that face-to-face communication will. Janelle also asserted, "it can create a false sense that you are doing something," echoing common critiques of "clicktivism." Beyond the listserv, the structure of the groups, both as grounded in a church and within a network was described as having the ability to reach a wide community, both their congregation and the wider population (their events are often public). Almost all of the individuals I talked with described it as a responsibility they felt, to continue to educate their communities. As Nell says, "In fact, I think in part, that has what our role has been, is to bring the congregation to be awake and alive to these issues...We are deepening, and I think it will keep deepening and deepening and deepening. In us personally, but also we are trying to have the congregation. We have people at all different places, so we are trying to do educational stuff for them and help people into that". Elena saw her role as "keep bringing the message" but notes that it is a "slow" process. With a physical space and institutional infrastructure and resources, they can facilitate events with relative ease. Sharing of space and mechanisms for contacting their members allows for a continued communication that ensures their community is aware of current news, events, actions, and ways to be engaged. The structure and foundation of the network and group hold the possibility to facilitate a way for people to engage in a politic of reconciliation or transformation in settler consciousness through spaces of ontological negotiations. The structure does not necessitate one over the other and doesn't necessarily have a casual relationship (I will not make that conclusion here), but it is important to note that the infrastructure that the individuals worked with was full of resources (monetary and physical) and had an impressive reach into the wider Ottawa city, which is not 
necessarily the case for many community groups seeking to do similar work in relationship building and community education.

\subsection{The Community Groups and Politics of Recognition}

As I have elucidated, I am using the concept of transforming settler consciousness to articulate how settlers engage in challenging setter coloniality. If white settlers are seeking to participate in challenging the injustices of settler colonialism, it is possible they will attempt to engage in this through a politic of recognition. In fact, the hegemonic hold that recognition-based reconciliation has in Canada and globally, it is seemingly probable, and definitely easier, that white settlers will engage in a politic of recognition if in their initial drive to address the injustices of settler colonialism. Settler coloniality is not simply different cultures not being recognized, nor just about unequal societal structures and systems of power, but is also deeply embedded in the Canadian identity, individual and collective. White settlers are the intended beneficiaries of settler coloniality and, as seen in the section above on settler identity, de-investing from it requires a transformation of their consciousness that is so deeply conditioned by settler coloniality. However, a politics of recognition does not necessitate transforming anything, not their consciousness, their actions, or the structures of settler colonization. For the five individuals I worked with, their storytelling demonstrated that politics of recognition was typical, with some conditions making its occurrence more likely. Now I turn to analyze the specificity of those conditions.

\subsubsection{Spaces of Education and Awareness-Building}

There was a large focus on holding educative and awareness-raising events. Nell and Elena both identified "learning" as a crucial first step to take as individuals and as a 
community. Nell describes this impetus in the following passage: "we felt the congregation needed to learn, we all needed to learn... We did mostly speaker things at that point... at that point there was resistance...well, the congregation was not where we were. In fact, I think in part, that has what our role has been, is to bring the congregation to be awake and alive to these issues." Similarly for Elena, "first we want to learn. We want to find out more about Indigenous people and history before what we can do. Because most people are used to fundraising, let's send money up north to these poor kids. We said, this time, lets not just provide charity... we want to understand more... We wanted to learn more as individuals and then to share that with the community and to bring out more information about the story and what was going on and how we could participate in this reconciliation that had been started by the larger church." Nell is speaking to their role in bringing awareness, making their community "awake and alive" to issues of settler colonial Canada. Elena is speaking to wanting to go beyond providing "charity" and juxtaposing it against reconciliation, the goal of their educative measures. Undoubtedly, education that challenges dominant settler narratives and historical imagination are necessary (Dion 2009; Regan 2012). We, as settlers, need to understand ourselves as historical beings, not the liberal individual, unencumbered by sociohistorical ties and morally autonomous, but as situated in a settler colonial structure that was created long ago and continues to exist through law, policy and learned ideology and norms (Boler and Zemblya 2003; Regan 2012; Mackey 2016). The 1996 Report of the Royal Commission on Aboriginal Peoples stated, "most Canadians are simply unaware of the history of the Aboriginal presence in what is now Canada and that there is little understanding of the origins and evolution of the relationship between Aboriginal and 
non-Aboriginal people that have led us to the present moment" (27). Author Susan Dion (Potawatomi-Lenape) asks, "if justice for Aboriginal people lies in remembering, but forgetting serves the supposed needs of the Canadian nation, where are the possibilities for accomplishing justice to be found?" $(2009,3)$. Nell speaks to a certain "remembering" when she described that, "to realize our first Prime Minister is the whole architect of the Indian residential system and the residential schools. I mean that is totally embedded in Canada... I'm not naïve about Canada anymore. I love living here, it is a wonderful place, and there are so many good things about it. However, its history is bloody, and it is founded on horrendous principles, and they were intentional." Dominant narratives about Canadian history, position Indigenous people as relics of the past or are full of dehumanizing stereotypes about Indigenous people in the present and challenging those narratives is important. However, there is danger in what Tuck and Yang (2012) describe as, the "cultivation of critical consciousness standing in for relinquishing stolen land." Acknowledging the importance of learning about settler colonialism and interrupting settler epistemology, they assert that the sole focus on raising one's critical consciousness can make it feel like you are making change, when in fact, it does not demand a fundamental change in settler colonial structures (Tuck and Yang 2012,19). As Taiaike Alfred $(2005,105)$ articulated that even progressive or "left" settlers will "usually hold a strong attachment to the colonial state and their privileges within settler society...silenced by being caught in the squeeze between their intellectual deconstructions of power and their moral cowardice when it comes to doing something about injustice in a real sense" $(2005,105)$. For Group 1, after years of hosting awareness-raising events, people within their community are much more receptive. 
Echoing everyone from Group 1, Nell explains, "Like now, we would have no trouble announcing these speakers and having a whole pile of people come, and we know that the congregation is behind us. So that is not an issue. In those days, you put something out, and you wouldn't get much interest. The Truth and Reconciliation Commission has made a huge difference with that. But I would like to think our educational efforts have as well." However, though people will show up to these events and speakers, only a handful of people are interested in engaging in the other pieces of the group, including direct solidarity work, the water group, book club or even the planning aspects. Moreover, as Janelle puts it, "that's been true all along." For Group 2, Elena explains that they only host one event a year, and while the community will show up to it, they are not interested in any more commitment. Elena explains, "you know, to set up a book club here or something, people weren't willing to put in that sort of time. It takes time to sit and think and talk about this. And they are not at that place". Education and awareness, as the only piece of work one does in efforts to transform their consciousness, can be "distractions, which relieve the settler of feelings of guilt or responsibility, and conceal the need to give up land or power or privilege" (Tuck and Yang 2012, 21). For both Group 1 and Group 2, education efforts is central to the groups mandate, but for the majority of their community is their only commitment in terms of seeking to challenge settler coloniality. While the settlers I talked to and the others directly involved in the group are engaged beyond just attending events, I would posit that their narrative reveals that when community members get comfortable simply attending events, they are learning within a politics of recognition. They are listening, and have interest and respect, for stories and truths that disrupt settler colonial narratives, but moving beyond a politic of recognition is 
not necessary and their settler consciousness, while perhaps shaken, is not engaged in a sustained transformation.

\subsubsection{Working without a Core Group}

As discussed, Group 2 has no group that meets regularly. In reality, there is one person, Elena, who operates an email listserv that provides information for the community and once a year coordinates an event. Elena said that in 2015 the group was more active but has since has remained relatively sedentary. While there have been attempts to have structured meetings, it has never come to fruition. Kevin explains that, for him, Group 2, "is just an information source. I don't feel too aligned with them because, I don't know what their purpose is. I am looking for something more tangible. So I need to find some other organizations to be a part of." Elena highlights that connecting through digital spaces like the listserv or social media, "is not like meeting people in person... [it is not] building a community..." While it plays an essential role in connecting and spreading information, digital spaces (listserv, email, online news sources, social media) were described by everyone as not facilitating the same type of relationship building in-person connections do. In discussing how settlers may react to the TRC, Roger Simon advances that "Canada has a severe lack of spaces where people might take the time necessary for serious thought and conversation" (Simon 137). So while Elena explains, that, "people weren't willing to put in that sort of time, and they were also... you know... it takes time to sit and think and talk about this. And they were not at that place", it elucidates that people were not interested in the serious conversation or spaces, where I would postulate a transformation in settler consciousness is possible. In juxtaposition, Elena describes that when the larger network first formed, they were "meeting once a month and then it 
started being once every three months, than four times a year, then it petered off, and we said no. We will support each other in our own communities... But those meetings were really crucial, they really helped to build up a commitment, to be able to sit in circle." Sitting in a circle meant the group solidified its structure and commitment to transforming their consciousness. Without a sustained group that meets with each other, organizing ongoing intent and action becomes impossible. Without time and commitment, which Elena explained were sparse, building relations, or engaging in solidarity work becomes impossible. Without an ongoing interruption to settler consciousness, I argue that the difference between ontologies can easily be interpreted as difference between cultures, keeping the group within a politics of recognition. As Elena explains,

"So I am finding that yes, there is more connection, and there is more that is being done... But it is slow, you know? For example, there was this [day]...there was this prayer that was said in a whole bunch of different languages, French, English, German, and people from the congregation... there were a few African languages... because we have a very diverse community....and I thought, well where is the Algonquin [language]? We are on Algonquin territory! The language of this land! So I've realized there is stuff that I need to do. Slow...very slow..."

This quote unveils that awareness may be spreading, but even in times when "diversity" is being celebrated (in and of itself a function of the politics of recognition), Algonquin presence is erased. Further, when Elena says, "there is stuff $I$ need to do," it becomes clear that without having a group, she feels the responsibility falls with her. Having one person attempt to facilitate a transformation in consciousness for an entire community is unrealistic. Though it holds that challenging settler coloniality, both the structures and 
consciousness that constitute it, is "slow" and an ongoing process, to expect one individual is seemingly making it very difficult for Group 2 to engage in anything beyond a politic of recognition.

\subsubsection{Relation without Kin Making}

It became apparent that there was a difference in the possibilities and limits of building relationships, contingent on the group's form. With no established, ongoing group, there was no commitment to the time or space needed to build relationships, to engage in ontological negotiations and to provide solidarity beyond a politic of recognition. Some of the ways in which relationality was discussed is telling. For example, Elena, who had no established sustained local group explained that there were no ongoing relationships with any of the Algonquin nations or Indigenous community organizations, except for three people from her community volunteering at an Indigenous community center. Elena went on to say, "we've only ever had one person here who was Indigenous....so when we had the first blanket exercise, she was our token Indigenous person, which I felt bad about...It was interesting because there is very little relationship between the congregation and [any Indigenous peoples]." While this should not imply that relationship should be built for the sake of self-gratification (for settlers) or in order to tokenize people, it became clear that without the time and ongoing commitment from a group of people, meaningful relationships and spaces beyond politics of recognition towards spaces of ontological negotiations.

Kevin, who was also without group, spoke about his perspective and approach to relationship building. First stating, "I don't have any [relationships with Indigenous communities], I have a couple resources, but I don't have any friends or relationships, 
personal relationship with Indigenous people. I know, I have some long term relationships with a few Inuit people, but I would not call them friends because they do not see me as friends." He goes on to explain that once he began to learn about the violence of the settler colonial state he felt that he "really needed to educate myself, so I started pursuing Indigenous people in the know" and that "early on, I was just trying to educate myself on Indigenous traditions. Everything, a lot of things I would learn it would go like "bing" and I would be like wow, this is really truth. This is the fundamental stuff that we are missing: connections to land, to each other, to community. I am coming to think that the European ethic is fundamentally flawed in a lot ways." Through these quotes, it becomes clear that Kevin's Western understanding of Canada, land, and relations have been destabilized. However, there is also a sense that relationships are being sought out with the principal goal of extracting knowledge. Deborah McGregor, who is Anishinaabe from Whitefish River First Nation, has done work for decades on Indigenous knowledge systems, governance, and sustainability. She demonstrates that Western sustainable development has conceptually misunderstood and failed to use Indigenous traditional ecological knowledge, despite the continual efforts of Indigenous nations seeking to share in order to protect future generations and the planet (McGregor, 2004). Colonial structures of power and persisting inequalities have meant that Indigenous knowledges have been utilized as another "object" to be colonized, exploited, and taken for Western societies use (McGregor, 2004). McGregor elucidates despite ongoing colonial relations and the mainstream co-optation, Indigenous peoples continue to share their knowledge. Kevin goes on to explain, "I've connected with an elder a couple of elders along the way a little bit, I have tried to hook into their indigenous 
approach to teaching. I've met a fellow at the moose hide campaign that is taking a stand against violence against women, out in the east end of Ottawa. He is indigenous, and he is a caretaker of a lot of the traditions, he teaches dance, he mentors a bunch of men. I asked him if I could participate...he is cautiously open but is like, where is this guy coming from kind of thing?" I posit it is important to think about how settler communities and individuals seek to engage with Indigenous knowledges, epistemologies, and ontologies. Reciprocity may look different in every situation, in some reciprocity may not even be wanted, I think one way to reflect on how relationship building may challenge settler colonialism is with Tallbear's call for obligations to kin making. The intent behind this type of relation is "exchange, not cruel evangelizing of settler lifeways" and involves the deliberate work "of kin-making in order to live" (Tallbear 2016, n.p.). Tallbear articulates that "we need kin to survive" as opposed to the isolating individualism of colonial capitalism (Tallbear 2016, n.p.). Relationships that do not hold the intent of "kin-making" that involves interdependency, interconnectedness and the valuing of all human and non-human life, than it likely does not challenge settler coloniality. Without this intent, reciprocity and relationship building, settlers risk treating Indigenous knowledges as something to be consumed for self-serving purposes, perpetuating colonial relations (even if they intend the opposite). Kevin further reveals that he has gone to Indigenous community events:

"I went to my first powwow at Silver Lake the summer before last, and I had never been to a powwow, I had never been to any Indigenous event, and my wife thought I was crazy. I went, it was the first time I had every seen health, happy, normal Indigenous families. My experience was addicted, dysfunctional, drunk, on the street. I had never seen a mother, father, and happy children. I was just pie-eyed on the street. I was just 
amazed. One man thought there was something wrong with me, he was really worried about me. I was taking a picture, he got really upset and came over and wanted me to delete it off of my camera because he thought I was some wacko."

Though his intent may have been to challenge settler colonial stereotypes and support events, the "pie-eyed" description and reaction from the man he describes, their approach to this engagement in relation is again colonial. There is a feeling of the Indigenous community being a spectacle that he can watch, take pictures, all while he gets to "learn." A part of white and settler privilege is the tendency and freedom to be oblivious to our own racial identity and the insidious nature of racism and colonialism (hooks, 1981; Helms 1993; Regan 2012; Hiller 2017). A consistent piece of guidance, provided by racialized academics and activists alike, is the need for awareness of not only racism but also whiteness- a mirror held up to our whiteness and our settler identity. It is a critical awakening that often catalyzes a re-evaluation of one's worldview (Boler and Zemblayas, 2003, pg 106) and accepting whiteness "as part of one's identity as socially meaningful and personally salient, and ultimately internalizing a realistically positive view of whiteness which is not based on assumed superiority" (Lawrence and Tatum, 1999, p.2). Here Kevin, while aware of his whiteness and settler identity, does not see how his identity shapes his approach to seeking knowledge and Indigenous relations. While his narrative reveals an inconsistent awareness of the insidious nature of whiteness, listening from the foundation of critical race theory, settler colonial studies and a political ontology framework, the insidious nature was evident to me, the listener. I consider the words of Malcolm X, who, when asked how white people could be allies and accomplices with Black people in 1964, he responded: 
"By visibly hovering near us, they are 'proving' that they are 'with us.' But, the hard truth is this isn't helping to solve America's racist problem. The Negroes aren't the racists. Where the really sincere white people have got to do their 'proving' of themselves is not among the black victims, but out on the battle lines of where America's racism really is - and that's in their home communities; America's racism is among their own fellow whites. That's where sincere whites who really mean to accomplish something have got to work."

Though I do not wish to negate the profound importance of fostering relation, this cannot come without the work of white setters "collecting each other" (a common phrase in community activist circles) to hold each other accountable and do the work of unlearning the colonial and racist behaviour, thoughts, actions embedded into settler coloniality. Multiple women referred to this work as integral to their group, and all four women mentioned how the book group served as a space to do this work. When asked if he wants to work in relationships as opposed to others, Kevin stated he was "allergic to white settler groups." He goes into the story about when he sought to work with a local coalition of Indigenous and settler people working to defend a sacred site on Algonquin territory. This conflict is well known for being extremely complicated because of the diverse positions of the nine Algonquin nations. Reflecting on a meeting, he attended Kevin recalls,

"I got in trouble... because I said you need to listen to the other side. Maybe some fair collaborative dialogue. I got a lot of yelling and angst back. It's common with white people, they are really invested in maintaining their position and they believe what they believe is absolutely right. Things have to change- but not them. You can't work with that. It really has to be a personal change for every white person on the inside. Like a profound change, not just a tweak and Canadian society really has to change... white privilege needs to be reduced if we are going to have equality. White people have to give up some of the privilege they have. And that giving up of power, is not something white people like to do. My British background, I 
come from... I have a lot of baggage. I have merchant slave traders, crusaders... How do you even start talking to people like that? I have no idea... Old people don't change much. I'm different. A lot of people tell me I'm different."

On one hand, it is not clear who "the other side" is, and in fact could be pointing to a moment when Kevin was calling on white people to listen to the diversity of perspectives from Algonquin people. However, Kevin goes on to explain “you can’t work with that”. Recall Malcolm X's quote- Kevin clearly does not want to do the 'work' of talking to fellow white people- particularly older white people. While he holds an understanding of white privilege, he is seeking to disassociate from "those" white people (even as he refers to his own "baggage"). Robin Di'Angelo discusses a tactic of white people distancing themselves from white supremacy, to assert themselves as one of the "good ones." There is a difference here between the four women whom I talked to. They all have been working in relation with Indigenous communities but also with white people, explicitly discussing their responsibility to understand and address their white privilege. Further, without working in solidarity with Indigenous nations and goals, it seems more likely that one's understanding of racism and colonialism remains within the framework of settler colonial liberalism. For example, Kevin states, "I think every person on this street should have knowledge and a relationship with somebody Indigenous. That's how you eradicate racism, is you have, knowing somebody of that group and having a heart relationship with them. That is the only way to overcome racism." He later goes on, "I think systems... governments, institution systems... they are built to maintain status quo. There are people who can affect that, but not me. I am more personal... I want to act in a community basis, in a personal basis. I think if each person helps one or two other people that are how real change happens. That is how you stop the suffering. Suffering is 
happening on an individual level. And to roll back the suffering you need to address it on an individual basis." Robin D'Angelo, a white scholar who has done decades of work with white people coming to terms with whiteness, describes the challenge of shifting the normative liberal understanding of racism as an individual problem perpetuated by individuals in society to a structural understanding (Di'Angelo, Rules of Engagement, p. 1). Rarely taught in Canadian schools or articulated in mainstream media, is the structural understanding of racism that sees it as a historically rooted, default system that institutionalizes an unequal distribution of resources and power, serving to benefit whites and marginalize racialized peoples. Embedded in in white supremacy is the idea that racists are the bad "apples," preventing white people from seeing white supremacy and the structural nature of racism, tied to the economic, political and cultural nature of settler coloniality (Di'Angelo, 2018). Di'Angelo articulates, "to not actively seek to interrupt racism is to internalize and accept it" (Di'Angelo, 2018, p. 1). With an individualized understanding, a politics of recognition is sufficient. There is a demand for respect and recognition of difference, and a focus on education and more "love" as opposed to a fundamental change to the structural foundation of society (Kendi 2017). When the four other women described the need for structural change in society, they spoke of learning from Elders and the struggles of the nations they stood in solidarity with. For example, Nell spoke of how it was on the front lines of the Oka Crisis that taught her about the need for fundamental change: "Watching those tanks come across that land in Kanehsatà:ke and hearing them rumble on the ground as I walked down to the river as I arrived and seeing this massive huge armoured vehicles. In my Canada?" For Janelle, it was her work with Barrier Lakes struggle against mining that has taught her the 
connection between colonial and capitalist interests. Without these types of relationships, it is likely that the understanding of anti-racism and anti-colonial work remains embedded within a politics of recognition.

\subsubsection{Protecting White Comfort}

Research in Indigenous studies and settler colonial studies recognizes that in order to disrupt the hegemony of settler colonialism, settlers in Canada need to see their complicity in the perpetuation of settler colonial structures (Wolfe 2006; Regan 2012). As discussed, this extends to the complicity of whiteness in the perpetuation of settler colonization. Racialized communities have been struggling against racism and white supremacy for centuries, and the need for white people to recognize and challenge their complicity in white supremacy is inherently tied to any struggle against settler colonialism. For white settlers, coming to a critical consciousness about Canada's violent settler colonial foundation entails coming to awareness of white supremacy and our whiteness (Hiller, 2017 p. 430). Though all five people I spoke to the intersection of whiteness and settler identity, there was limited discussion on what that intersection meant in terms of their responsibility in the work they did with their community group. Still, whiteness continued to arise throughout the conversations. Janelle shared a story about when her group was just beginning:

"It was smart, because when we introduced it to the congregation before anybody came in, and I looked out, and our congregation is usually really present, everybody is just there and curious and it was like looking at deer in headlights. Somehow hearing the words Native or indigenous people, caused them to go numb. And that is ancient training. So when [the first speaker] arrived, he came to speak about the beauty about who he is and who Indigenous people are. He came with no axe to grind at all and did not go into any detail about any of the horrific things that had happened. He 
brought a huge bear rug and original equipment and just spoke about the Native reverent for life and the way that manifests and how native children are brought up to be kind and very respectful of life. It was beautiful. It was Indigeneity $101 \ldots$ And it was a good thing because after, [I was told] that some of the congregation were angry, that it was Sunday morning and they did not want to be exposed to this kind of suffering or knowing about these people. I was so shocked because our claim to fame, we are apparently really open to unity with other cultures."

Here we can see Janelle describing the "ancient training" of settler coloniality and white supremacy. It is a privilege of whiteness and settler identity to be able to ignore the violence and oppression experienced by Indigenous peoples by the very systems that intentionally benefit us. Scholar Dina Gillio-Whitaker, who is from the Colville Confederated Tribes, takes up Robin Di'Angelo's idea of white fragility and Peggy McIntosh's white privilege, and discusses settler fragility and settler privilege, drawing the connection between white supremacy and colonization, both woven into the political and legal basis "Canada." Gillio-Whitaker (2018) explores how settler privilege is tied to white privilege, but is actually more surreptitious because it is encoded through the "indoctrination of national pride, imagine community and the nation-state system and goes beyond racism." When settlers see their settler privilege, this does more than illuminate our social location, it calls into question the legitimacy of the country and the belief that we have a right to the land we live on. Settler fragility, the author explains, is a consequence of privilege that results in the often angry denial of one's privilege and refusal to see one's complicity in settler colonization (Gilio-Whitaker, 2018). There is settler fragility weaved throughout this story Janelle shared, particularly the piece about the anger that came from the communities' response. Embedded in the idea that "it was good" to "ease" the group into the injustices Indigenous people face, is an instance of a 
politics of recognition explicitly intended to maintain white and settler comfort. Tuck and Yang's (2012) prominent list of 'settler moves to innocence' describes the tendency for settlers to seek to escape the uncomfortable feelings and realizations that come when one understands their complicity in settler colonization (p. 3). Both Gilio-Whitaker and Tuck and Yang describe the search for white or settler comfort, the comfort that comes with being the main and intended beneficiaries of settler coloniality and white supremacy. When Janelle describes that it was necessary to not discuss the "horrific things" (of colonization), only the "Native reverent for life" there is the implied recognition of Indigenous "culture," but a direct rejection of the structural nature of colonization. Within this space of a politics of recognition, settlers can remain comfortable in their settler identities. Even within this politic of recognition though, there is settler fragility and consequent anger, clearly disturbed by the very presence of Indigenous people. As many have pointed out, the very existence of Indigenous peoples in the present challenges our settler justifications of our colonizing nature (Yegenoglu, 1998; Mackey 2005; Regan 2010; Gilio-Whitaker 2018). Settler fragility and the prioritization of white comfort was also apparent in the multiple stories that Elena shared about Group 2. For example: "the local Native Friendship Centre has a program serving vulnerable Indigenous people...there were 2 or 3 volunteers from here, including myself... I was hoping our community could get more involved with the centre through this project, but we weren't able to get very many people. I think part of it is that it is quite... the requirements to be a volunteer... you had to have training. It's a difficult, very vulnerable population, there are other ways to volunteer with the Centre without having to be involved with street people, and I think for some people it was just too 
much. But yeah, so I'd say that the connections that happened more when we have had "safe" [she used air quotes] Indigenous people." When Susan Dion articulated the need for education for Canadians on the history of colonization, she warned information sharing in a way that settlers can digest and hear is problematic and allows for settlers to ignore their complicity (Dion 2009, 6). Without regular programming and a group, Group 2 seems to be still have the problem of having to make events "digestable", whereas Nell, Janelle, and Amber all described the community of Group 1 to have shifted and are now more comfortable in uncomfortability. Nell pointed out "[in the beginning] there was resistance... well... the congregation was not where we were. In fact, I think in part, that has what our role has been, is to bring them...to be awake and alive to these issues. Like now, we would have no trouble announcing these speakers and having a whole pile of people come, and we know that they are behind us." The speakers, they described, are on issues beyond a politic of recognition and celebration of Indigenous culture, but on the issues including sovereignty, land claims, corporate interest attacks on First Nation communities and more. From the stories shared, it appears that an ongoing, consistent group that continuously brings forth settler colonization in front of their community and builds a connection with Indigenous communities, which they now have an ongoing relationship with, has meant that both the group and the community around them are pushed outside of their settler comfort. Without being continuously unsettled, the need for settler comfort appears to be harder to contest.

\subsection{Spaces with Possibilities for Ontological Negotiation}

\subsubsection{Sustained Slowing Down of Reasoning}


In the politics of recognition, I discussed how the five people who shared their stories with me had described the impact of the education and awareness-raising spaces. I articulated that a large piece of what they unveiled was that though recognized as a critical first step, it was also possible to enter the education spaces without moving beyond a politic of recognition. Settlers were able to consume information that possibly spoke to what is often ignored or invisiblized in mainstream conversations around Canada and its relationship to Indigenous peoples, but it did not necessitate a transformation in settler consciousness. Said differently, that form of listening did not demand settlers engage in a fundamental challenge to settler coloniality. In a slightly paradoxical way, the narrative inquiry also revealed that spaces of "education" also hold the potential to transform settler consciousness. Explicitly, listening to Indigenous peoples, whose ontological and epistemological experiences offer a counter-narrative to settler coloniality (Furniss, 1999; Razack, 2002; Lawson, 2004; Regan, 2006) holds the transformational potential of non-Indigenous people to seeing, being, feeling beyond settler coloniality (Stengers 2004; Regan 2006; Vazquez 2012; Simpson 2016; Rojas 2016). There were moments shared where settlers slowed down their reasoning thereby holding space for hesitation around their ontological assumptions. For Nell, this slowing down of reasoning had come with a variety of shifts for her reality. One she described was:

"We are being challenged and this is something that is coming out strong with [two Algonquin women who they have an ongoing relationship with] who we worked on last year on the hard heart work of reconciliation series, to not just have some notion of "The Noble Indian" but to realize that we have to come at it from recognizing our own Indigenous nature. Like where are we Indigenous to? And until we come to terms with our own connection 
to land, we can't really understand. So we are just coming from a head place. It's not, not coming from a place that is honouring the incredible difference there is. I tend to be someone who tries to not... to see that we are all one... and we are... and we are also very different and we need to really... Within that difference there are all kinds of difference... So part of what we are trying to do is to decolonize our own minds and that is hard work. And sometimes we don't even know what that is. So having to go to a place of not knowing and being willing to be taught and being certainly not "what do we do?" which is important, but how do we be different, in a whole different way, and a different relationship of listening and respect. In various places along the journey I thought I knew, and then the further along we go, I know less and less and less. And sometimes I think I am doing something good and I have some friends now who are brave enough and courageous enough to challenge me."

In this short passage, Nell describes some of her experiences of slowing down reason, "knowing less and less and less" as she enters spaces of ontological negotiation. When she refers to being prompted to thinking of her own "Indigenous nature," she was explicitly directed to think about that in terms of connection to land. As previously discussed, Indigenous communities and scholars have long pointed out that settler coloniality treats land as a resource, whereas land is more than just territory, but often an anchor or framework of Indigenous ontologies (Coulthard, 2010). When Tuck and Yang discuss "all about the land", it is not just about giving a stolen resource back, but is about the need for an ontological shift and an honouring of Indigenous sovereignty. Nell goes on to talk about "honouring incredible difference," which rings familiar to that "radical difference" Maria Lugones discusses. Nell struggles to describe the difference, but they need to not "see that we are all one," clearly trying to resist liberal discourse of equality. When she refers to the need to "decolonize the mind," one is reminded of Tuck and Yang's warning against using decolonization as a metaphor. To me, this piece of the story is articulating Nell's understanding of the need for an ontological shift, beyond Tuck and 
Yang's settler move to innocence. When she goes on to say "how do we be different, in a whole different way, and a different relationship of listening and respect" she is referring the need to transform her consciousness- both thought and action, ontological and societal-structural. Amber shared a story of meeting three different Elders throughout a few months and receiving the same three lessons each time. They included: "first take care of your own house. The second find your own ancestral roots. The third is, stop stealing ours. So those are the three things that I am trying to live out, not only trying, that I am living out in many ways." Amber is discussing continual, repetitive, slowing down of reasoning wherein she was instructed to "clean up her own house", which is referring the house of settler coloniality. Janelle articulates in a similar way, "we had the grace of Native people being willing to come and teach us so we could learn, but always it would come to 'what can we do?' And almost always they would say two things. One, it's about relationship and relationship means, you have to be willing to be open and staying in contact. And I could see that going over our heads. Like somehow the word reconciliation went into only legal terms. Like let's punish the bad guys. The government should be ashamed of itself. Let's give lots of money and that will help for the reserve and then the coast is clear. We will have paid our debt. That is simplistic Western thinking. What is needed is relationship, because native people know that debt will never be repaid." Janelle is speaking to how through being in sustained ontological negotiations, she has come to understanding relationship and reconciliation from settler colonial ontologies is different and insufficient for the transformation of settlerIndigenous relations. Further, being in sustained ontological negotiations differs from the earlier relations based on a drive for opportunities to witness "healthy Indigeneity" or 
extract knowledge. Janelle's words demonstrate accountability, reciprocity, humility and a "slowing down of reason" that points to something resembling Tallbear's description of kinship relations and the obligation to stay committed and open to one another. Many scholars have importantly articulated that non-Indigenous people must purposively seek to interrogate the gap between Indigenous and Western epistemes to hold up the mirror to our settler selves (Ermine 2007; Kuokkanen, 2011). Willie Ermine (2007) argues that there is an "ethical space" created when two societies, two worlds (he uses the term worldview), are poised to engage each other. It can be a framework to understand the different positionalities of Indigenous peoples and Western society (p 193). When nonIndigenous people enter in an "ethical space" with Indigenous peoples, the Western gaze is met by counter gaze, a sort of mirror held up by and to settlers-- when listening to Indigenous knowledges, stories, histories, we actually see ourselves and our own colonizing identities, narratives and societies (200). Both Nell and Amber are describing a moment, in this ethical space, where one sees the ongoing reality of colonization and our complicity. The stories that were shared with me show that sustained slowing down of reasoning meant people were more likely to look in that mirror. This further supports Chris Hiller's work that found that settlers engaged in solidarity work with Indigenous struggles and decolonial praxis often came from the necessary foundation of listening to Indigenous peoples, that was part and parcel of relationship-building with Indigenous peoples $(2017,427)$. It is listening in relation that forces an awakening, catalyzes action for settlers and also interrupt the dominant colonial assumptions and categories around relations and difference (Hiller 2017, 427). Hiller's work found that settlers through jarring moments of listening and relationships one, "can look away, but if the encounter 
affects us in a way that is sufficiently personal, if the jar is powerful enough with sufficient effective weight, or if it is repeated, it may remain with us, embedding within us ... spark[ing] a cycle of reflection and action that draws us into decolonizing practices and new relations of responsibility" (422).

To understand the deep demands of listening in the context of ontological negotiations, Vazquez's (2012) work with epistemic decolonization emphasizes the need for an awareness of the outside of modernity, or settler coloniality, if we are to transform and move to alternatives ways of being. Vazquez ponders the capacity of modernity to partake and witness this move as he advances the questions: "Can modernity listen to the other side of colonial difference?" and "Would modernity open towards intercultural dialogue be recognizable as modernity?" (Vazquez, 2012). Modernity is built on a double negation: an exclusion of the other and a denial of that exclusion (Vazquez, 2012). Based on this double negation, modernity claims itself as a universal truth, so when confronted with a different paradigm, modernity cannot accept the possibility of another truth. Through the "slowing down reasoning" through the traveling between worlds, there is a space and time of encounter and as Lugones describes, a lack of commensurability is likely. Recall, Viverios de Castro (2004) description of ontological encounters, where equivocations- not just a misunderstanding of language- but "a failure to understand that understandings are necessarily not the same, and that they are not related to imaginary ways of "seeing the world" but to the real worlds that are being seen" $(2004,11)$. When settlers are destabilized from settler colonialism's universalized discourses, there comes the possibility to understand that equivocal categories from diverse worlds exist and thus the work to find "partial connections" (Strathern 2004, 54) through translation becomes 
possible (de Lima Costa 2013, 85). Here the violent tendencies of settler coloniality motive to destroy Indigenous epistemologies and ontologies can be challenged. In this narrative inquiry, the equivocal nature of "water" and the space of partial connections and listening are described and were a space for ontological negotiation and a transformation of settler consciousness. Janelle, Nell, and Amber talked at length about a 5-part event on Water that was very transformative for them as individuals and as a group. From it grew a "Water Allies" group that does direct solidarity work with Indigenous nations facing struggles for clean water and water sovereignty. Nell described the 5-part series: "it was a whole again, different level of reconciliation. It took it deep down into encounter... and very different ways of knowing... it was incredible. And again we had 60 people there. This year already we held a storytelling event on water and Grandmother came and did a water ceremony. Several of us raised a bunch of money for her for the water walk." For Nell, "encounter," meant a different way of knowing, and later she described her ongoing commitment to water, suggesting a different way of being in relation to water. Janelle went on to discuss how the event impacted her:

"We brought in a Native historian, to talk about the history of the river from an indigenous perspective, we had someone from the city council to say what's the city up to, they brought in the latest issue about Chalk River which they are about to poison with toxic nuclear waste. The best was Grandmother...she had brought back a very old traditional ceremony and the whole idea that women are in charge of the water. It is in their womb, they need good water to make good babies. SO she came in and taught us about water and taught us the ceremony. She bequeathed it to us. We had the permission to do that ceremony on our own, which is very special...That has been a great joy for me, my awakening, especially around water, thanks to Grandmother Francine and me, I will never see water the same. It is a living entity, not something you just gobble up." 
With multiple voices present from different ontologies, the crisis facing water was brought to the Group 1 community's attention. However, the 5-part series went beyond just "awareness," it became a site of slowed down reasoning and translation. Recall, Claudia de Lima Costa's assertion, "translation - based not only on a linguistic paradigm but more importantly, on an ontological one ---is a key element in forging political alliances and feminist epistemologies that are pro-social justice, anti-racist, antiimperialist and decolonial” (de Lima Costa 2013, 91). Through ontological negotiation, water as the equivocal category became the focal point of translation, and over time, the three settlers relationship to water was fundamentally changed. Not only did they suggest they have a new understanding of water as not just resource, but as "living," they became committed to action around supporting water and water sovereignty. As Janelle said, "that is now my main work, working with water..." When Tallbear explains, "Kinship obligations to nonhuman kin were also violated by the settler state. The decimation of humans and nonhumans in these continents has gone hand in hand" (Tallbear 2016, n.p), we can see that Janelle's commitment to water speaks to the obligation to non-human beings. This example of water as an equivocation demonstrates that translation of this sort allows for the existence of multiple worlds and holds the possibility of tying partial connections through them.

\subsubsection{Relations: Solidarity and Alliances}

All five settlers discussed the importance of relationships and alliances. Janelle, Elena, and Nell all spoke about specific relationship or solidarity work with different Algonquin nations struggles. Amber spoke of her support for struggles, and relationships with different Elders and communities. Both Amber and Kevin did not have ongoing 
relationships with Indigenous communities. As previously discussed, Group 1 had ongoing relationships, but Group 2 did not. Amber described that the church Group 1is a part of has "a very good reputation with Indigenous communities around... at least some for sure. There is a very long history of working for Right relations, long before I got there, very heartful work and many people have made that commitment." All the individuals from Group 1 referred to this long history that has built trust with individual Algonquin people and communities. There is a growing body of literature on how Indigenous and non-Indigenous activists or communities work together in struggles for social change. As previously discussed, settlers have a role to play in the struggle against settler colonization, namely seeing the ways we are complicit and actively working in anti-colonial struggles in solidarity with Indigenous visions of decolonization. Transforming settler consciousness is cultivating settler accountability, challenging the normative power dynamics of settler colonialism, fostering relationships, all through and within a lifetime commitment. Indigenous and non-indigenous relationships are layered and complex, converging at the intersection of dynamic societal and individual forces and manifesting in a myriad of ways. Rick Wallace's book Merging Fires (2013) looked at three case studies where transformations in learning occurred as non-Indigenous individuals engage in solidarity actions in Ontario and found that material and strategic support, practices that respected Indigenous leadership, knowledge, and decision-making, trust-building, reciprocity, and "speaking the truth" helped build alliances. Through research on decolonizing solidarities, Boudreau-Morris (Davis, Denis \& Sinclair, 2019) argues that motivation to engage must not be self-interest and demands giving up power and privilege, echoing Tallbear's call for "acting out of obligation to the indigenous 
collective. And this not a moralistic sense of obligation, but it has been crafted through the steady work of kin-making in order to live" (Tallbear 2016, n.p). Often the work is against settlers short term political and economic interests, but means fulfilling moral, spiritual commitments and is in long-term interests of everyone, "particularly if indigenous resurgence assists in combatting climate change, ever-growing economic inequality, and other social and political problems" (Davis, Denis and Sinclair, 2019, 2). Davis and Shpuniarsky (Davis, 2010) found that alliances challenge settlers' ontological barrings through interaction with Indigenous spirituality and culture. These findings mirror a lot of what the five settlers stories revealed in this narrative inquiry. Some are alliances brought together by shared goals, and some relationships are born from solidarity. Some spaces of social change are born from consciousness-raising efforts, and some are political or legal. Some are Indigenous-led, some settler-led. Scholars have made an effort to document, reflect, and analyze these efforts in attempts to share lessons learns, mistakes made, and ways of moving forward. Research on alliances has found that alliances, coalitions, and solidarity struggles are spaces of learning (especially for nonIndigenous peoples) and social change (Davis, Denis, and Sinclair, 2019). The narrative inquiry revealed that relationships were pivotal in transforming their settler consciousness but also very layered and complex. Of course, this narrative inquiry only revealed the settler perspective, so is limited, but did point to the impact that relationships have and the impact they have on settler's commitment to ontological negotiation and a fundamental challenge to settler coloniality. Nell, who has been engaged in Indigenous solidarity work for decades explained, "the engagement I had in Kanehsatà:ke was foundational. I would never be the same after that." She would go on to say, "Encounter 
has been very important. I would say more and more, not enough. But it tends on relationship building. And you can't just rush into that and you can't just suddenly arrive on the scene like a newborn and say "I have a relationship!" It doesn't come out of that, it comes out of building a relationship." For Nell, relationship calls her to be "an advocate," and she explicitly explained: "it is important that I listen first for what Indigenous people are asking for instead of assuming, which is always an issue. Being an ally, I am learning to really listen and let the leadership come, and I support. So me, trying to build up a community of people who can be allies in a good way is an ethical response." Again, this rings similar to Tallbear's call for settlers action needs to be "about learning how to live here in relation with this place and with peoples who were long co-constituted in relation to these lands and waters and skies" (Tallbear 2016, n.p). For Nell, organizing a large series of events on the "hard heart work of reconciliation" with Indigenous women forced her to confront her assumptions and habits: "That was very hard... the planning was an interesting challenge, but it was so worth it. And what came out was amazing. We started with one then, and it ended with something completely different... It was a really experience of learning to be an ally. I'm used to being a leader, but learning to be an ally and learning to be lead. So those kinds of things happen in different ways and different places". "Those kinds of things" Nell is referring to are the ontological negotiation and shifts that happen through relationship. Janelle's relationship with Barriere Lake has meant responsibility and accountability. She describes a recent action: "We did one-night ad hoc one the other day because Barrier Lake was in trouble, the copper mine was trying to take over, trying to build a road in and then digging a copper mine. You know, "we can because Canadian law says we can"... unbelievable. And the same elder came down with 
his brothers and said we need some help. So we pulled off a big evening- a teach-in. There was ten of us in the kitchen, we brought chili, someone made bannock, and they presented what was going on. There were over 100 people there. Out of nothing over 100 people showed up. So it is there, there is an underground." Through an ongoing connection with Barriere Lake, solidarity has become an ongoing, fluid, and everchanging relationship. Similarly, for Elena, it was through relationship that she found commitment to challenging settler colonialism. She explains, "I find it is because of my connection with Indigenous people and teachings that I am now passionate about that. Now the whole political side, you know, it is always, I stand up whenever the Algonquin people are standing up against Zibi, I feel like I have to give them my voice, I have to sign my name, I have to be present, for any kind of demonstration that is for a political process to try to get the message to the government or whatever. So I do attempt to do that, and I certainly have, as much as I can." Again, speaking to the obligation to kinmaking, she goes on to describe that standing in solidarity with Algonquin people against the desecration of a sacred site has demanded that she figures out "how to live ethically on this land...", she asks herself "how do I find out what Algonquin people expect of me or request for me and then how do I respond to that." Elena, Janelle, and Nell all spoke about the need to not make assumptions about what solidarity should look like, but have a responsibility to learn and listen to what is needed in each context and relation. Elena explains, "it is the recognition to the complexity of it... to me, that is really important. But to live ethically, I think, is to recognize that there is no simple answers and that we just need to keep learning." Janelle speaks to how relationships taught her to be willing to be open to different definitions of reconciliation. Again, here is a slowing down of 
reasoning. Her description of changing relations beyond settler coloniality was as follows: "the first place is to humbly say, we come to you, in complete willingness to own what we did and willingness to hear even more and whatever ritual you feel is needed, we will participate in that. Like that is deep. That's one piece and I feel like I've hardly touched the surface of that." Elena speaks to a changing understanding of social change after years of solidarity work.

"I always used to feel, like I'm here I'll support but what's the point. Its David vs. goliath. But now I see it differently. I see it as, you know, they are going to build this building, but they say, you know "in 100 years, the falls will still be here, but the Zibi development will be gone". And its like wow that's a long way to wait. But it's like, just because we aren't getting what we dreamt of, they aren't going to shut us up. You know? And I'm thinking, wow, what a different way to be. And that is the thing... a different frame of thinking... has very much enriched me. So now, I used to go feeling almost a little bit like, I had a lot of admiration, but I also felt, this is crazy, why spend so much effort on this, this doesn't seem so smart. And now I have a totally other perspective. I have more of a respect for another way of being and thinking and that voice has to be out there. And it's good. And if it bothers other people, than so be it."

Doing solidarity work and building relationships changed Elena's ontological understanding of social change. Her ways of knowing, doing, and being have changed. Further, there was a shift in her understanding of time. Throughout the stories shared with me, time was discussed in paradoxical ways. At some points, the settlers named that their engagement in transforming their consciousness was impelled by the dominant version of reconciliation that sees a 'turning the page' on a 'dark history' of Canadian and now Canada is "progressing" forward. This is very much was within the idea of neutral, shortterm, linear "settler time" discussed in Chapter 3. But here, Elena is speaking to a different understanding of time. Instead of short-sighted "progress", Elena describes 
sacred land enduring one-hundred years from now, beyond the capitalist interest of the Zibi development. Though still fighting for its protection, Elena has come to see that the sacredness of land is not dictated by the schedule of corporate or colonial interests and schedules. Elena's description of her learning process highlights some complexity of living out new perspectives and new ways of being. Four of the folks I interviewed reflected on the fact that building relations is a process, and living in relations and in ways of being that challenges settler coloniality is a challenge. As Nell put it, "we... acknowledge that we were in process, that we are working and moving towards and are not there. And that we were living in it, not just thinking it, but trying to live into right relations. Aspirational."

\subsubsection{Temporality: The Church and The Group}

A significant amount of the time was spent talking about the benefits of working in a group and how the group has impacted their ongoing work at seeking to challenge settler colonialism. What was striking was the sense of temporal durability. The permanency of the church institution creates a sense of longevity and allows for relations to build, as it has for decades. The long term planning is apparent in the way some described how initiatives were created. For example, Janelle explained that there was a core group of people in the community that wanted to ensure the wider community was tuned into what was happening with the Truth and Reconciliation Commission. She explains that after the first year of the network where they were hosting many of the first "awareness-raising events" the thought was: "we have had this opportunity to learn, now our feet need to do something here. So why don't we have this year be a year of preparation to go to a TRC hearing and sit there and witness. So let's prepare to witness with an open heart. So 
everything we did that year were teachings to enable us to open to the hearings." Amber discussed how they were operating through what she called the "Western-style" of gathering in regular meeting formats. She described it was not working to facilitate getting the work done, and now has more "fluidity" and "support" built into the structure. Nell described it as "a pod of people doing specific things, support each other and meet occasionally." For her, it is a sign of changing times:

"It is a different age and a different way of organizing. I think we are in a major shift in culture and old ways of organizing don't work so well. And I'm an old lady and I don't like that, because I like the old ways... not all... But having to find different ways of connecting and experimenting...it is a very quantum way of organizing. And it works. It's more than a movement. Everyone is welcome, and people just pick up the piece that interests them."

The obligation to each other and the work remains, but the demands of "the Western" and "old" way of organizing no longer dictates their gatherings. Amber, Nell, and Janelle all mentioned feeling supported in their various efforts within the group and the work they do outside of it. Still holding meetings when needed, the group members, whose numbers fluctuate between 6-10, call on each other to plan specific events, support specific protests, rallies or actions and will do big planning ideas together. Group 1 members I talked to spoke to the fact that being in a group kept her accountable and committed, and as Nell says, "it keeps it before us and the community." Being connected to a wider network of their community, but also the city of Ottawa network allows their reach to spread quickly and can call on others for support if needed.

Another piece of the wide Ottawa network is a book club. The book club is open to all and currently has both Indigenous and settler individuals and meets every week. Only three of the individuals were involved with the book club, and they spoke to the 
importance of their experience in it. A reoccurring theme through the interviews was discussed the need to do the work to, as Nell put it, "deal with our own racism." For Elena, the book club was a place this happened: "I think the very first step was the book club because we were all non-Indigenous women reading Unsettling the Settler by Paulette Regan. And we kept saying, we need to have an Indigenous person around, but then we were like, no this is our job to do this, we need to talk about it first and not expect them to be there to hold our hand." Similarly, Nell talked about how it is a place to process their own emotions and thinking, "we read and then personally share our reactions to the chapter or chapters. And the stuff gets quite deep, and it is quite profound. In the group, we share what we are struggling with ourselves and on our journey." When discussing her responsibility living on Algonquin land as a settler, Janelle reflected, "every time you speak to a native person from a place of shame, they say get off your shame, go do something, yea. And then we say, what should we do. And then they say speak to other white people, clean up your own mess, don't expect us to come and give to you or teach you. You go be responsible. So you get off that shame and guilt fast because it doesn't really do anything." This sense of responsibility that Janelle, Elena, and Nell revealed was about the work both in the book club and in their communities. This responsibility echoes both academic and community writing on the need for white people to see their complicity in white supremacy. Though all writers will not make the connection between settler coloniality and white supremacy, this call to action reflects research in Indigenous studies and settler colonial studies recognizes that argues that in order to disrupt the hegemony of settler colonialism, non-Indigenous Canadians need to see their complicity in the perpetuation of settler colonial structures 
and actively must work to challenge it (Wolfe 2006; Regan 2012). In a 2017 essay, Iljeoma Oluo, an author who writes on race and racism in North America, speaks directly to white people,

"As much as I'd like you to see me-as much as I'd like systemic racism to simply be a problem of different groups not seeing each other-I need you to see yourself, really see yourself, first. This is the top priority...People of color have been begging you to see what you are doing and why. We've been begging you to see what you came from and the true legacy you have inherited. We've begged you to see your boot on our necks as long as it's been there. Find yourselves white people. Find yourselves so that you can know what whiteness is. Find yourselves so that you can determine what you want whiteness to be. Find yourselves so that you can stop your loved ones from voting for a definition of whiteness that you no longer want to subscribe to. Find yourselves so that racism no longer surprises you."

The book club is a space where some of the women are "finding themselves" and coming to know their whiteness. Robin Di'Angelo has articulated that white fragility, "a state in which even a minimum amount of racial stress becomes intolerable, triggering a range of defensive moves." This fragility often means white people will victimize themselves, despite being the perpetrators of racism and beneficiaries of white supremacy. To have a space to reflect on one's complicity in settler coloniality and white supremacy is for these women, seemingly a way to thwart their fragility (though that is an ongoing task). The settlers discussed their feeling of responsibility face their own complicity, though their was a mix of feeling that was work to be done in a group or individually. Whereas Janelle, Elena, and Nell discussed this work in terms of the group work, Kevin and Amber discussed it more in terms of their personal journey (though that does not mean they do not do that work in their community efforts). For Amber this meant she "put more of my energy in doing what [she] feels is necessary for [her] to clear the settler 
issue, stuff, in me first, so that I will be able to come to any relations to Indigenous people from a perspective of not feeling guilty or ashamed". Ally Henny, who is an African-American writer and social commentator on anti-black racism, articulates that, "in order to dismantle racism we must deconstruct whiteness. Sometimes deconstructing whiteness can feel like centering whiteness, but in reality (or at least when it is done well) deconstructing whiteness removes it from the center because deconstruction denormalizes whiteness" (Henny, 2018). The work being done to talk to "other white people" as Janelle put it can be seen as a piece of this and both the ongoing community work and the book club are spaces where this takes place. When asked how working in a group impacted their journey in transforming their settler consciousness, they all spoke to the importance of being able to contribute ideas and resources. As Amber put it, "we all bring the piece that we have and when we bring it together and put it into a pot, and we benefit from it. Together it is part of a process that is moving something forward." Janelle spoke to having a group has taught her, "that if you want something to happen, if you have a dream, that is manageable and that has a time frame, everybody can do a little piece. If you can introduce that clearly, people will jump on. People's hearts will jump on. It's so important to know this, if you create a safe enough and easy enough bridge, it makes people so happy." Janelle saw the focus on community and relationship building as a challenge to settler coloniality prioritization of individualism. Working in a group challenged her assumptions and understandings of change: "our education system, our laws, nothing it does not teach us that, it teaches us all about the individual. The greatness of the individual and people try to be impressive, and they try to go farther climb the mountain, it is all about the "I." But it's so much better to work in the "we". So that's a big 
learning for me." Again, this speaks to the obligation of kin-making. Working with a small group that supports each other and are like-minded facilitated a space to slow down reasoning for Janelle, "[We] were there because they cared and wanted to talk to each other. Everyone has an orientation towards questioning, how could we create the right energy that you could call spiritual. Nobody was like "I want to be rational", all I want is the facts." The group dynamic takes the work beyond colonialty's emphasis on rationality and incorporates spirit and heart (which is from Western ontology is seen as the opposite of rationality). Nell spoke to groups allowing people to work through the tensions and challenges in seeking to transform society, "I think it is called life. I think that that what life is about. It is about living in the highest point of tension possible. And not denial and pretending things are different then they are and not drowning in the guilt so you don't

take responsibility for how things are. It's not an easy. I worry about people are not in that kind of tension. I want to bring people into that tension, because that is where you get creative and that's where the rubber meets the road. That's where you need a group of people to support that place.” The opening up of space for deepening and expanding with ontological shifts came through tension, confusion and slowing down of reason. The stories shared about "the tensions" and "the learnings" articulated that working in a group facilitated a sense of commitment and accountability to each other and to the work of challenging settler coloniality.

\subsubsection{Spiritual Grounding: Partial Connections}

Both Group 1 and 2 are based out of churches, and so it was not surprising that spirituality was discussed in every interview. When Janelle discussed the impact that her work through Group 1 has had on her life, she explained "it has changed [her] 
fundamental sense of what is real." This sentiment was similar to the stories the others told. Janelle went on to say, "it is so deep, it has changed my spirituality, I've fallen in love with nature in a whole new way, it's changed my sense of responsibility, not just to this generation or to this family, that it's too the earth, which includes me and the people. My life purpose has changed because of it." As introduced earlier, Strathern's (2004) idea of "partial connections" articulations the relationship the describes the composition of something that is "neither singular nor plural" (54) but a myriad of connections. Marisol de la Cadena takes up Strathern's concept to articulate how the "indigeneity in the Andes... can be conceptualized as a complex formation, a historic-political articulation of more than one, but less than two, socionatural worlds" (de la Cadena 2010, 347). De la Cadena's analysis is applicable to how the five settlers described the transformation in settler consciousness saw their indoctrination into modernity/coloniality shaken, often through a partial connection to their spiritual grounding. Their faiths varied, though most of them referred to Christianity as the central religion/spirituality in their lives. When settlers are destabilized from settler colonialism's universalized discourses, there comes the possibility to understand that there is a multitude of worlds that exist, as do "partial connections" between them. For Amber, understandings of land as sacred and land as more than territory, are teachings she has learned from Algonquin Elders but resonates with her feminist spiritualities. She explains, "for me, the fact that I have participated in feminist spirituality and goddess based rituals for so long, is grounding and it just makes sense to me when we are talking about land as sacred, and all is sacred, I have come to understand this through my feminist and women's teachings." Similarly, Elena spoke to how her understanding of land has changed through both teachings from Anishinaabeg 
teachers and Christianity: "So we are part of it. It is a spiritual thing. So certainly my understanding of land has become more spiritual; as I grow older and with my own experiences with mediation and Christian mediation...But I do also feel that the understanding of the Indigenous peoples of their connection to land has influenced how I see the world, the natural world around me." Kevin talks about a slowing down of reasoning that comes before/with the partial connections are made. For him, it is the realization that "there are so many things that are coded into through our upbringing that we don't even realize. I've come to not trust my judgement. My answers are not going to come from my head, like they have my whole life, I've been so dependent on my intellect my whole life." He goes on to say that "I have a strong faith in the Creator. And a strong faith in that we all need to do something and that there is a destiny. I am waiting to be informed. My Christian background, it is very similar to Indigenous, they seek direction from outside themselves and there really is not a lot of difference in the real traditional. There is a different between religion and faith. I think there is many parallels with Christian faith and Indigenous spiritualism." This narrative inquiry revealed that the spiritual grounding of these filled spaces of ontological negotiation with partial connections from their faiths. While not explored in depth, the partial connections and parallels between spiritualties and Indigenous ways of being was mentioned by all five settlers and held great significance for each of them.

\subsection{Not One Or The Other: Politics Of Recognition And Ontological Negotiation}

After listening to the stories of the five settlers, it has become clear that the relationship between politics of recognition and ontological negotiations as ways of settlers seeking to challenge settler colonialism is not linear or mutually exclusive. The manifold trajectories 
of how white settlers cannot easily be delineated and yet this complexity is not surprising. Individually, our social locations, politics and experiences differ and lead us to different journeys. Collectively, as the violence of settler colonialism becomes more widely acknowledged, the rhetoric of reconciliation amplifies and Indigenous resurgence grows, the way forward beyond settler coloniality is evolving, conceptually defined and redefined with expectations and social resistance flows always changing. Chapter 5, the conclusion, will tie together this analysis of the complex stories that have lent insight into how white settlers might attempt to engage in radical social change of settler coloniality. 


\section{Chapter 5: Settler Responsibility: The Paradoxes, Challenges and}

\section{Pitfalls}

As the violence of settler coloniality continues to play out in a myriad of ways, Indigenous academics continue to provide a critical analysis of the Canadian states (in)action, including Coulthard's (2014) scholarship on the danger of the liberal politics of recognition or Simpson's (2016) on the dangers of the affective state and politics reconciliation. Analysis such as Secwepemc leader and lawyer Manuel's $(2015 ; 2017)$ work on the Canadian state and its use of law to continually steal land, Gitxsan scholar and activist Cindy Blackstock's (Blackstock, 2019) work around the ongoing discrimination against Indigenous children, or Anishinaabe scholar Lynn Gehl's (Deer, 2019) work around the gender discrimination in the Indian Act are incredibly important as they describe the ongoing settler colonial agenda. The need for ongoing analysis of the Canadian state's actions is necessary: settler coloniality is the very fabric of Canada and the ongoing violence and dispossession experienced by Indigenous nations and peoples is the direct intended consequence (Cardinal et al. 2004; Wolfe 2006; Veracini 2010; Manuel 2015). Indigenous resistance against colonial forces has existed as long as colonialism, and increasingly so, Indigenous resurgence is growing. While Tuck and Yang (2012) and others have explained that decolonization is a movement that answers to Indigenous futures, resurgence, and survival, there remains a question of what settlers must do to dictate their future beyond the limitation and violence of settler coloniality. Research in Indigenous studies and settler colonial studies has argued that to disrupt the 
hegemony of settler colonialism, settlers need to understand not only how they benefit from settler colonization but also how we are complicit in and benefit from its continuation (Mackey 2005; Wolfe 2006; Regan 2006, 2012; Morgensen 2009; Snelgrove, Dhamoon \& Corntassel, 2014). The ontological and epistemological nature of settler coloniality shape the way settler Canadians understand reality, nation, citizenship, relationality-their consciousness (Mackey 2002; Regan 2006, 2012; Wolfe 2006). Starting from the premise that settlers have the responsibility to do the work of transforming their consciousness in order to dismantle settler coloniality, this thesis sought to explore how community groups of settlers were attempting to engage in this responsibility. In the beginning, I specifically asked what about this initiative did or did not impact people to challenge the status quo of settler colonization? Through a narrative inquiry, I found that the community groups facilitated, in no linear or dichotomous way, both a space for politics of recognition or space for ontological negotiation. While the former does not require a transformation in consciousness or settler coloniality, the later holds the possibility of doing so. I found that specific conditions described by the settlers involved had an impact on what type of transformative (or not) space they engaged in. I attempted to center this work vis-à-vis the visioning, guidance, and analysis provided of Indigenous activists and scholars on ways that relations between settlers and Indigenous peoples may transpire in the struggle against settler colonization. This centering is important for the task of transforming settler consciousness for a myriad of reasons. Indigenous people are targeted by settler colonization and how it will be uprooted, should be dictated by them. Any other way would be reproducing colonial relations. Further, the "logics of settler colonialism" that shape white settler identity and subjectivity, also 
means there are limits what white settler perspective (my own) can see in terms of systems of oppression, and listening to the lived experiences of those who experience oppression, at whatever intersection is critical. This research, along with the sources throughout this thesis offers insights into pathways forward, with and through transforming settler consciousness. Specifically looking at work done on the importance of (un)learning, slowing down reasoning, spaces of uncomfortability, and then lessons from particular alliances and solidarities. What is clear is the way forward is incomplete and always emerging. The work of activists and academics alike demonstrate that there is necessary work to be done by those who hold systemic power and privilege if the possibilities of justice are to be realized. Scholars in settler colonial studies have begun to look at how (white) settlers are seeking to be a part of changing oppressive systems that are largely built to benefit them. Davis et al. (2017) analyzed a compilation of twentyfive initiatives happening across Canada run by an array of groups- NGOs, churches, educational institutions, community organizations, grassroots activists. This research offers critical insights into the complexities and tensions of settler consciousness and changing relationships in this era of so-called reconciliation. They found that there was a focus on awareness-raising, without providing direct support to communities or acknowledging the structural power settlers still hold, the central question of land reclamation/reparations and Indigenous sovereignty. The authors found that a "tension exists in knowing how big a role Indigenous peoples should play in settler education, and in striking a balance between, on the one hand, learning from Indigenous peoples, knowledge and pedagogies, and on the other, settlers taking responsibility for their own education and unlearning of dominant narratives and histories. Finding ways to include 
Indigenous voices and perspectives respectfully without burdening Indigenous peoples is a balance to be considered" (Davis et al. 2017, 10). Further, the authors recognized some important tensions, including the choice of language and discourse, often liberal, failing to understand settler colonization as an ongoing system of oppression, including liberalism's recognition politics. These findings are similar to a study done by Denis and Bailey (2016) who asked forty settler Canadians that attended the Truth and Reconciliation Commission's events about their perspective on reconciliation and allyship. They found that most agreed with the TRC's vision of respectful relationships, more awareness for settlers, cultural understanding, healing, and change in policies, however there was limited discussion or support for land rights, self-determination, and Indigenous sovereignty. Both Davis et al (2017) and Denis and Bailey's (2016) findings echo the work of many others: the politics of recognition and the reconciliation movement born from it does not require any transformation in settler coloniality. Working with five white settlers, allowed for their storytelling to become a source of knowledge on the complex meanings, intentions, understandings, and choices that settlers share in their process of seeking to challenge settler coloniality and transforming their consciousness. Complemented by a political ontology framework and knowledges from Indigenous studies, critical race and settler colonial theory, this narrative inquiry allowed for the analysis "created and constructed through stories of lived experiences" of specific located experiences of five white older settlers and the meanings created by them (Etherington 2013, 5). As a part of community groups in Ottawa, the methodology allowed me to think about how the group, space, institutional resources that shaped their experiences. Following a narrative inquiry allowed me for the nuanced, sometimes 
contradictory nature of this process and revealed the entangled and complex ways in which the community groups did, or did not, catalyze transformed settler consciousness and social action for the individuals involved. The stories shared revealed that the structure of the community groups shaped the possibilities of what the groups and individuals were able to do in terms of action. Both groups were church-based and connected to a city-wide network that was all connected since the inception of both. For one, being nested in an institution such as a church meant they groups had access to resources, sometimes monetary, physical space for events and a kitchen. This is access that often grassroots groups struggle to attain, but provided many opportunities for both groups to carry out solidarity and education-based events. Furthermore, being connected to a wide network of across the city meant that the groups could call on each other for support, had a broad group of people to reach in emergency calls to action and were able to share ideas and resources.

The narrative inquiry revealed that the pieces that facilitated a politics of recognition included the spaces of awareness-raising, working without a core group, building relationships without reciprocity, and a focus on protecting white comfort. For settler's engaged in seeking to challenge settler coloniality, it is essential to see the universalizing attempts and understand the settler colonial underpinnings of the reconciliation project orchestrated by the state. The mainstreaming of the reconciliation project has seen wellmeaning settlers swept up into it. However, reconciliation, as defined by the state limits the potentials of transformation on an individual and collective level, and it does not facilitate a transformation in settler consciousness. Both Groups mandates online indicate they are committed to the TRC recommendations, specifically those pertaining to 
reconciliation between the church and Indigenous peoples. Within the stories shared with me, there was limited discussion on critiquing the reconciliation project, though there were clear indications that some were more bought into it than others and more so that certain elements of the groups facilitated a politics of recognition. Education and awareness were a clear priority for both groups, and the individuals described it as necessary, and their responsibility to bring light to the violence of settler colonialism to their communities. It has long been founded that settler narratives of history and relations with Indigenous nations need to be interrupted because they perpetuate lies and a rosy picture of the past and present. However, there is a danger in what Tuck and Yang (2012) refer to a "critical consciousness" becoming the only site of "action" on the part of settlers. While it is necessary to understand the intentionally hidden violence of settler coloniality, learning and awareness does demand a transformation of society's structures and can make settlers feel like they "are doing their part." The individuals involved in the group described, some in frustration, how though more people from their wider community are willing to come to educational events now as compared to years previous, there is minimal commitment beyond that. The focus on education can open the conversation or window for transforming settler consciousness, the commitment to challenge settler coloniality, but it clearly can also allow settlers to remain in a politic of recognition comfortably. Chapter 4 reflected on how the focus on education and awareness can lead to complacency, taking no action beyond "learning" and freezing people in a politics of recognition. In some ways, a politics of recognition can open the conversation or window for transforming settler consciousness through ontological negotiation. The understanding and relinquishment of settler privilege did not happen 
without the cultivation of critical consciousness and in some cases a politics of recognitions launched that cultivation. In a complicated and paradoxical way, relations were also central to the process of transforming settler consciousness and the movement between a politics of recognition and ontological negotiation. The white settlers I interviewed were in different kinds of relationships: with individuals, with Algonquin nations, with Indigenous organizations. Undeniably, building relationships is extremely important in challenging settler coloniality because it challenges the colonial relational patterns and allows for ontological negotiation, but in some instances actually reified a recognition approach. Some relations were grounded in reciprocity, facilitating spaces of slowing down reasoning and translation. Other relations were extractive and self-seeking, acknowledging the need to "respect" Indigenous culture and people, but not actually engaging a transformation of relational dynamics or other aspects of settler coloniality. It must be acknowledged that building relations is really fraught and, for settlers, this complexity must not be lost in our romanticization of "building relationships". For Group 2, it was even more difficult to move beyond a politics of recognition because it operates without a core group, functioning as a listserv and Elena serving as the only organizer of events. With only one event a year, there was no sustained interruption to settler narratives, and visions for dismantling settler coloniality were rare. Further, there was a limited chance for relationship building with Indigenous communities or alliances with local struggles. Elena described the community as being open to the events, clearly "respecting" and okay with "celebrating" Indigenous culture, but beyond that, there was little interest- there was comfort in the politics of recognition. Overall, there was a severely limited possibility of forming an ongoing commitment to a transformation in 
settler consciousness for the wider community. The narrative inquiry further revealed that without relationships formed with Indigenous nations in the context of a group with a formed commitment to solidarity and action, relations with Indigenous peoples were being sought out in the interest of "gaining knowledge" and "extracting understanding." Without working in solidarity with Indigenous nations and goals, one's understanding of racism and colonialism remains within the framework of settler colonial liberalism, where a politics of recognition is sufficient to deal with. Lastly, facilitating a politics of recognition was the prominence of protecting white comfort. Settler coloniality is built to provide comfort and stability for white settlers. A politics of recognition makes claims to accommodating Indigenous identity-related assertions while maintaining settler coloniality and its comfort for white settlers. The stories shared revealed that there were times when ensuring the groups' communities were only exposed to a celebration of Indigenous culture, "safe Natives" and shielded from hearing the violence and ongoing struggles. Indigenous nations are experiencing. This keeps settlers firmly in a politics of recognition; able to say they are learning and respecting Indigenous peoples, without actually challenging settler coloniality.

Alternatively to a politics of recognition, certain parts of the groups can be seen facilitating a space where ontological negotiation happened, compelling a transformation in settler consciousness and demanding a challenge to settler coloniality beyond a politic of recognition. Canadian settler coloniality, as a part of the universal project of capitalist and colonial modernity that began in the $17^{\text {th }}$ century with the so-called "Age of Reason," inherently make universalized claims to being the only ontological possibility, deeming others not modern or legitimate. Resisting and transforming away from this 
universalizing colonial project, there need be a commitment to a plurality of worlds, and as Rojas (2016) proposes a "deep relational ontologies between humans, and humans and nature" (Rojas 2016, p 369). To help explain how the individuals described how certain aspects of their groups entered spaces of this deep relationality, I used the Strenger's (2004) concept of a 'slowing down of reason' where there is hesitation to conform to the ontologies of settler coloniality, a space opened to deep relationality, ontological negotation, incommensurability between worlds and possible calls for translation (not simply linguistic, but ontological). Nell at one point described her experience of working with a group of Algonquin women, "having to go to a place of not knowing", to stop herself from recreating colonial habits. An ontological shift to a way of being beyond settler coloniality requires what Maria Lugones (1987) 'world'-traveling. This "travelling" allows the "worlds"- ontologies and epistemologies that have been denied by modernity/coloniality, has denied the possibilities of loving and communicating between "radical difference." Within ontological negotiation or 'world'-traveling, with a slowing down of reasoning, difference is not a matter of culture, but of ways of being. Where a politics of recognition wants to respect and then assimilate difference, world-traveling and ontological negotiation recognize the radical difference as something not to be flattened, and settlers must resist the colonial impulse to do so. Recognizing and respecting Indigenous cultures and assimilating them into settler coloniality is not justice or a transformation of society, and through the narrative inquiry, it was revealed some ways facilitated settlers to resist that assimilative impulse. The parts of the community groups that facilitated spaces of ontological negotiations included the sustained slowing down of reasoning, relationships within Indigenous communities and alliance-building, 
the temporal dimensions of the group and the spiritual grounding of the individuals involved. Group 2 were a very busy group of individuals, who were continuously engaged in various alliances and initiatives, working with both settlers and Indigenous folks to plan events and many were involved in a weekly book club. The ongoing commitment, deep relationships and continued commitment to learning more across radical difference meant that there was a sustained "slowing down of reason," where the individuals reported their reality, understanding, and spirituality constantly being challenged and changing from the conditioning and assumptions of settler coloniality embedded within them. Further, the individuals with commitments to different (mostly Algonquin struggles) described that it was these relationships and being a part of resisting colonial violence, that were a site of transformation and what solidified their ongoing commitment. It was through relations, 'world'-traveling and political action where the challenging of settler coloniality occurred. Notably, this ongoing commitment through a slowing down of reasoning and relations was, in part, made possible by the temporal dimensions of the group. Being nested within the church, not only provided resources but also allowed for long-term planning, visioning, and most importantly, lasting relationships. Lastly, the settlers shared stories of what Strathens (2004) calls "partial connections" wherein 'worlds' cannot be seen as completely separate or meshed, but linked through a myriad of connections. Many described the transformation in settler consciousness through the colonial assumptions being destabilized through a partial connection within their spirituality. Paradoxically, despite the monotheist foundations of Christianity, the white settler's spirituality still made them more to ontological shifts. The partial connections around meaning and reality saw ontological shifts occur with some 
ease, and as Janelle pointed out, allowed for a change in her "fundamental sense of what is real. It is so deep, it has changed [her] spirituality... it's changed [her] sense of responsibility, not just to this generation or to this family, that it's too the earth, which includes me and the people." The settlers were engaging in sustained slowing down of reasoning, were articulating understandings of relationships and responsibility that reflected what Kim Tallbear (2016) describes as kinship relations. Tallbear explains that she sees "Indigenous peoples critiques and ongoing agreement making a continued call for non-Indigenous people to engage in good relations (n.p.)" and that good relations is not about smoothing radical difference, but about settlers "learning how to live here in relation with this place and with people's who were here long co-constituted in relation to these land waters and skies (n.p)." Further learning from the stories of the five settlers showed that the spaces of ontological negotiation and 'world'-traveling opened up space to discuss land in a myriad of ways. First, it facilitated the discussion around the understanding the if settler colonialism is, "the unbroken pace of invasion, and settler occupation, into Native lands... decolonization, as a process, would repatriate land to Indigenous peoples, reversing the timeline..." (Tuck and Yang 2012, 25). Second, that ontologically, land is not merely a resource or object, but rather an anchor or framework of Indigenous ontologies, ways of knowing, experience and relating with the world (Coulthard 2010, 1). There was an acknowledgment for the need for an ontological shift and an honouring of Indigenous sovereignty in a way that respects ontological differences, beyond that of Canada's colonial-capitalist liberal pluralism. Through sustained slowing down of reason through relationships and 'world'-traveling, settlers 
came to see land as central in the conversation of challenging settler colonialism, beyond the confines of settler colonial definitions.

Tuck and Yang (2012) discuss how different struggles of liberation are incommensurable, do not have the same goals and in fact, often the aims contradict one another. The aim to make the goals commensurable often has the consequence of invisibilizing Indigenous struggles for rights and land $(2012,39)$. The settlers described solidarity with nations through direct action or support, not through different struggles of liberation, which perhaps allowed for this risk of this attempted commensurability irrelevant to their journey. However, still relevant for the broader task of settlers is Tuck and Yang's discussion on how incommensurability is not something to overcome, but to hold space for, exist within, be. Incommensurability is an acknowledgment that decolonization will require a change in "the order of the world" and "a dangerous understanding of uncommonality that un-coalesces coalition politics" $(2012,39)$. In reflections and ongoing questions of settler responsibility, we must interrogate how settlers are moving beyond moves to innocence and engaging in that complicated unknown terrain of uncoalesced coalition politics. Partial connections might be part of how coalition politics can exist in solidarity, without compromise, using the friction between them as the foundation upon which to build society beyond settler coloniality. In a similar vein, is how it will be necessary to see how settlers are resisting colonial universalizing impulses and learning to 'world'-travel without assimilating or flattening differences of ontologies. Donna Harraway's idea of "staying with the trouble" may prove useful here. In the midst of global ecological devastation, Donna Harraway (2016) discusses that humans are lured to a make an imagined futures of stopping the pending disasters that are looming and to 
escape the present and its complexities to make way for the future. This temptation pulls us to colonial impulses, Harraway calls for us to "stay with the trouble': staying present in a myriad of times, places, matters and meanings, and ontologies. It will be necessary to hold ourselves, as white settlers, accountable to the way we transform our consciousness to space where different relationalities, temporalities, and spatiality can emerge. Tuck and Yang (2012) explain that decolonization seeks explicitly to answer Indigenous futurity: the dreaming and building of a new and better future. Settler fragility and the consequent 'moves to innocence' answers settler futures (p 3) and center settler identities, feelings, and interests without supporting decolonization's demand for Indigenous sovereignty and the return of land (Tuck and Yang 2012, 28). Staying with the trouble may provide the space for settlers to transform their consciousness and begin to answer to their settler futures that support decolonization and seeks to create a world beyond the confines of settler coloniality. As Amber puts it, "a growing awareness that how we have been doing things has not been working, so we better find a different way. I think there is some awareness growing that Indigenous have their relationship with the land, is something for us to relearn or remember and we need that given the climate change. To me, I do think that there is something about the times right now. There is a pulse right now that is saying, wake up, wake up, wake up. And some people are hearing that and saying you know, I'm going to wake up and some are drugging themselves so that they don't. And we are seeing both happen in bigger numbers. For me, it is like the dark, and the light are playing out. That is what I feel is happening." As an increasing number of settlers "wake up," there is a myriad of ways the community groups of settlers are taking up calls for changing relations between Indigenous peoples and Canada and seeking to transform the 
structures of settler coloniality. The stories shared by the five settlers brought light to some of the complexities, contradictions, and possibilities of transforming settler consciousness, particularly within the context of community groups. While Indigenous peoples must define decolonization, settlers must see their complicity in the ongoing violence of Canada and more importantly do the ontological and political work of transforming the foundation of settler coloniality and beyond the violence inherent in it. 


\section{Appendices}

\section{Appendix A Interview Questions}

1. How long have you been involved with your [community group name] group?

a. Why did you join [community group name]?

2. How has your engagement with [community group name] changed what it means to live ethically as a settler on traditional Indigenous territories?

3. What impact has the [community group name] group had on how you are personally motivated to take action in support of Indigenous rights?

4. How have relationships with different Indigenous communities shaped the work of [community group name] and your own engagement with this work?

5. How does working and learning with a group of people, as opposed to individually, impact your engagement?

6. How have digital "spaces", i.e. emails, bulletins, Facebook, social media, impacted how [community group name] works and how you engage with it?

7. How has [community group name] impacted how you emotionally process the "uncomfortable" (i.e. the guilt, anger, incommensurable) that can come with understanding the realities of settler colonialism?

8. Has your work with [community group name] changed your understanding of land? If yes, how? 
Bibliography

Alfred, T. (2005). Wasase: Indigenous Pathways Of Action And Freedom. University of Toronto Press.

Alfred, T., \& Corntassel, J. (2005). Being Indigenous: Resurgences against contemporary colonialism. Government and Opposition, 40(4), 597-614.

Alfred, T. (2009). Restitution is the real pathway to justice for Indigenous peoples. Response, responsibility, and renewal: Canada's truth and reconciliation journey, 179-87.

Anderson, H., \& Gehart, D. (2007). Collaborative therapy: conversations and relationships that make a difference. Brunner-Routledge, New York.

Andersen, C. (2009). Critical Indigenous studies: From difference to density. Cultural Studies Review, 15(2), 80-100.

Anderson, S. G. (2016). Stitching through Silence: Walking With Our Sisters, Honoring the Missing and Murdered Aboriginal Women in Canada. Textile, 14(1), 84-97.

Asch, M. (2014). On Being Here to Stay: Treaties and Aboriginal Rights in Canada. University of Toronto Press.

Asch, M., Borrows, J., \& Tully, J. (Eds.). (2018). Resurgence and Reconciliation: Indigenous-settler Relations and Earth Teachings. University of Toronto Press.

Bannerji, H. (2000). The dark side of the nation: Essays on multiculturalism, nationalism and gender. Canadian Scholars' Press.

Banivanua, T. M. (2010). Carving wilderness: Queensland's national parks and the unsettling of emptied lands, 1890-1910. In Making settler colonial Space (pp. 73-94). Palgrave Macmillan, London

Battell Lowman, E. \& Barker, A. J. (2015). Settler: Identity and colonialism in 21st century Canada. Fernwood Publishing. 
Blackstock, C. (2019, January 18). For Indigenous kids' welfare, our government knows better; it just needs to do better. Retrieved from https://www.theglobeandmail.com/opinion/article-for-indigenous-kids-welfare-ourgovernment-knows-better-they-just/

Blaser, M. (2009). Political ontology: cultural studies without 'cultures'?. Cultural Studies, 23(5-6), 873-896.

Blaser, M. (2013). Notes towards a political ontology of 'environmental' conflicts. Contested ecologies: Dialogues in the South on nature and knowledge, 13-27.

Brake, J. (2019, June 24). 'Let us rise with more energy': Saganash responds to Senate death of C-262 as Liberals promise, again, to legislate UNDRIP. Retrieved from https://aptnnews.ca/2019/06/24/let-us-rise-with-more-energy-saganash-responds-tosenate-death-of-c-262-as-liberals-promise-again-to-legislate-undrip/

Boler, M., \& Zembylas, M. (2003). Discomforting truths: The emotional terrain of understanding differences. Pedagogies of difference: Rethinking education for social justice, 110-136.

Borrows, J. (2002). Recovering Canada: The resurgence of indigenous law. University of Toronto Press.

Cairns, A. (2011). Citizens plus: Aboriginal peoples and the Canadian state. UBC press.

Cardinal, T., Griffiths, R., Clarkson, A., Highway, T., Johnston, B., King, T., ... \& Taylor, D. H. (2004). Our story: Aboriginal voices on Canada's past. Doubleday Canada.

Carlson, E. (2017). Anti-colonial methodologies and practices for settler colonial studies. Settler Colonial Studies, 7(4), 496-517.

Chakrabarty, D. (2008). Provincializing Europe: Postcolonial thought and historical difference. Princeton University Press.

Charmaz, Kathy. (2006) Constructing grounded theory: A practical guide through qualitative analysis. Sage.

Coulthard, G. (2010). Place against empire: Understanding Indigenous anti-colonialism. Affinities: A Journal of Radical Theory, Culture, and Action. 
Coulthard, G. S. (2014). Red skin, white masks: Rejecting the colonial politics of recognition. Minneapolis: Minnesota.

de Lima Costa, C. (2013). Equivocation, Translation, and Performative Interseccionality: Notes on Decolonial Feminist Practices and Ethics in Latin America. A GLO N, 73.

Crenshaw, K. (1990). Mapping the margins: Intersectionality, identity politics, and violence against women of color. Stan. L. Rev., 43, 1241.

Daly, E., \& Sarkin, J. (2011). Reconciliation in divided societies: Finding common ground. University of Pennsylvania Press.

Davis, L. (eds). Alliances: Re/Envisioning Indigenous-Non-Indigenous Relationships. University of Toronto Press, 2010.

Davis, L. (2016). Paper 8: Fostering Citizenship Engagement in Indigenous/NonIndigenous Relations. Conference Paper, Queens University. Retrieved from https://www.queensu.ca/sps/sites/webpublish.queensu.ca.spswww/files/files/Events/Conf erences/RCAP/Papers/LynneDavisRCAP\%20Backgroundpaper.pdf

Davis, L., Denis, J., \& Sinclair, R. (2017). Pathways of settler decolonization. Routledge.

Davis, L., Hiller, C., James, C., Lloyd, K., Nasca, T., \& Taylor, S. (2017). Complicated Pathways: Settler Canadians Learning to Re/frame Themselves and Their Relationships with Indigenous Peoples. Settler Colonial Studies, 7(4), 398-414.

Dean, A. (2015). Remembering Vancouver's disappeared women: Settler colonialism and the difficulty of inheritance. University of Toronto Press.

Denis, J. S., \& Bailey, K. A. (2016). 'You Can’t Have Reconciliation Without Justice': How Non-Indigenous Participants in Canada's Truth and Reconciliation Process Understand Their Roles and Goals. In The limits of settler colonial reconciliation (pp. 137-158). Springer, Singapore.

de la Cadena, M. (2010). Indigenous cosmopolitics in the Andes: Conceptual reflections beyond "politics". Cultural anthropology, 25(2), 334-370.

Dion, S. D. (2009). Braiding histories: Learning from Aboriginal peoples' experiences and perspectives. UBC Press. 
Di'Angelo, R. (2011). White fragility. International Journal of Critical Pedagogy, 3(3), 54-70.

DiAngelo, R. (2018). White fragility: Why it's so hard for white people to talk about racism. Beacon Press.

Epp, R. (2008). We Are All Treaty People: Prairie Essays. University of Alberta.

Ermine, W. (2007). The Ethical Space of Engagement. Indigenous Law Journal, 6(1).

Escobar, A. (2008). Territories of difference: place, movements, life, redes. Duke University Press.

Escobar, A. (2015). Territorios de diferencia: la ontología política de los "derechos al territorio". Cuadernos de antropología social, (41), 25-38.

Googoo, M. (2019, March 19). Nova Scotia judge grants temporary injunction against Mi'kmaw water protector, supporters. Retrieved from

http://kukukwes.com/2019/03/19/nova-scotia-judge-grants-temporary-injunction-againstmikmaw-water-protectors-supporters/

Gilio-Whitake, D. (2018). Settler Fragility: Why Settler Privilege Is So Hard to Talk About. Retrieved January 05, 19, from https://www.beaconbroadside.com/broadside/2018/11/settler-fragility-why-settlerprivilege-is-so-hard-to-talk-about.html

Haig-Brown, C. (2012). Decolonizing diaspora. In Decolonizing philosophies of education (pp. 73-90). SensePublishers.

Haraway, D. J. (2016). Staying with the trouble: Making kin in the Chthulucene. Duke University Press.

Harris, C. I. (1993). Whiteness as property. Harvard law review, 1707-1791.

Heffernan, M. (2011). Wilful Blindness: Why We Ignore The Obvious. Simon and Schuster.

Helms, J. E. (1990). Black And White Racial Identity: Theory, Research, And Practice. 
Greenwood Press.

Helms, J. E. (1993). I also Said," White Racial Identity Influences White Researchers". The Counseling Psychologist, 21(2), 240-243.

Helms, J. E. (1995). An update of Helm's White and people of color racial identity models. In Versions were presented at the Psychology and Societal Transformation Conference, U Western Cape, South Africa, Jan 1994, and at a workshop entitled" Helm's Racial Identity Theory," Annual Multicultural Winter Roundtable, Teachers CollColumbia U, New York, Feb 1994. Sage Publications, Inc.

Henderson, J. A., \& Wakeham, P. (Eds.). (2013). Reconciling Canada: Critical perspectives on the culture of redress. University of Toronto Press.

Henny, A. (2018, October 15). Retrieved from https://www.facebook.com/allyhennypage/

Hiller, C. L. (2013). Placing ourselves in relation: Euro-Canadian narratives of grappling with Indigenous sovereignty, title, and territory (Doctoral dissertation, Wilfrid Laurier University).

Hiller, C. (2017). Tracing the spirals of unsettlement: Euro-Canadian narratives of coming to grips with Indigenous sovereignty, title, and rights. Settler Colonial Studies, 7(4), 415-440.

Hooks, B. (1981). Ain't I a Woman Black Women and Feminism. Boston: South End.

Hunt, S. (2015). Violence, Law and the Everyday Politics of Recognition. NAISA Paper Presentation, Washington, D.C.

Hunt, S. (2014). Why are we hesitant to name white male violence as the root cause of \#MMIW? Rabble.ca. Retrieved from: http://rabble.ca/news/2014/09/why-are-wehesitant-to-name- white-male-violence-root-cause-mmiw

Hunt, S. (2013) More Than A Poster Campaign: Redefining Colonial Violence. Decolonization: Indigeneity, Education \& Society. Retrieved from: https://decolonization.wordpress.com/2013/02/14/more-than-a-poster-campaignredefining-colonial-violence/ 
Etherington, K. (2004). Becoming a reflexive researcher: Using our selves in research. Jessica Kingsley Publishers.

Etherington, K. (2007). Ethical research in reflexive relationships. Qualitative inquiry, 13(5), 599-616.

Etherington, K. (2013). Narrative approaches to case studies. Access on September $20^{\text {th }}$, 2018.

https://www.keele.ac.uk/media/keeleuniversity/facnatsci/schpsych/documents/counsellin $\mathrm{g} /$ conference/5thannual/NarrativeApproachestoCaseStudies.pdf

Jago, R. (2018, February 11). Gerald Stanley And The Fear Of The "Indian". Retrieved from https://www.canadalandshow.com/gerald-stanley-colten-boushie-and-fear-of-theindian/

Jafri, B. (2012). Privilege vs. complicity: People of colour and settler colonialism. Equity Matters, 21.

Johnson, L. (2014). Adapting And Combining Constructivist Grounded Theory And Discourse Analysis: A Practical Guide For Research. International Journal of Multiple Research Approaches, 8(1), 100-116.

Johnson, R. (2019, April 12). Ontario budget's cuts to Indigenous Affairs a setback for reconciliation, says Carolyn Bennett | CBC News. Retrieved from https://www.cbc.ca/news/indigenous/ontario-budget-indigenous-affairs-cut-1.5096723

Kane, L. (2019, April 25). Feds not interested in Indigenous reconciliation, WilsonRaybould says. Retrieved from https://bc.ctvnews.ca/feds-not-interested-in-indigenousreconciliation-wilson-raybould-says-

1.4393866? fbclid=IwAR10qBFFLS3uvoiDwZ4Hk5Wg8WyYzITKz1gEZ4zrrf1zVBry2c SAUg_Hhq8\#_gus\&_gucid=\&_gup=Facebook\&_gsc=QMQp3TX

King, H., \& Pasternak, S. (2018). Canada's Emerging Indigenous Rights Framework: A Critical Analysis (Vol. 22). Yellowhead Institute.

Kino-nda-niimi Collective. (2014). The Winter We Danced: Voices From The Past, The Future, And The Idle No More Movement.

Kovach, M. (2011). Indigenous Methodologies and Modified Grounded Theory Method. 
Retrieved from http://www.thesummerinstitute.ca/wpcontent/uploads/IndigenousMethodologies.pdf

Kuokkanen, R. (2011). Reshaping The University: Responsibility, Indigenous Epistemes, And The Logic Of The Gift. UBC Press.

LATOUR, BRUNO. 1993. We Have Never Been Modern. Cambridge, MA: Harvard University Press

Lawrence, S. M., \& Tatum, B. D. (1998). White racial identity and anti-racist education: A catalyst for change. Beyond heroes and holidays: A practical guide to k-12 anti-racist, multicultural education, and staff development, 217-229.

Lawrence, B. (2012). Fractured homeland: Federal recognition and Algonquin identity in Ontario. UBC Press.

Lawson, A. (2004). The anxious proximities of settler (post) colonial relations. Blackwell Publishing.

Lugones, M. (1987). Playfulness, “world”-travelling, and loving perception. Hypatia, 2(2), 3-19.

Mackey, E. (2002). The house of difference: Cultural politics and national identity in Canada. Toronto, ON: University of Toronto Press.

Mackey, E. (2005). Universal rights in conflict: 'Backlash' and 'benevolent resistance'to indigenous land rights. Anthropology today, 21(2), 14-20.

Mackey, E. (2014). Unsettling expectations:(Un) certainty, settler states of feeling, law, and decolonization 1. Canadian Journal of Law \& Society/La Revue Canadienne Droit et Société, 29(2), 235-252.

Mackey, E. (2016). Unsettled expectations: Uncertainty, land and settler decolonization. Fernwood Publishing.

Macoun, A., \& Strakosch, E. (2013). The ethical demands of settler colonial theory. Settler Colonial Studies, 3(3-4), 426-443.

Maddison, S., Clark, T., \& De Costa, R. (2016). The Limits of Settler Colonial Reconciliation. Singapore: Springer. 
Mahtani, M. (2002). Interrogating the hyphen-nation: Canadian multicultural policy and'mixed race'identities. Social Identities, 8(1), 67-90.

Manuel, A., \& Derrickson, G. C. R. M. (2015). Unsettling Canada: A national wake-up call. Between the Lines.

Manuel, A., \& Derrickson, G. C. R. (2017). The reconciliation manifesto: Recovering the land, rebuilding the economy. James Lorimer \& Company.

Marcos, Sylvia. "Mesoamerican women's indigenous spirituality: Decolonizing religious beliefs." Journal of Feminist Studies in religion 25.2 (2009): 25-45.

Martineau, J., \& Ritskes, E. (2014). Fugitive indigeneity: Reclaiming the terrain of decolonial struggle through Indigenous art. Decolonization: Indigeneity, Education \& Society, 3(1).

McLaren, A. (1990). Our own master race: Eugenics in Canada, 1885-1945. University of Toronto Press.

Morgensen, S. L. (2009). Un-settling settler desires. Reflections and resources for deconstructing colonial mentality, 157-158.

Morgensen, S. L. (2014). White settlers and Indigenous solidarity: Confronting white supremacy, answering decolonial alliances. Decolonization: Indigeneity, Education \& Society, 26.

Napoleon, V. (2013). Thinking about Indigenous legal orders. In Dialogues on human rights and legal pluralism (pp. 229-245). Springer, Dordrecht.

Oluo, I. (2018). So You Want To Talk About Race. Hachette UK.

Oluo, I. (2017, February 07). White People: I Want You To Understand Yourselves Better. Retrieved from https://medium.com/the-establishment/white-people-i-dont-wantyou-to-understand-me-better-i-want-you-to-understand-yourselves-a6fbedd42ddf

Omi, M., \& Winant, H. (1993). On The Theoretical Status Of The Concept Of Race. Race, Identity and Representation in Education, 3-10. 
O'Neal, L. (2017, November 01). Ibram Kendi, one of the nation's leading scholars of racism, says education and love are not the answer. Retrieved from https://theundefeated.com/features/ibram-kendi-leading-scholar-of-racism-sayseducation-and-love-are-not-the-answer/

Quijano, A. (2000). Coloniality of power and Eurocentrism in Latin America. International Sociology, 15(2), 215-232.

Patrick, K. (2016). Not just justice: inquiry into missing and murdered Aboriginal women needs public health input from the start. Canadian Medical Association Journal, cmaj160117.

Perry, Adele. Whose Sisters and What Eyes? White Women, Race, and Immigration to British Columbia. In Epp \& Iacovetta (eds) Sisters or strangers?: immigrant, ethnic, and racialized women in Canadian history. Vol. 44. University of Toronto Press, 2016.

Peters, E. J., \& Andersen, C. (Eds.). (2013). Indigenous In The City: Contemporary Identities And Cultural Innovation. UBC Press.

Philip, M. N. (1992). Frontiers: Selected Essays and Writings on Racism and Culture, 1984-1992. Stratford, Ont.: Mercury Press.

Povinelli, E. A. (2002). The cunning of recognition: Indigenous alterities and the making of Australian multiculturalism. Duke University Press.

Razack, S. (Ed.). (2002). Race, Space, And The Law: Unmapping A White Settler Society. Between the Lines.

Regan, P. Y. L. (2006). Unsettling the settler within: Canada's peacemaker myth, reconciliation, and transformative pathways to decolonization (Doctoral dissertation).

Regan, P. (2010). Unsettling the Settler Within: Indian Residential Schools, Truth Telling, and Reconciliation in Canada. Vancouver: UBC Press.

Rifkin, M. (2013). Settler common sense. Settler Colonial Studies, 3(3-4), 322-340.

Rojas, C. (2016). Contesting the colonial logics of the international: Toward a relational politics for the pluriverse. International Political Sociology, 10(4), 369-382. 
Rose, N. (1998). Inventing Our Selves: Psychology, Power, And Personhood. Cambridge University Press.

Saad, L. (2018). Me and My White Supremacy Workbook.

Said, E. (1978). Imaginative geography and its representations: Orientalizing the oriental. Race critical theories: text and context, 15-37.

Santos, Boaventura De Sousa. (2006). The Rise of the Global Left: The World Social Forum and Beyond. New York: Zed Books.s[spep?

Simon, R. (2013). Towards a hopeful practice of worrying: The problematics of listening and the educative responsibilities of Canada's Truth and Reconciliation Commission. Reconciling Canada: Critical perspectives on the culture of redress, 129142.

Simpson, A. (2016). Reconciliation and its discontents: Settler governance in an age of sorrow. University of Saskatchewan, Saskatoon, SK, Canada. https://www. youtube. com/watch.

Simpson, A. (2017). The ruse of consent and the anatomy of 'refusal': Cases from indigenous North America and Australia. Postcolonial Studies, 20(1), 18-33.

Simpson, L. (2008). Lighting the Eighth Fire: The Liberation, Resurgence, and Protection of Indigenous Nations. Winnipeg: Arbeiter Ring Publishing.

Simpson, L. (2011). Dancing on our turtle's back: Stories of Nishnaabeg re-creation, resurgence and a new emergence. Arbeiter Ring Pub.

Simpson, L. (2014). Not murdered and not missing: Rebelling against colonial gender violence. Leanne Betasamoke Simpson.

Simpson, L. B. (2016). Indigenous Resurgence And Co-Resistance. Critical Ethnic Studies, 2(2), 19-34.

Singer, J. W. (2000). Entitlement: The paradoxes of property. Yale University Press.

Smith, A. (2012). Indigeneity, settler colonialism, white supremacy. Racial formation in the twenty-first century. 
Snelgrove, C., Dhamoon, R. K., \& Corntassel, J. (2014). Unsettling settler colonialism: The discourse and politics of settlers, and solidarity with Indigenous nations.

Decolonization: Indigeneity, Education \& Society, 3(2).

Srivastava, S. (2006). Tears, Fears and Careers: Anti-Racism and Emotion in Social Movement Organizations. The Canadian Journal of Sociology / Cahiers Canadiens De Sociologie, 31(1), 55-90. doi:10.2307/20058680

Stasiulis, D., \& Jhappan, R. (1995). The fractious politics of a settler society: Canada. Unsettling settler societies: Articulations of gender, race, ethnicity and class, 11, 95-131.

Stengers, I. (2004). The Cosmopolitical Proposal. Making things public: Atmospheres of democracy, 994, 994.

Strakosch, E. (2016). Beyond colonial completion: Arendt, settler colonialism and the end of politics. In The Limits of Settler Colonial Reconciliation (pp. 15-33). Springer, Singapore.

Strakosch, E. (2016). Neoliberal Indigenous policy: Settler colonialism and the 'postwelfare'state. Springer.

Strathern, M. (2004). Partial connections: updated edition. Savage, MD: Rowman \& Littlefield.

Sundberg, Juanita. Decolonizing Posthumanist Geographies. Cultural geographies, 21.1 (2014): 33-47.

Svirsky, M. (2017). Resistance Is A Structure Not An Event. Settler Colonial Studies, 7(1), 19-39.

TallBear, K. (2016). Failed settler kinship, truth and reconciliation, and science. Indigenous peoples, technoscience, environment, 16.

Thielen-Wilson, L. (2012). White terror, Canada's Indian residential schools, and the colonial present: From law towards a pedagogy of recognition (Doctoral dissertation).

Thobani, S. (2000). Closing ranks: Racism and sexism in Canada's immigration policy. Race \& Class, 42(1), 35-55. 
Todd, Z. (2016). An Indigenous Feminist's Take On The Ontological Turn:'Ontology'is Just Another Word For Colonialism. Journal Of Historical Sociology, 29(1), 4-22.

Truth and Reconciliation Commission of Canada. (2015). Truth and Reconciliation Commission of Canada. House of Commons.

Tuck, E., \& Yang, K. W. (2012). “Decolonization is Not a Metaphor.” Decolonization: Indigeneity, Education \& Society, 1(1).

Vázquez, R. (2012). Towards a decolonial critique of modernity. Buen Vivir, relationality and the task of listening. Capital, Poverty, Development, Denktraditionen im Dialog: Studien zur Befreiung und interkulturalität, 33, 241-252.

Veracini, L. (2010). Settler Colonialism: A Theoretical Overview. Springer.

Verran, H. (2014). Anthropology as ontology is comparison as ontology. Fieldsights. Theorizing the contemporary. Cultural anthropology online, 13.

Viveiros de Castro, Eduardo Journal of the Royal Anthropological Institute 4(3):469-488.

Viveiros de Castro, E. (2004). Perspectival anthropology and the method of controlled equivocation. Tipiti: Journal of the Society for the Anthropology of Lowland South America, 2(1), 1.

Wallace, R. (2013). Merging Fires: Grassroots Peacebuilding between Indigenous and Non-Indigenous Peoples in Canada. Fernwood Publishing.

Walcott, R. (2004). 'A Tough Geography': Towards a Poetics of Black Space (s) in Canada. Unhomely States: Theorizing English-Canadian Postcolonialism, 277-88.

Wolfe, P. (2006). "Settler Colonialism and the Elimination of the Native." Journal of Genocide Research, 8(4), 387-409.

Yegenoglu, M. (1998). Colonial fantasies: Towards a feminist reading of Orientalism. Cambridge University Press.

Consciousness. (n.d.). Retrieved from https://www.dictionary.com/browse/consciousness 
Council of Canadians. Judge orders temporary injunction to bar Mi'kmaq water protectors. (2019, March 19). Retrieved from https://canadians.org/blog/judge-orderstemporary-injunction-bar-mi'kmaq-water-protectors

Indigenous Action Media. (2016, October 13). Accomplices Not Allies: Abolishing the Ally Industrial Complex. Retrieved from http://www.indigenousaction.org/accomplicesnot-allies-abolishing-the-ally-industrial-complex/

Montreal Indigenous Community Network. (2019, March). Indigenous Ally Toolkit. Retrieved from http://reseaumtlnetwork.com/wpcontent/uploads/2019/04/Ally_March.pdf

National Inquiry into Missing and Murdered Indigenous Women and Girls. (2019). The Reclaiming Power and Place: The Final Report of the National Inquiry into Missing and Murdered Indigenous Women and Girls. (Volumbeb). Retrieved from https://www.mmiwg-ffada.ca/final-report/

Unistoten Camp NO PIPELINES: Background of the Campaign. (n.d.). Retrieved from http://unistoten.camp/no-pipelines/background-of-the-campaign/

Reconciliation means not having to say sorry a second time: Conversation with Cindy Blackstock, First Nations Child and Family Caring Society. (2014, October 07). Retrieved April 8, 19, from https://www.amnesty.ca/blog/reconciliation-means-nothaving-to-say-sorry-a-second-time-conversation-with-cindy-blackstock-f 